\title{
ANÁLISE DA ADAPTAÇÃO MARGINAL DE BARRAS Ni-Cr TIPO PROTOCOLO DE BRANEMARK PELO MICROSCÓPIO ÓPTICO E PELO MICROSCÓPICO CONFOCAL A LASER
}

RÉGIS EDUARDO OLIVEIRA JACCOUD 



\section{ANÁLISE DA ADAPTAÇÃO MARGINAL DE BARRAS Ni-Cr TIPO PROTOCOLO DE BRANEMARK PELO MICROSCÓPIO ÓPTICO E PELO MICROSCÓPICO CONFOCAL A LASER}

Dissertação apresentada à Faculdade de Odontologia de Ribeirão Preto da Universidade de São Paulo, para obtenção do Título de Mestre no programa de Reabilitação Oral.

Area de concentração: Reabilitação Oral

Orientadora: Profa. Dra. Alma Blasida Concepcion Elizaur Benitez Catirse 


\section{FICHA CATALOGRÁFICA}

\section{Elaborada pela Biblioteca Central da USP - Ribeirão Preto}

Jaccoud, Régis Eduardo Oliveira

Análise da adaptação marginal de barras $\mathrm{Ni}-\mathrm{Cr}$ tipo protocolo de Branemark pelo microscópio óptico e pelo microscópico Confocal a laser / Régis Eduardo Oliveira Jaccoud - Ribeirão Preto, 2016.

148p. : 33 il. ; $30 \mathrm{~cm}$

Dissertação de Mestrado apresentada a Faculdade de Odontologia de Ribeirão Preto/USP. Area de concentração: Reabilitação Oral, 2016.

Orientadora: Profa. Dra. Alma Blasida Concepcion Elizaur Benitez Catirse

1. Soldagem com Maçarico 2. Soldagem TIG (tungstênio gás inerte) 4. Adaptação marginal 5. Microscópio confocal a laser 6. Microscópio óptico 
FolHa de APRovação

\section{RÉGis EduARdo Oliveira Jaccoud}

Dissertação apresentada à Faculdade de Odontologia de Ribeirão Preto da Universidade de São Paulo, para a obtenção do Título de Mestre em Odontologia pelo programa de Reabilitação Oral

Area de Concentração: Reabilitação Oral

Orientadora: Profa. Dra. Alma Blasida Concepcion Elizaur Benitez Catirse

\section{Aprovado em:}

BANCA EXAMINADORA

$\operatorname{Prof}(\mathrm{a}) \cdot \operatorname{Dr}(\mathrm{a})$ :

Instituição:

Julgamento: Assinatura:

Prof(a).Dr(a).:

Instituição:

Julgamento: Assinatura:

$\operatorname{Prof}(\mathrm{a}) \cdot \operatorname{Dr}(\mathrm{a}) .:$

Instituição:

Julgamento: Assinatura: 

DEDICATÓRIA 

Aos meus pais, José Wilson e Marisa, que sempre se dedicaram e não mediram esforços para dar o melhor para seus filhos. Colocaram a educação em primeiro lugar, além dos princípios que iremos levar por toda a vida.

Aos meus irmãos Elaine e Rodolfo, que sempre estiveram do meu lado, me apoiando, mesmo ficando distantes fisicamente, sempre estaremos juntos.

A minha esposa Anamaria, o grande amor da minha vida, pela cumplicidade, paciência, carinho e amor. Por aceitar comigo este desafio, junto com o nascimento de nossa filha.

A minha filha Isadora, a coisa mais importante da minha vida, razão pela qual me dedico todos os dias, para fazer o que eu amo, e te dar tudo que você merece, este trabalho é especialmente para você. 

AGRADECIMENTOS ESPECIAIS 

A Professora Dra. Alma Blásida Concepción Elizaur Benitez Catirse, minha Orientadora, que soube me conduzir nessa jornada. Pelo excelente trabalho que faz no dia a dia, formando $e$ incentivando jovens futuros cirurgiões dentistas e pós-graduandos, em uma Odontologia ética e coerente.

A Professora Dra.Takami Hirono Hotta, grande amiga, a quem tenho grande admiração, primeiro pela pessoa bondosa, sincera e perserverante que é, segundo pela excelente professora, sempre procurando ajudar a todos, sem medir esforços. 


A Deus, por me proporcionar este momento único, e ter me colocado nessa profissão maravilhosa, que tenho orgulho em exercer, para poder ajudar pessoas e realizar sonhos.

Ao Prof. Dr. Wilson Matsumoto, pessoa fantástica e meu grande mestre na odontologia. A todos os ensinamentos passados e a paciência de um monge, the tornam esta pessoa especial.

A Profa. Dra. Regina Maura Fernandes, minha grande inspiração profissional, e grande amiga. Dedicada ao extremo e sempre procurando levar o que há de melhor para seus alunos $e$ pacientes.

A Profa. Dra. Regina Guenka Palma Dibb, pela ajuda com o trabalho em especial nas medições do aparelho Confocal, juntamente com a Profa. Dra. Juliana Jendiroba Faraoni Romano, sempre disposta a ajudar com sua bondade contagiante.

A Profa Dra. Adriana Cláudia Lapria Faria Queiroz, pela ajuda com o Microscopio Optico, por tirar todas às duvidas durante o trabalho e pela dedicação no dia a dia.

À Faculdade de Odontologia de Ribeirão Preto, da Universidade de São Paulo, nas pessoas da Profa. Dra. Léa Assed Bezerra da Silva e do vice-diretor Prof. Dr. Arthur Belém Novaes Júnior, por me formar e proporcionar os melhores momentos da minha vida.

Ao programa de Pós-Graduação em Odontologia (Reablitação Oral) representado pela Profa. Dra. Rossana Pereira de Almeida Antunes, sempre disposta a ajudar a todos.

A toda a equipe da Dentlab e João Motoca, laboratório onde foram realizadas todas as etapas laboratoriais. Vocês estão no caminho certo, procurando elevar o nome da prótese dentária e da odontologia, afinal o que seria de um bom protesista, sem um grande protético. Essa parceria é fundamental.

A todas as pessoas que estiveram comigo, e que contribuíram para a concretização deste trabalho. 

RESUMO 



\section{JACCOUD, REO. Análise da adaptação marginal de barras $\mathrm{Ni}$-Cr tipo protocolo}

de Branemark pelo microscópio óptico e pelo microscópico Confocal a laser. 2016. 148p. Dissertação (Mestrado em Reabilitação Oral). Faculdade de Odontologia de Ribeirão Preto, Universidade de São Paulo.

\section{RESUMO}

A ausência de adaptação passiva em prótese sobre implantes pode sobrecarregar implantes, componentes protéticos e tecido ósseo, levando à perda óssea marginal e até da osseointegração. A soldagem é utilizada com frequência para melhorar o assentamento de estruturas metálicas de próteses em geral e de próteses sobre implantes. Além disso, a precisão no assentamento da peça protética pode estar relacionada com os cuidados na técnica de confecção da mesma. Assim, o objetivo deste trabalho foi avaliar, por meio de microscopia óptica e confocal a laser, a adaptação marginal de barras metálicas tipo protocolo de Branemark, de ligas de niquel-cromo ( $\mathrm{NiCr}$ ) em monobloco e soldadas, confeccionadas a partir de enceramento convencional. Para isso, foi confeccionado um modelo mestre, simulando quatro implantes sobre o qual foram adaptados transferentes e análogos que serviram para transferir a posição dos implantes para o modelo de gesso. Os enceramentos obtidos pelo método convencional foram fundidos em monobloco e em partes separadas (seccionados), sendo os últimos, posteriormente soldados utilizando as técnicas convencional a maçarico e TIG (Tungsten Inert Gas). As leituras da adaptação da barra em cada implante foram feitas nas peças em monobloco $(n=5)$ e nas peças seccionadas $(n=10)$, antes e após as diferentes técnicas de soldagem. Pelo método de medição de microscopia óptica, foram realizadas as medições em duas regiões pré-determinadas (Vestibular e Lingual), com três repetições, totalizando 6 leituras por implante. Já no método de microscopia Confocal a laser, foi realizada somente na Vestibular. Para comparar os dados obtidos quanto ao desajuste marginal entre componente protético/implante, considerando-se as peças em monobloco, as peças soldadas, as técnicas de soldagem (maçarico e TIG), os métodos de medição e a posição dos implantes, foram realizados testes estatísticos, onde para cada uma das análises realizadas foi determinada a aplicação do Teste de Normalidade (Shapiro-Wilk ou KolmogorovSmirnov (alfa $=5 \%)$ ) para determinação da distribuição da amostra. Para a amostra com distribuição normal foi determinada a utilização do teste paramétrico, Análise de Variância, enquanto que a amostra com distribuição não normal, determinou-se a utilização do teste não paramétrico de Kruskal Wallis. Os resultados encontrados foram estatisticamente significantes para comparação método e técnica, sugerindo que as peças em monobloco apresentaram maior desadaptação que as peças soldadas, e que as peças soldadas pela técnica convencional não apresentaram 
diferença estatística, em relação as soldadas pela técnica TIG. Em relação a comparação dos métodos de medição, houve diferença estaticamente significante, onde a microscopia Confocal a laser obteve os maiores valores de desadaptação. A interação técnica e método não houve diferenças estatísticas. Na comparação de diferentes secções e soldada, para os 2 métodos de medição, em relação ao fator Secção, não houve diferença significante onde 3 secções apresentam os menores resultados e as soldadas tiveram igualdade em relação a 1 secção. Pelo fator Técnica houve diferença estatisticamente significante, onde a técnica convencional obteve as maiores médias. A interação Secção e Técnica, não teve efeito significante. A adaptação marginal da peça em relação a posição do implante na arcada, não houve diferença estatística, para ambos os métodos. Houve diferença apenas no fator Técnica, pela microscopia óptica, onde a Monobloco teve os maiores resultados e a Solda Convencional e TIG, tiveram igualdade nos resultados. A investigação de sistemas de confecção de estruturas da prótese e de técnicas de soldagem é importante na busca pela produção de próteses sobre dente ou sobre implante com precisão no ajuste marginal que possa ser comprovado visual e numericamente utilizando-se recursos tecnológicos que assegurem a utilização clínica das peças protéticas.

Palavras chave: Soldagem com Maçarico, Soldagem TIG (tungstênio gás inerte), Adaptação marginal, Microscópio confocal a laser, Microscópio óptico 
ABSTRACT 



\title{
JACCOUD, REO. Marginal adaptation analysis of $\mathrm{Ni}-\mathrm{Cr}$ bars Branemark
} protocol type from optical microscope and laser Confocal microscope. 2016. 148p. Dissertação (Mestrado em Reabilitação Oral). Faculdade de Odontologia de Ribeirão Preto, Universidade de São Paulo.

\begin{abstract}
The lack of passive adaptation in prosthesis over implant can overload implants, prosthetics components and bone tissue, leading to marginal bone loss and even osseointegration. Weldering is used frequently to improve the settlement of metal structures of prosthetic in general and prosthesis over implants. In addition, the settlement precision of the workpiece may be related to the care in the technique of manufacturing the same. The objective of this study was to evaluate, through optical and confocal Laser microscopy, the marginal adaptation of metal bars Branemark
\end{abstract} protocol type alloy nickel-chromium $(\mathrm{NiCr})$ monoblock and welded, made from conventional waxing .For this, a master model was made to simulate four implants were adapted over which transferents and analogs that served to transfer the position of the implants for the cast model. Waxing obtained by the conventional method were cast in one-piece and separate parts (sectioned), the latter being subsequently welded using the conventional techniques blowtorch and TIG (Tungsten Inert Gas).The bar adjustment of readings in each implant were made in monoblock pieces $(n=5)$ and the severed pieces $(n=10)$ before and after different weldering techniques. By optical microscopy measurement method, measurements were performed in two predetermined regions (Vestibular and lingual), with three replications, totaling 6 readings per implant. However in the methodology of Confocal laser microscope, was done only on Vestibular. To compare the data obtained on the misfit between prosthetic/implant component, considering the pieces monoblock, the welded parts, the weldering techniques (torch and TIG), measurement methods and the position of the implants, tests were performed statistical where for each of the analyzes determined the application of Normality Test (Shapiro-Wilk test and Kolmogorov-Smirnov test (alpha $=5 \%)$ ) to determine the distribution of the sample. For the sample of normal distribution was determined using the parametric test, analysis of variance, while the sample with non-normal distribution was determined using the nonparametric Kruskal-Wallis test. The results found were statistically significant for method and technique comparison, suggesting that the monoblock parts showed higher misfit than welded parts, and the parts welded by conventional technique showed no statistical difference in relation welded by TIG technique. Regarding the comparison of measurement methods, there was no statistically significant difference, where the Laser Confocal microscopy obtained the greatest misfit. The technical interaction and method there were no statistical 
differences. When comparing different sections and welded to the two measurement methods, in relation to Section factor, there was no significant difference where 3 sections have the lowest results and welded had equality with 1 section. The technical factor was no statistically significant difference, the conventional technique had the highest averages. The interaction and Technical Section had no significant effect. The marginal adaptation of the play in relation to the implant in the arch position, there was no statistical difference for both methods. There was a difference only in the technical factor, by optical microscopy, where Monoblock had the greatest results and Conventional Welding and TIG, had equality in results. The research of making the prosthesis structures systems and weldering techniques is important in the search for production of prosthetic tooth or on precisely implant the marginal adjustment that can be verified visually and numerically using technological resources to ensure clinical use of prosthetic pieces.

Key words: blowtorch soldering, soldering, TIG (Tungsten Inert Gas), marginal adaptation, Confocal laser microscope, optical microscope. 



\section{LISTA DE Figuras}

Figura 1- $\quad$ Modelo mestre e os análogos em posição.................................. 82

Figura 2 - $\quad$ Numeração dos implantes e paralelismo entre eles..................... 82

Figura 3 - $\quad$ Transferentes unidos com fio dental........................................... 83

Figura 4 - $\quad$ Transferentes unidos com resina Duralay................................ 83

Figura 5 - $\quad$ Seccionamento broca Carbide............................................... 83

Figura 6 - União após seccionamento e união com Duralay.......................... 83

Figura 7- $\quad$ A- Material de moldagem silicone de Condensação; B- Molde.... 84

Figura 8 - $\quad$ Modelo de gesso com análogos em posição................................. 84

Figura 9 - $\quad$ Cilindros plásticos adaptados no análogo do microunit................ 85

Figura 10 - Barras em resina acrílica unidas aos cilindros plásticos............... 85

Figura 11- Enceramento da barra finalizado.............................................. 85

Figura 12 - A- Secção da barra após encerada, para alivio de tensão; B-

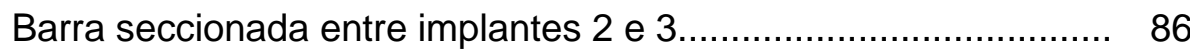

Figura 13 - Revestimento Fosfatado.......................................................... 86

Figura 14 - Espatuladora a vácuo....................................................... 86

Figura 15 - A- Condutos de alimentação; B- Anel de inclusão de silicone....... 87

Figura 16- A - Padrão de cera posicionado dentro do anel de fundição em 2 partes; B - Preenchimento com revestimento fosfatado............... 87

Figura 17 - A- Forno para anel, EDG 3000; B- Cilindro de revestimento no interior do forno..................................................................... 88

Figura 18 - Centrifuga para fundição....................................................... 89

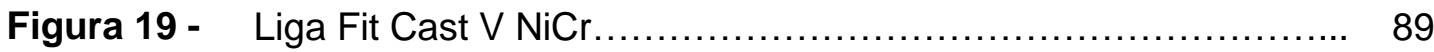

Figura 20 - A e B - Desinclusão; C- Jateamento com óxido de alumínio; D Separação das Peças.............................................................. 89

Figura 21 A e B - Kit Retificador Conexão para remoção de irregularidades

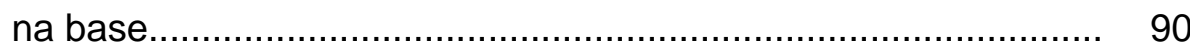

Figura 22 - Estrutura pronta no modelo mestre............................................ 90

Figura 23 - Processo de Solda Convencional a maçarico............................... 91

Figura 24 - Processo de Solda TIG....................................................... 92

Figura 25 - Barras prontas para medição.................................................... 92

Figura 26 - Leituras no Microscópio Óptico................................................... 93

Figura 27 - Imagem da Adaptação Marginal no MO.................................... 93

Figura 28 - Modelo mestre posicionado com corpo de prova para medição

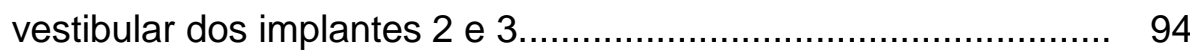


Figura 29 - Guia de Silicone para padronização das medições dos implantes distais (1 e 4) na vestibular....................................................... 94

Figura 30 - Modelos posicionados na mesa, com corpo de prova em posição, para padronização das medições dos implantes na lingual................................................................................ 95

Figura 31 - Microscópio Confocal a Laser.................................................... 95

Figura 32 - $\quad$ A e B - Leituras realizadas no microscópio Confocal a Laser...... 96

Figura 33 - Modelo posicionado, mostrando a inviabilidade da medição por lingual...................................................................................... 97 
LISTA DE TABELAS 



\section{LISTA DE TABELA}

Tabela 1 - Resumo da Análise de Variância

Tabela 2 - Médias de adaptação marginal $(\mu \mathrm{m})$ para 0 fator Técnica.

Tabela 3 - Médias de adaptação marginal $(\mu \mathrm{m})$ para 0 fator Método

Tabela 4 - $\quad$ Adaptação marginal $(\mu \mathrm{m})$ para a Interação

Tabela 5 - $\quad$ Resumo da análise de Variância.

Tabela 6- Médias de adaptação marginal $(\mu \mathrm{m})$ para 0 fator Secção...

Tabela 7 - Médias de adaptação marginal $(\mu \mathrm{m})$ para 0 fator Técnica.

Tabela 8 - $\quad$ Médias de adaptação marginal $(\mu \mathrm{m})$ para a Interação................. $\quad 105$

Tabela 9 - Resumo da análise de Variância

Tabela 10 - Médias de adaptação marginal $(\mu \mathrm{m})$ para 0 fator Secção

Tabela 11 - Médias de adaptação marginal $(\mu \mathrm{m})$ para 0 fator Técnica.

Tabela 12 - Médias de adaptação marginal $(\mu \mathrm{m})$ para a Interação

Tabela 13 - Resumo do Teste Kruskal Wallis para adaptação marginal Técnica x Implante.

Tabela 14 - Resumo da Análise de Variância 109

Tabela 15 - Médias (log) de adaptação marginal para 0 fator Técnica.

Tabela 16 - Médias de adaptação marginal $(\mu \mathrm{m})$ para 0 fator Técnica.

Tabela 17 - Médias (log) de adaptação marginal para 0 fator Implante.

Tabela 18 - Médias de adaptação marginal $(\mu \mathrm{m})$ para 0 fator Implante.

Tabela 19 - Médias (log) de adaptação marginal para a Interação Técnica x Implante.

Tabela 20 - Médias de adaptação marginal $(\mu \mathrm{m})$ para a Interação Técnica $\mathrm{x}$ Implante. 




\section{LISTA DE GRÁFICOS}

Gráfico 1 - Médias de adaptação marginal $(\mu \mathrm{m})$ para o fator Técnica............... 102

Gráfico 2 - $\quad$ Adaptação marginal $(\mu \mathrm{m})$ para o fator Método............................... 102

Gráfico 3 - $\quad$ Adaptação marginal $(\mu \mathrm{m})$ para a Interação Método x Técnica......... 103

Gráfico 4 - $\quad$ Adaptação marginal $(\mu \mathrm{m})$ para o fator SECÇÃO........................... 104

Gráfico 5 - $\quad$ Adaptação marginal $(\mu \mathrm{m})$ para o fator Técnica............................. 105

Gráfico 6 - $\quad$ Adaptação Marginal para Interação Secção x Técnica no CF........ 106

Gráfico 7 - Adaptação marginal $(\mu \mathrm{m})$ para o fator Secção................................ 107

Gráfico 8 - $\quad$ Adaptação marginal $(\mu \mathrm{m})$ para o fator Técnica.............................. 107

Gráfico 9 - $\quad$ Adaptação Marginal para a Interação Secção x Técnica - MO...... 108

Gráfico 10 - Adaptação marginal $(\mu \mathrm{m})$ para o fator Técnica............................ 110

Gráfico 11 - Adaptação marginal $(\mu \mathrm{m})$ para o fator Implante............................. 111

Gráfico 12 - Adaptação marginal $(\mu \mathrm{m})$ para Interação Técnica x Posição do

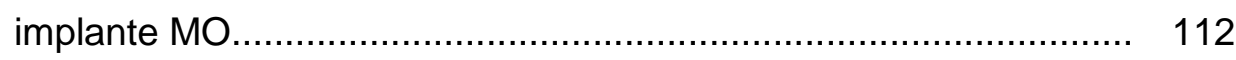



SUMÁRIO 



\section{SUMÁRIO}

RESUMO

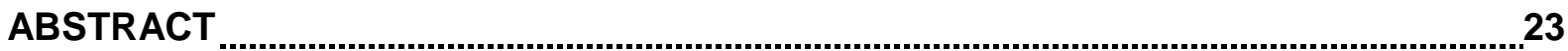

LISTA DE FIGURAS

LISTA DE TABELAS

LISTA DE GRÁFICOS

1. INTRODUÇÃO

2. REVISÃO DE LITERATURA

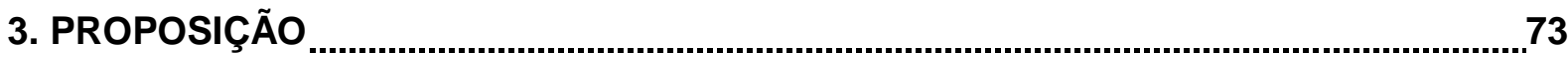

4. MATERIAL E MÉTODOS

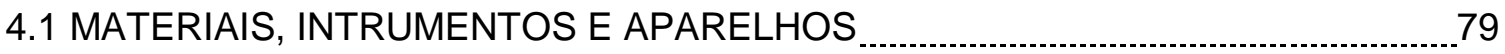

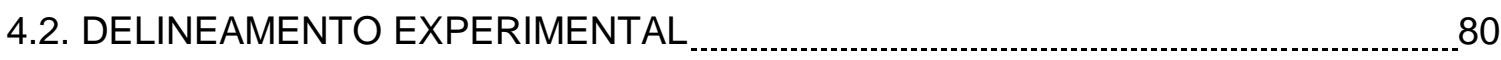

4.3 DELINEAMENTO ESTATISTICO

4.4 MÉTODOS

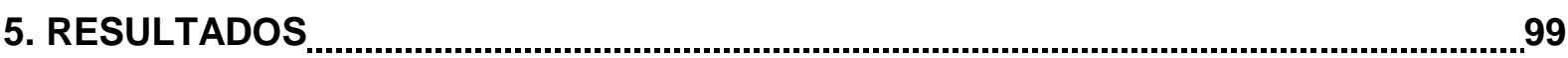

6. DISCUSSÃO

7. CONCLUSÕES

REFERÊNCIAS BIBLIOGRÁFICAS

ANEXOS 

INTRODUÇÃO 



\section{INTRODUÇÃO}

Os implantes osseointegráveis ampliaram a forma de reabilitação oral dos pacientes total e parcialmente edêntulos com tratamentos previsíveis e baseados em evidências científicas (MERICSKE-STERN et al, 2000). Entretanto, durante o processo de confecção da prótese, alguns problemas técnicos podem surgir e devem ser minimizados, ao longo de todo o processo, para a conclusão do trabalho com excelência.

A interface pilar/implante é uma região, extremamente importante na reabilitação protética, onde um grande estresse é gerado. $O$ tipo de componente selecionado e os resultados das fases clínicas e laboratoriais podem acarretar em um desajuste marginal (ADELL, et al; 1981; SKALAK,1983; BRUNSKI e SKALAK 1993; ROMERO, et al.; 2000).

O sucesso de uma reabilitação oral está relacionado com a utilização de técnicas e materiais adequados que possibilitem que uma prótese fixa, suportada por dentes ou implantes, apresente uma distribuição uniforme de forças e uma adaptação exata e passiva (ROSENSTIEL et al, 2001; MISCH, 2009) e, com o advento da inovação tecnológica no setor odontológico, mais opções de técnicas e de materiais estão sendo colocados à disposição do profissional, somando-se ao convencional.

Como no implante não há a presença do ligamento periodontal, o mesmo não apresenta a capacidade adaptativa do dente, então, na prótese sobre implante, a adaptação passiva das estruturas é requisito importante para o sucesso do tratamento reabilitador (BRUNSKI e SKALAK,1993).

Essa falta de passividade pode gerar inúmeros problemas, dentre eles, os biológicos como infiltração bacteriana, periimplantite, dor, inflamação, perda óssea; e os mecânicos como sobrecarga, afrouxamento de parafusos, fratura de parafusos, afrouxamento do componente, fratura do componente, fratura da prótese, fratura do implante, perda da osseointegração. Normalmente, esses problemas não aparecem isoladamente, mas sim atuando de forma associada ou simultânea, causando a fadiga do sistema ( BRANEMARK, 1983; SKALAK, 1983, JEMT 1991).

O nível de desajuste ainda é bem controverso na literatura, variando de 10 $\mu \mathrm{m}$ a $150 \mu \mathrm{m}$ (BRANEMARK, 1983; JEMT, 1991) e quanto menor for o desajuste maior será a longevidade do tratamento reabilitador. 
No entanto, deve ser considerada a dificuldade técnica na obtenção dessa adaptação, principalmente, em próteses extensas ou com estruturas metálicas fundidas em monobloco (AMERICAN DENTAL ASSOCIATION, 1972). Fundições em monobloco que tenham extensão maior que três unidades não são recomendadas devido à distorção produzida pela expansão não uniforme do revestimento (STADE et al., 1975). Uma forma de contornar essa dificuldade é o emprego da soldagem para proporcionar melhor adaptação que as fundições em monobloco com comprimento semelhante (ANUSAVICE et al., 1985; ANUSAVICE, 2005).

A soldagem dos segmentos da prótese reduz possíveis defeitos durante a fabricação da estrutura metálica favorecendo a adaptação e distribuição de forças, minimizando traumas ou falhas na prótese (SOUZA et al., 2000).

Os materiais para prótese dentária, além das propriedades mecânicas, devem apresentar biocompatibilidade, resistência à corrosão e facilidade de trabalho, permitindo um excelente controle da qualidade técnica, especialmente no que se refere à fundição e ao processo de soldagem. Dentre os materiais que atendem a esta finalidade estão as ligas de níquel-cromo, cobalto-cromo, paládioprata, prata-paládio, ouro-paládio-prata, ouro-paládio e mais recentemente, o titânio e suas ligas (AMERICAN DENTAL ASSOCIATION, 1972).

Quanto ao processo de soldagem, novas técnicas e equipamentos foram desenvolvidos para a prática odontológica como a solda a laser (GORDON e SMITH, 1970) e a solda a arco elétrico em atmosfera de gás inerte - TIG (Tungsten Inert Gás) (UENO,1994) que vieram somar à técnica convencional com maçarico ou chama direta (MARQUES, 1991; ANUSAVICE, 2005,).

A técnica de soldagem por chama direta apresenta oxidação, porosidade e sobreaquecimento que é causado pelas altas temperaturas necessárias para atingir a fluidez da solda até o preenchimento do espaço a ela destinado, podendo levar a distorções (ANUSAVICE et al, 1985), contraindicando o seu uso em casos de próteses parciais fixas com grandes espaços e com cantilever.

A solda a laser apresenta vantagens sobre a convencional por produzir energia concentrada em um tempo operacional muito curto gerando assim menos distorção, entretanto, apresenta resultados de resistência variáveis (BERTRAND et al, 2001) o que não ocorre com a solda TIG cujos valores de resistência são semelhantes aos do monobloco com menos porosidades e com facilidade de 
utilização. Portanto, é indicado para locais com exigência de alta resistência (ROCHA et al, 2006; SILVA et al, 2012).

Existem várias técnicas para medir a precisão da adaptação de estruturas metálicas sobre implantes como materiais de impressão, diferentes tipos de microscópios (óptico, de varredura, confocal a laser), strain gauges, scanners (JEMT et al, 2012) e dentro desta variedade, ou mesmo em um só tipo, podem ser encontradas grandes variações nos resultados.

A investigação de sistemas de confecção de estruturas da prótese e de técnicas de soldagem é importante na busca pela produção de próteses sobre dente ou sobre implante com precisão no ajuste marginal que possa ser comprovado visual e numericamente utilizando-se recursos tecnológicos. 

REVISÃO DE LITERATURA 



\section{REVISÃo DE LITERATURA}

STADE et al. (1975) avaliaram os procedimentos de soldagem pré e pós cerâmica. Foram avaliados três espaços $(0.31 \mathrm{~mm}, 0.51 \mathrm{~mm}$ e $0.76 \mathrm{~mm})$ e duas soldagens. Fendas maiores produziram uniões mais resistentes. As juntas mais resistentes foram obtidas com fendas mais largas e técnica de soldagem em forno. Fendas muitos largas $(0,76 \mathrm{~mm})$ não são recomendadas pela possível distorção devido a contração da maior quantidade de solda necessária. Entretanto, na prática, muitos pontos de solda em área que excedem os $0,31 \mathrm{~mm}$ recomendados não mostram resistências diminuídas.

SCHIFFLEGER et al. (1985) relataram em seu artigo que a construção de uma prótese parcial fixa em monobloco apresenta algumas vantagens como: avaliação imediata da adaptação, resistência máxima do conector e ganho de tempo com a eliminação do processo de soldagem. No entanto, os autores enfatizaram que a confecção do monobloco exige habilidade e disciplina. A pesquisa analisou próteses parciais fixas de três, quatro e cinco elementos fundidos em monobloco. Com o auxílio de um microscópio, os autores verificaram a melhora de $50 \%$ no assentamento das fundições após a secção da estrutura metálica e a distorção foi menor nas próteses parciais fixas de três elementos e maior nas próteses de cinco elementos.

ZIEBERT et al. (1986) relataram que a fundição em monobloco elimina o processo da soldagem e maximiza a resistência do conector. No entanto, os autores verificaram que a qualidade da adaptação marginal em monobloco foi inferior àquelas obtidas após a soldagem em uma análise de 15 próteses parciais fixas fundidas em monobloco, que depois foram seccionadas e unidas pelo processo da soldagem. As discrepâncias marginais foram maiores na margem distal do retentor posterior e na margem mesial do retentor anterior em todos os grupos testes.

SARFATI e HARTER (1992) confeccionaram próteses parciais fixas de 4 elementos fundidos em monobloco e em 2 peças unidas por soldagem antes da aplicação da cerâmica. A precisão das duas técnicas foi comparada e avaliada em um modelo mestre. As próteses fixas obtidas em monobloco apresentaram desajustes marginais verticais menores que as próteses obtidas por soldagem.

KALLUS e BESSING (1994) investigaram os afrouxamentos dos parafusos de ouro das próteses e parafusos dos pilares de próteses implantossuportadas após 
5 anos e a relação com diferentes parâmetros clínicos, como a adaptação da estrutura metálica. Os autores observaram que a incidência do afrouxamento do parafuso do pilar foi insignificante e que os afrouxamentos dos parafusos das próteses não estavam relacionados diretamente à falta de adaptação das estruturas metálicas, e que a falta de adaptação não levava necessariamente à perda da osseointegração. Afirmaram ainda, que um dos principais fatores no afrouxamento dos parafusos estava relacionado à capacidade, experiência e rigor do operador.

WANG e WELSCH (1995), considerando que o titânio possui grande número de propriedades desejáveis para uso em odontologia como a baixa densidade, excelente biocompatibilidade e boa resistência à corrosão, mas que, no entanto, a soldagem do titânio representa uma das principais limitações no uso de próteses de titânio, pelo fato da contaminação com oxigênio e hidrogênio provocar diminuição significativa na resistência do titânio e das ligas de titânio, realizaram um estudo no qual compararam os métodos de soldagem a laser, tungsten inert gas (TIG) e a solda com radiação infravermelha para unir o titânio puro e a liga Ti-6Al-4V. Hastes originais que não foram submetidas à soldagem foram usadas como controle. As rupturas ocorreram na região da solda por fratura coesiva e a liga Ti-6Al-4V mostrou resistência à tensão significativamente maior que as amostras de titânio puro. As técnicas de soldagem propiciaram corpos de prova com resistência à tensão marcadamente mais baixa que os respectivos controles. As alterações na microestrutura e microdureza foram avaliadas nas zonas afetadas e não afetadas pelo calor. Os valores de microdureza aumentaram na zona afetada pelo calor em todas as amostras testadas.

JEMT (1996) mediu e comparou a precisão de adaptação de próteses implantossuportadas em desdentados totais usando réplicas do modelo mestre e os implantes intraorais como referência. Sete próteses maxilares e dez próteses mandibulares foram selecionadas aleatoriamente e medidas por meio de uma técnica fotográfica tridimensional. Quando os modelos mestres foram usados como referência, a média da distorção tridimensional do ponto central dos cilindros de ouro foi $37 \mu \mathrm{m}$ (SD 18) e $75 \mu \mathrm{m}$ (SD 40) para as próteses mandibulares e maxilares, respectivamente. O correspondente desajuste médio foi $90 \mu \mathrm{m}$ (SD 51) e $111 \mu \mathrm{m}$ (SD 59), respectivamente, quando os implantes intraorais foram usados como referência. A distorção tridimensional média foi significantemente maior para as medidas intraorais em ambas as arcadas. O autor relatou que todos os casos deste 
estudo possuíam adaptações clinicamente aceitáveis, ou seja, com grau de adaptação que não provoca problemas clínicos a longo prazo, mesmo que algum implante apresentasse desajuste marginal de mais de $200 \mu \mathrm{m}$. Além disso, a distorção total foi significantemente maior para as próteses maxilares quando o modelo mestre foi usado como referência. Entretanto, para as medidas intraorais, nenhuma diferença estatisticamente significante foi observada na adaptação entre as arcadas. Possivelmente, isto poderia ser explicado pelas evidências de que as medidas intraorais das próteses mandibulares indicaram a deformação e rotação da mandíbula que não foi observado nas próteses maxilares.

JEMT et al. (1996) pesquisaram em diferentes centros (EUA e Suécia) onde são desenvolvidos sistemas e métodos para medir, o ajuste da interface de próteses. Dois sistemas são baseados em técnicas por contato, um por laser e outro por um sistema fotométrico. Todos os sistemas são capazes de fornecer como dados tridimensionais $\mathrm{X}, \mathrm{Y}$, e os eixos de coordenadas $\mathrm{Z}$ valores que podem ser transformadas em dados lineares e angulares que caracterizam as superfícies de apoio de pilares ou réplicas do pilar e os seus componentes de acoplamento no âmbito prótese. O "centroide", um único ponto calculado a partir dos dados coletados, foi a unidade de medida, derivada para estas superfícies de rolamento, que foi utilizado para comparar os sistemas. Todos os quatro métodos podem detectar desajustes que são relevantes no contexto clínico; no entanto, apenas um sistema pode ser usado intra-oral. Quando qualquer sistema de medição é avaliado, os dados devem ser sempre examinados para repetibilidade para estabelecer a confiabilidade do sistema. Esta investigação feita em comparações entre a medição e os métodos utilizados para os quatro centros. Comparações eram maiores do que 5 um e, portanto, desajustados deve ser calculado em termos menores de 10 um. Este último ponto é importante para o clínico que se baseia em relatórios de pesquisa sobre a precisão de ajuste ao selecionar o tratamento para cuidar das necessidades de reabilitação protética de implantes de seus pacientes.

VALLITTU (1997) estudou a resistência à fadiga das ligas de ouro usadas em próteses metalocerâmicas com e sem soldagem convencional. Quando as superfícies fraturadas dos espécimes foram examinadas por microscopia eletrônica, os resultados mostraram que nos espécimes com soldagem havia uma diminuição considerável de resistência comparada aos espécimes sem soldagem. O tipo da falha era coesiva e havia mais porosidade na estrutura. Esses resultados sugeriram 
que devido às forças de mordida pode ocorrer fratura nas próteses parciais fixas por fadiga do metal. Concluiu-se que para evitar falhas por fadiga neste tipo de soldagem, deve-se evitar a união nos locais de cantilever e em prótese parcial fixa com grandes espaços edêntulos.

RIEDY et al. (1997) avaliaram a precisão de ajuste entre uma estrutura de implante em um modelo de paciente que consistia, em cinco pilares de implantes localizados na área sínfise mandibular. Uma peça fundida foi comparada com estruturas Procera usinadas e soldados a laser. Cinco estruturas de cada tipo foram medidas com um digitalizador de laser e um programa de gráficos do computador para determinar um único ponto representado como o "Centróide" para cada estrutura e cada componente pilar do implante. As diferenças entre os centroides emparelhados para cada estrutura/interface do pilar são relatadas como $\mathrm{X}$ e do eixo y deslocamentos e lacunas do eixo z. A direção de $X$ e foi determinada deslocamentos do eixo y. Houve diferença significativa $(p<0,05)$ na precisão de ajuste entre ambos, os de peça fundido e as estruturas Procera, quando comparado com os pilares na simulação modelo paciente. As estruturas soldadas a laser exibiram um ajuste mais preciso do que a fundição de uma peça, com significativa diferença em quatro dos cinco as interfaces protéticas, quando avaliadas pela diferença eixo z significativo nos pontos centroides.

MICHAELS et al. (1997) avaliaram o resultado biológico das forças induzidas por uma superestrutura de prótese sobre implantes má adaptada, colocado em um modelo de tíbia coelho branco da Nova Zelândia. Nove coelhos tinham dois implantes dentários colocados nas 2 tíbias. Após 6 semanas, um animal foi sacrificado para ser usado como controle, e os animais restantes tiveram a adaptação ou má adaptação de prótese superestruturas, ligados aos implantes avaliadas durante 12 semanas. Implantes, foram avaliados clinicamente, radiograficamente, e histomorfométricamente no nível microscópico eletrônico de varredura. Nenhuma evidência clínica, radiológica, ou histomorfométrica foram encontradas, apesar de remodelação óssea foi anotado. Dadas as limitações de tamanho da amostra, modelo animal utilizado, duração da ligação superestrutura protética, o estudo do desajuste da prótese deve ser avaliado com outro modelo animal, tal como um modelo de primata intra-oral, para determinar a relação entre o desempenho clínico e histológico. 
WEE et al. (1999) realizaram revisão da literatura sobre estratégias avançadas para melhorar a adaptação em prótese sobre implantes. Nesta revisão os autores observaram várias categorias de falhas que podem ocorrer na confecção de prótese sobre implantes: (1) durante a moldagem deve-se estar atento a: flexão mandibular, técnica de moldagem, material de moldagem e a tolerância entre o implante ou pilar intraoral e o transferente; (2) na confecção do modelo, estar atento à tolerância entre o transferente e o respectivo análogo, à técnica de confecção do modelo, aos materiais para modelo e à curvatura da arcada dental; (3) na confecção do padrão da estrutura, atentar para a tolerância de fresagem entre o análogo do pilar ou implante e cilindro calcinável e distorções do acrílico e/ou da cera; (4) na fundição da estrutura metálica, estar atento aos procedimentos de inclusão, expansão térmica, qualidade do revestimento e da liga metálica; (5) na confecção da prótese propriamente dita, manusear com cuidado a resina acrílica ou a cerâmica e (6) na instalação da prótese, também, é exigido muita atenção em todos os detalhes. A fim de superar todos esses problemas foram descritos vários métodos para melhorar a adaptação da prótese, porém, mesmo com essas estratégias avançadas, o resultado final da prótese é um pequeno desajuste marginal. Todos esses fatores dificultam ou mesmo impedem a obtenção da adaptação passiva.

KAN et al. (1999) afirmaram que a adaptação passiva de estruturas metálicas sobre implantes é um pré-requisito para o sucesso a longo prazo da osseointegração. Entretanto, não existe guia científico que defina o que é, como obter e como medir a adaptação passiva. Dessa maneira, esses autores propuseram, através da revisão da literatura, discutir adaptação passiva e revisar os vários métodos sugeridos para avaliar a adaptação da estrutura sobre implantes. Os autores concluíram que os níveis de adaptação passiva são empíricos e que existem diversos métodos para avaliar a interface prótese-implante, porém, individualmente nenhum fornece resultados objetivos. Dessa maneira, é sugerido que os clínicos utilizem a combinação de várias técnicas para minimizar os desajustes marginais.

MODENESI et al. (2000) relataram que os métodos de soldagem por arcosubmerso e MIG são utilizados para soldagem de grandes estruturas enquanto que o plasma e o método TIG podem ser utilizados em pequenas estruturas. O processo de união por arco de plasma tem sido usado na engenharia como alternativa ao método TIG, no entanto, a soldagem por plasma é bastante complexa e requer equipamento com custo mais elevado se comparado com o processo TIG. A 
soldagem TIG pode ser usada na forma manual ou mecanizada e é considerada como um dos processos de soldagem a arco que permite melhor controle das condições operacionais, permitindo a execução de soldas de alta qualidade e excelente acabamento, particularmente, em juntas de pequeno diâmetro (inferior a $10 \mathrm{~mm}$ e mais comumente entre 2 e $3 \mathrm{~mm}$ ). As vantagens principais do processo TIG citadas, são: excelente controle da peça de fusão; soldagem de precisão ou de elevada qualidade, sem uso de metal de adição; soldagem de peças com pequena espessura; produz soldagem de ligas especiais; gera pouco ou nenhum respingo; exige pouca ou nenhuma limpeza após a soldagem; permite soldagem em qualquer posição.

ROMERO et al. (2000) estudaram 3 técnicas diferentes para correção da falta de passividade de estruturas sobre implantes. Foram produzidas 30 barras sobre um modelo de metal, com 2 pilares em cada, sendo uma distância de $10 \mathrm{~cm}$ respeitadas entre eles. Medições iniciais foram feitas com o uso de um microscópio, sendo 3 medidas em cada implante. As amostras foram divididas em 3 grupos, onde no grupo 1 foram seccionadas e unidas com a mesma liga da barra, grupo 2 foram seccionadas e unidas com solda convencional, e grupo 3 foram secionadas e soldadas com solda de arco de plasma. Novas medições foram realizadas após esse processo onde o grupo 3 teve a melhor média de desadaptação, ficando dentro dos $10 \mu \mathrm{m}$ descritos na literatura.

SAHIN e ÇEHRELI (2001) fizeram revisão sobre o significado da adaptação passiva na prótese sobre implante e definiram adaptação passiva como a "adaptação ideal”, um dos mais significativos pré-requisitos para a manutenção da interface osso-implante. Para obter a adaptação passiva ou uma sobreestrutura livre de tensão, a estrutura metálica deveria, teoricamente, induzir zero de tensão nos implantes e tecido ósseo circunjacente na ausência de carga externa. Porém, os procedimentos clínicos e laboratoriais empregados para confecção das estruturas metálicas são inadequados para fornecer a adaptação passiva absoluta. Embora algumas complicações na prótese sobre implantes sejam atribuídas à ausência de adaptação passiva, o seu efeito no sucesso do tratamento parece ser questionável.

BERTRAND et al. (2001) avaliaram a precisão, qualidade e reprodutibilidade da técnica de soldagem a laser, para a reparação de prótese dentária metálica, tal como aplicado às ligas de Ni-Cr-Mo e Cr-Co-Mo. O método de solda foi avaliada com um pulso de Laser de $\mathrm{Nd}$-Yag. A eficiência de união foi medida com ensaios de 
tração. A fim de entender essa diferença, exames metalográficos, de raio $\mathrm{X}$ e análise de microssonda foram realizadas através da área soldada e comparados com a parte de molde. Verificou-se que uma ligeira mudança na química das ligas de $\mathrm{Ni}$ - $\mathrm{Cr}$ teve uma forte influência sobre a qualidade da união. A liga de Co-Cr apresentou uma excelente soldabilidade. Uma mudança muito importante na microestrutura, devido ao efeito de o laser foi apontado na zona de soldadura, aumentando a sua microdureza. O nível mais elevado de carbono e de boro em um dos dois $\mathrm{Ni}$-Cr foi encontrado para ser responsável pela sua fraca soldagem habilidade. No entanto, para os outros, a profundidade máxima de soldadura verificou-se ser em torno de dois milímetros, que é uma espessura habitual, dos componentes que têm que ser reparadas.

COSTA et al. (2004) avaliaram a distorção linear das próteses sobre implantes, fundidas em monobloco e fundidas em secções e soldadas a laser e por brasagem. Foi avaliada em um modelo de uma mandíbula edêntula com cinco análogos de pilares de implantes, paralelos entre si, com distância de $10 \mathrm{~mm}$ medidos de centro a centro. Sobre estes foram parafusados novos cilindros de ouro, com torque de $10 \mathrm{~N} / \mathrm{cm}$. Então, foram executadas 15 sobre-estruturas metálicas que foram divididas: GC - Adaptação passiva dos cilindros de ouro; GM - monobloco, GB - segmentos soldados por brasagem e, GL - segmentos soldados a laser. Observaram-se as estruturas fixadas com parafusos novos em microscópio de mensuração. A medição foi realizada na vestibular direita e esquerda e da mesma forma na lingual da interface cilindro/análogo. Os resultados mostraram que a menor discrepância marginal média foi observada no grupo de soldagem a laser $(13,58$ $\mu \mathrm{m})$, em seguida o grupo da brasagem $(24,33 \mu \mathrm{m})$ e por último, o grupo monobloco $(40,00 \mu \mathrm{m})$.

HART e WILSON (2006) estudaram a resistência à soldagem em prótese fixa implantossuportadas com cantilever, confeccionadas em titânio. A solda foi realizada pelos métodos laser com e sem preenchimento e pelo método TIG. Foram feitos testes de resistência flexural máxima e fadiga, comparando os métodos e o preenchimento. Verificou-se que o preenchimento influenciou na resistência da soldagem a laser. As falhas recentes em cantilevers de prótese parcial fixa são esperadas quando esta soldagem for realizada sem adição de metal. A soldagem com tungsten inert gás produziu juntas com maior resistência à fadiga. Os autores 
afirmaram que o método de soldagem TIG pode ser usado quando são exigidas uniões com alta resistência.

ROCHA et al. (2006) avaliaram a resistência flexural da soldagem de várias ligas odontológicas: titânio, ligas de $\mathrm{Ni}-\mathrm{Cr}$ e Co-Cr usando os métodos TIG e o laser Nd:YAG . Sessenta corpos-de-prova cilíndricos com $3 \mathrm{~mm}$ de diâmetro foram confeccionados (20 de cada material), seccionados ao meio e soldados por TIG ou por laser de Nd:YAG, com e sem material de preenchimento. Quatro grupos foram formados $(n=15)$. I: soldagem a laser de Nd:YAG; II: soldagem à laser usando material de preenchimento; III: soldagem com TIG; IV: grupo controle (sem soldagem). Os resultados mostraram que o grupo com soldagem TIG aumentou a resistência quando comparado com o grupo sem soldagem. Em relação ao preenchimento houve aumento significativo para as ligas $\mathrm{Ni}-\mathrm{Cr}$ e $\mathrm{Co}-\mathrm{Cr}$ que obtiveram melhores resultado com os corpos com preenchimento. Ao se comparar os diferentes processos de soldagem, diferença estatisticamente significante foi encontrada entre a solda TIG e o laser com ou sem preenchimento, sendo o grupo TIG mais resistente à flexão. Portanto, a soldagem com TIG apresentou melhores resultados que a soldagem com o laser de Nd:YAG para os três materiais testados.

HENRIQUES et al. (2007) estudaram a a influência dos procedimentos de soldagem e refusão sobre o teste de fadiga das ligas Steldent, Dentorium e Biosil de cobalto-cromo, como ligas novas, e em uma mistura de novo e ligas fundidas previamente quando submetidos ou não submetido a procedimento de solda convencional. O processo de solda foi realizado em espécimes da haste de 1,7 mm de diâmetro feita com nova, ou com uma mistura de liga de novo e reutilizada ( $\mathrm{n}=$ 10 por grupo). Os resultados foram comparados com aquelas das hastes intactas. A resistência à fadiga foi realizada com uma máquina de ensaio que simulação cíclica de inserção e remoção de próteses parciais. Após falha, a superfície de fratura foi examinada com um microscópio eletrônico de varredura. Não houve diferenças significativas entre os novos e reutilizados espécimes, soldada ou não ( $p>0,05)$, 0 que sugere que pode ser possível de reutilizar o excesso de cobalto-cromo ligas sem comprometer a resistência à fadiga.

BARBOSA et al. (2007) compararam o desemprenho de 3 laboratórios de prótese dentária, por análise de ajuste vertical de pilares UCLA calcináveis nos processos de fundição e solda de uma mesma prótese. Quatro próteses fixas foram construídas por cada laboratório usando pilares UCLA calcináveis. A avaliação foi 
feita por microscopia electrónica de varredura com uma ampliação de 500x nas regiões mesial e distal de cada elemento da prótese, perfazendo um total de 24 medições por laboratório. No processo de fundição, os valores apresentados pelos laboratórios diferiram significativamente entre si $(p=0,004)$. Depois de soldar, os valores apresentados pelos laboratórios não apresentaram diferença significativa ( $p$ $=0,948)$. Pode concluir-se que os valores de ajuste obtido no estágio de fundição de pilares UCLA podem ser influenciados quando processados por diferentes laboratórios, e que se solda convencional aumentou o grau de desajuste da estrutura, independente do laboratório que fez.

TORRES et al. em 2007 realizaram uma pesquisa onde mediram e compararam a passividade e adaptação marginal de estruturas fabricadas em 3 diferentes materiais, titânio comercialmente puro CP Ti, NiCrTi e CoCr. Quinze estruturas simulando barras para prótese fixa em um modelo com cinco implantes foram fabricados e dispostos em três grupos diferentes de acordo com o material utilizado. O ajuste da interface no âmbito do pilar foi medida utilizando um microscópio óptico, quando apenas um parafuso foi apertado manualmente em um pilar (ajuste passivo) ou quando todos os parafusos de foram apertados com $10 \mathrm{~N}$ $\mathrm{cm}$ de torque (ajuste vertical). Os dados foram analisados estatisticamente usando testes de Mann-Whitney (alfa $=0,05)$ Kruskal-Wallis. Nos resultados a média e o desvio padrão de ajuste passivo e em forma vertical, são apresentados, respectivamente: CP Ti [88 (74) $\mu \mathrm{m}$ e 22 (9) $\mu \mathrm{m}$, Co-Cr [229 (184) $\mu \mathrm{m}$ e 66 (35) $\mu \mathrm{m}$, $\mathrm{Ni}$-CR-Ti [200 (175) $\mu \mathrm{m}$ e 32 (24) $\mu \mathrm{m}$. Não houve diferenças significativas entre ajuste passivo de $\mathrm{Co}-\mathrm{Cr}$ e estruturas $\mathrm{Ni}-\mathrm{Cr}-\mathrm{Ti}(\mathrm{p}=0,313)$, mas ambas as ligas foram estatisticamente diferentes do CP Ti ( $p<0,001$ e 0,035, respectivamente), que apresentou os melhores resultados. Como para o ajuste vertical, CP Ti e ligas de $\mathrm{Ni}$ Cr-Ti foram estatisticamente semelhantes $(p=0,162)$ e apresentaram um melhor ajuste vertical do que liga de $\mathrm{Co}-\mathrm{Cr}(\mathrm{p}<0,001)$. Dentro das limitações deste estudo, foi possível concluir que as estruturas fundidas em monobloco resultaram em ajuste passivo inaceitável e ajuste vertical, não importa qual o material tinha sido usado para fabricá-los. No entanto, os melhores resultados foram obtidos usando Ti CP seguido por ligas de $\mathrm{Ni}-\mathrm{Cr}$ - $\mathrm{Ti}$ e de $\mathrm{Co}-\mathrm{Cr}$, respectivamente.

ATOUI (2008) comparou a soldagem de titânio comercialmente puro pelo método TIG ("tungsten inert gas") com o método de soldagem a laser através dos ensaios de tração, flexão e da avaliação do desajuste marginal de supra-estuturas 
implantossuportadas, por meio de microscopia óptica. Os resultados mostraram que as técnicas de soldagem TIG e laser apresentaram resultados estatisticamente semelhantes em todos os ensaios, porém em relação ao desajuste marginal as estruturas metálicas seccionadas apresentaram valores menores que as técnicas de soldagem, ou seja, as soldagens promoveram um aumento na desadaptação das supra-estruturas para prótese implantossuportada.

BARBOSA et al. (2008) investigaram se existe uma correlação direta entre o nível de desajuste vertical na interface pilar/implante e perdas de torque (destorque) do pilar. Um modelo de trabalho foi obtido a partir de uma matriz metálica com cinco implantes de 3,75 x 9 milímetros hexágono externo com plataforma padrão (4,1 $\mathrm{mm}$ ). Quatro estruturas foram enceradas utilizando pilares tipo UCLA e uma peça em titânio comercialmente puro. $O$ desajuste foi analisado com um microscópio de comparação após $20 \mathrm{Ncm}$ de torque. O maior valor de desajuste observada por abutment foi utilizada. O torque necessário para afrouxar o parafuso foi avaliado usando um torquímetro digital. As perdas de torque foram avaliadas, e assumidos como porcentagem do torque inicial $(100 \%)$ dado aos parafusos de pilares. A correlação de Pearson $(=0,05)$ entre os valores de desajuste $(29,08 \pm 8,78 \wedge \mathrm{m})$ e a percentagem de destorque $(50,71 \pm 11,37 \%)$ não apresentaram correlação estatisticamente significativa $(p=0,295)$. Dentro das limitações deste estudo, podese concluir que os grandes desajustes verticais não implicam necessariamente em valores mais elevados destorque.

ELIASSON et al. (2010) compararam a precisão do ajuste de estruturas

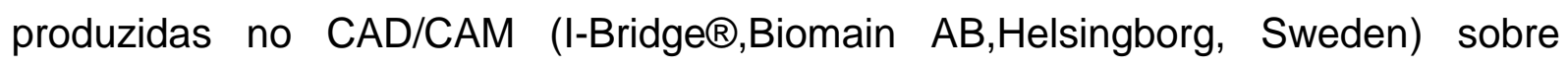
implantes padrão Branemark (Nobel Biocare AB, Göteborg, Sweden) e sobre Nobel Replace (Nobel Biocare $A B$ ). Dez estruturas de teste foram fabricadas para um modelo mestre para cada sistema de implante. Cinco estruturas adicionais foram fabricadas por cinco modelos diferentes, simulando casos clínicos como controles (Brånemark System). A distorção das posições de ponto de centro de implantes foi medida em $x, y$, e $z$ eixos e em três dimensões usando uma máquina de contato e um programa de computador desenvolvido especificamente para medir esta finalidade. MannWhitney U-test foi usado para comparar as diferenças de distorção dentro e entre os grupos. A distorção máxima na largura do arco (eixo x) e a curvatura (eixo dos y) foi a 71 e $55 \mathrm{~mm}$ em todos as estruturas, respectivamente. A distorção média em números absolutos em $x, y, z$-eixos e três dimensões de 
estruturas do grupo controle foi de $23,26,4$, e $34 \mu \mathrm{m}$, em comparação com menos de 12, 12, 2, e $17 \mu \mathrm{m}$ para Branemark e NobelReplace respectivamente. As estruturas de controle mostraram significativamente $(p<0,05)$ maior média e alcance de distorções no x e y-eixos e em três dimensões em comparação com estruturas de teste. Todas as estruturas medidas apresentaram sinais de desajuste, o que indica que não existe uma estrutura que teve um ajuste passivo de adaptação. As estruturas produzidas num ambiente clínico de rotina, parecem apresentar maiores níveis de distorção, quando comparado com estruturas produzidos em situações controladas. Entretanto, todas as estruturas medidas apresentaram níveis de precisão de ajuste dentro limites considerados clinicamente aceitáveis em estudos anteriores de estruturas sobre em pilares.

PARK et al. (2010) descobriram que adaptação marginal é um fator muito importante, considerando o sucesso a longo prazo da restauração. No entanto, a adição de porcelana no coping pode causar distorção e levar a um ajuste inadequado que expõe mais material de cimentação ao meio bucal e provoca cáries secundárias. O objetivo deste estudo foi comparar a adaptação marginal de 2 sistemas de coroa total cerâmica, antes e depois de revestimento de porcelana. Este estudo também foi destinado a verificar a adaptação marginal de coroas originado de usinagem verde de blocos parcialmente sinterizadas de zircônia (Lava $\mathrm{CAD} / \mathrm{CAM}$ ) e que de coroas obtidas por meio de usinagem de blocos totalmente sinterizadas de zircônia (Digident CAD/CAM). MATERIAIS E MÉTODOS: 20 coroas foram feitas por cada sistema e da adaptação marginal foi avaliada através de um microscópio de luz com processamento de imagem (Accura 2000) em 50 pontos que foram selecionados aleatoriamente. Cada coroa foi medida duas vezes: a primeira medição foi feita após a obtenção de um 0,5 milímetros enfrentamento e a segunda medição foi feita depois de revestimento de porcelana. As médias e desvios padrão foram calculados e a estatística entre os 2 grupos foram feitas usando o teste $t$ independente e dentro do mesmo grupo por meio de teste $t$ pareado. RESULTADOS. O significado e desvios-padrão da adaptação marginal foram 61,52 $\pm 2,88 \mathrm{~mm}$ para as coroas de cerâmica Digident CAD / CAM de zircônia antes de folheados de porcelana e 83,15 $\pm 3,51 \mathrm{~mm}$ após revestimento de porcelana. Coroas cerâmicas Lava CAD / CAM de zircônia apresentaram médias e desvios-padrão de $62,22 \pm 1,78 \mathrm{~mm}$ antes da aplicação da porcelana e 82,03 \pm 1,85 mm após revestimento de porcelana. Ambos os grupos apresentaram diferenças significativas 
quando se analisa as fendas marginais antes e depois da cerâmica de revestimento dentro de cada grupo. No entanto, não foram encontradas diferenças significativas quando se comparam os espaços marginais de cada grupo antes de revestimento de porcelana e depois de revestimento de porcelana também. CONCLUSÃO. Os 2 sistemas de cerâmica pura mostraram espaços marginais que estavam dentro de uma faixa relatada clinicamente aceitável de discrepância marginal.

MACHHA et al. (2011) realizaram um estudo para avaliar as propriedades mecânicas de ligas de metais base soldadas por duas técnicas diferentes, que foram soldagem a maçarico e soldagem a laser e comparados com a fundição em monobloco. As propriedades mecânicas avaliadas foram a resistência à tensão, a porcentagem de alongamento e a dureza do ponto de solda. Além disso, foram estudadas, também as propriedades de corrosão e a aparência no microscópio eletrônico de varredura. Os resultados mostraram que, a resistência à tensão, dos monoblocos foram maiores que as amostras soldadas tanto com maçarico como à laser. As uniões à laser apresentaram maiores valores de dureza quando comparados à solda a maçarico. No microscópio eletrônico de varredura pode-se observar maior quantidade de porosidades nas soldas a maçarico. Isto contribuiu para a redução da resistência da união. A solda a maçarico mostrou-se com menor resistência à corrosão quando comparados com a solda a laser e com as peças fundidas em monobloco. Os autores concluíram que, a soldagem a laser apresentou propriedades com valores intermediários entre a fundição em monobloco e a soldagem a maçarico.

BIANCHINI et al. (2011) realizaram um estudo cujo objetivo foi avaliar o desajuste entre o intermediário protético e a infra-estrutura metálica de uma prótese fixa de três elementos aparafusada sobre dois implantes, observando se os procedimentos de seccionamento da peça e posterior soldagem são realmente necessários. O estudo foi baseado em um modelo que reproduzia infraestrutura metálica de uma prótese fixa de três elementos aparafusada sobre dois implantes. $E$ de um total de dezoito infraestruturas metálicas foram formados três grupos: no grupo NS as peças foram fundidas em monobloco e não foram seccionadas, no grupo CS as peças receberam uma soldagem convencional e no grupo LW as peças foram soldadas a laser. A análise em microscópio óptico mostrou que o grupo Monobloco apresentou o maior desajuste marginal. Os grupos da soldagem convencional e da soldagem a laser apresentaram resultados, estatisticamente 
semelhantes entre si e melhores que o grupo Monobloco. Os resultados mostram que mesmo para próteses pouco extensas de três elementos a infraestrutura deve ser seccionada e soldada para evitar ou reduzir os gaps entre a infraestrutura metálica e os intermediários protéticos.

BYRNE (2011) relatou que a adaptação de próteses fixas múltiplas é um problema previsto. Restaurações com adaptações pobres podem acelerar falhas mecânicas, devido a cáries dos dentes pilares ou falhas no parafusamento. A soldagem e união por laser ou TIG apresentam um importante papel na tentativa de superar a má adaptação das próteses múltiplas. Esta é a primeira de uma série de artigos de revisão sobre o estado da arte e ciência da soldagem em relação à adaptação de próteses múltiplas cimentadas e parafusadas. É apresentado um arquivo completo de revisão sobre informações e achados científicos. Textos sobre materiais dentários e prótese foram revisados. Dados científicos foram retirados de inúmeros trabalhos de laboratórios até e incluindo 2009. Este primeiro artigo foca os princípios de soldagem e a precisão dimensional na soldagem. Existem algumas discussões e sugestões para futuras pesquisas e desenvolvimento. A soldagem pode melhorar a precisão dimensional ou reduzir as distorções de próteses fixas múltiplas. Muitas variáveis podem afetar o resultado na técnica de soldagem.

JEMT et al. (2012) compararam os dados sobre precisão de ajuste, de duas técnicas de medição de alta precisão e, também, os resultados obtidos utilizando programas de software para as avaliações de ajuste, considerando tanto um "virtual", bem como uma "física". Cinco estruturas de titânio produzidas pelo sistema CAD/CAM (Implant Bridge Procera®, NobelBiocare AB, Göteborg, Suécia) foram fabricados a partir de medições de modelo/padrão individuais, simulando uma situação clínica. As medições entre as estruturas e modelos, foram realizadas por meio de uma máquina de medição de coordenadas (CMM; Zeiss PrismoVast, Carl Zeiss IndustrielleMesstechnik $\mathrm{GmbH}$, Oberkochen, Alemanha), ligado a um computador e uma scanner tridimensional óptico, de alta resolução (Atos 4M SO, GOM International AG, Widen, Suíça). Coletados os dados sobre as distorções entre as estruturas e modelos, foram analisados e comparados entre as duas técnicas de medições. Também foi realizada uma comparação entre as avaliações dos ajustes "virtuais" e "físicas", com base em dados do scanner tridimensional. Ao usar programas de avaliação "virtuais" de ajuste, a média geral distorção tridimensional entre o implante e os pontos centrais da estrutura em valores absolutos foi de 37 
(SD 22) e $14 \mu \mathrm{m}$ (SD 8) para a CMM e para as medições virtuais, respectivamente. Correspondente a distorção média tridimensional, quando se utiliza uma avaliação "física" o desajuste no programa digitalizador foi de $43 \mu \mathrm{m}$ (SD 24) ( $p<0,001)$. A média horizontal (eixo $\mathrm{x}$ ) das medições da distância entre os dois implantes distais dos modelos e das estruturas foram 33,772 e 33,834 mm para a técnica de CMM. Medidas correspondentes para o scanner tridimensional foram de 33,798 e 33,806 $\mathrm{mm}$, respectivamente. As distâncias horizontais entre o scanner tridimensional foram, para a maioria das medições, maiores do que para as medições CMM. Conclusão: As medições de ajuste entre estruturas e os modelos podem variar dependendo do que técnica é usada e como as avaliações de ajuste em relação ajuste "virtual" ou "física" é abordado.

MARTÍNEZ-RUS et al. (2011) analisaram o efeito de diferentes técnicas de fabricação, na marginal adaptação de copings de zircônia. Material e métodos. Um primeiro pré-molar inferior extraído foi preparado para uma restauração completa cobertura e posteriormente repetido 40 vezes em um polímero de cristal líquido (LCP). Copings cerâmicos $(n=10)$ foram fabricados sobre os modelos LCP usando os seguintes sistemas: infiltrada com vidro temperado-zircônia de alumina (In-Ceram Zirconia) e ítrio tetragonal policristalina de zircônia com cátions (In-Ceram $Y Z$, Cercon, e Procera Zirconia). A discrepância marginal foi avaliada usando um sistema de análise de imagem. Os dados foram analisados utilizando uma ANOVA unilateral e teste de Scheffé $(\alpha=0,05)$. Resultados. Os gaps marginais médios foram 29,98 \pm 3,97 $\mathrm{mm}$ para o grupo In-Ceram Zirconia, 12,24 $\pm 3,08 \mathrm{~mm}$ para o $\mathrm{In}$-Ceram YZ grupo, 13,15 $\pm 3,01 \mathrm{~mm}$ para o grupo Cercon, e 8,67 $\pm 3,96 \mathrm{~mm}$ para o grupo Procera. Diferenças significantes foram encontrados entre os 4 sistemas $(P<.05)$. Conclusões. A precisão obtida marginal para os 4 sistemas de coroa de cerâmica à base de zirconia analisadas estavam dentro da gama de aceitação clínica (120 $\mu \mathrm{m})$.

TEIGEN e JOKSTAD (2012) pesquisaram a utilização de liga cobalto-cromo em substituição as ligas áureas. Uma auditoria retrospectiva dos prontuários de todos os pacientes que tinham recebido próteses dentárias fixas implantosuportadas (FDP) antes de 1996 foi identificado em uma clínica prática privada. Dados foram registrados para FDP fabricados a partir de quatro combinações de estruturas de liga leve e material de revestimento, isto é, 3 tipos de ouro e cobaltocromo, com dentes de acrílico, cerâmica ou pré-fabricados. Os dados extraídos dos prontuários foram submetidos a testes estatísticos exploratórias, incluindo análises 
de sobrevida de Kaplan-Meier. FDPS implanto-suportada feita a partir de ligas de ouro ou estruturas de cobalto-cromo e facetadas com dentes de acrílico, cerâmica ou pré-fabricadas demonstrar o desempenho clínico comparável. As combinações do biomaterial não parecem influenciar o sucesso ou a sobrevivência dos implantes.

BARBI et al. (2012) realizaram um estudo para um melhor entendimento sobre a adaptação passiva na interface prótese/pilar de superestruturas de cobalto-cromo. Foram avaliadas três diferentes técnicas de soldagem: maçarico, laser e TIG. Os autores concluíram que os métodos usados para unir as estruturas protéticas de Co-Cr apresentaram influência na adaptação passiva. A soldagem TIG produziu resultados melhores que as soldagens a maçarico e laser, apesar das diferenças os valores médios de desajuste marginal, das três técnicas, ficaram abaixo dos $100 \mu \mathrm{m}$.

SILVA et al. (2012) avaliaram a resistência flexural de corpos de prova, de níquel-cromo, unidos pela soldagem com chama direta, TIG e laser. Foram confeccionados três grupos: chama direta (C), TIG (T) e laser (L), onde os corpos de prova foram seccionados transversalmente. Em razão das características das soldagens laser e TIG que ocorrem apenas perifericamente, foram realizados outros dois grupos: laser (L1) e TIG (T1), em que os corpos de prova foram seccionados em chanfro de $45^{\circ}$. Os corpos de prova tiveram suas extremidades unidas com resina duralay e cada grupo passou pelo seu respectivo processo de soldagem, torneamento, simulação de cocção da porcelana e, finalmente, submetidos aos testes de flexão. Os valores numéricos registrados foram de 1,79 GPa (M) (grupo controle), 1,37 GPa (C), 0,99 GPa (T), 1,26 GPa (T1), 1,03 GPa (L) e 1,09 GPa (L1). Concluiu-se que todos os grupos laser e TIG apresentaram resultados semelhantes entre si; os grupos laser e TIG com preenchimento foram semelhantes ao grupo Chama direta e todos os grupos soldados foram diferentes estatisticamente do grupo.

BHERING et al. (2013) realizaram um estudo, onde foram avaliadas a influência do processo de fundição e carregamento cíclico de estruturas protéticas em destorque de parafusos protéticos e desajuste marginal de próteses implantosuportadas. Foram selecionadas 20 amostras, cada uma constituída por um conjunto de um implante (3,75 hexágono externo 13 milímetros, padrão Branemark, um pilar protético calcinável (UCLA) e um parafuso protético. Depois que as amostras foram obtidas, os parafusos protéticos foram apertados com o torque de 
$30 \mathrm{~N} / \mathrm{cm}$ e aguardaram por 24 horas, a fim de avaliar destorque inicial. Os parafusos foram reapertadas e fendas marginais foram avaliados. Todas as amostras foram submetidas a 106 ciclos de carga, realizada com 2 frequência $\mathrm{Hz}$ e 130 de carga $\mathrm{N}$. Os espécimes foram reavaliados de desajuste marginal e destorque após a mecânica carregamento (desajuste marginal final / destorque final). Pode-se concluir que os pilares sobrefundidos apresentaram valores de desajuste mais baixos quando comparados com os pilares totalmente fundidas. Nenhuma diferença foi observada em valores de destorque de parafusos protéticos. Depois de carga mecânica não houve diferença no desajuste marginal e destorque entre os grupos.

MORENO et al. (2013) realizaram um estudo onde com o objetivo de obter estruturas metálicas precisas sobre 6 implantes com o uso do CAD/CAM, utilizando o scanner intraoral. Foram usados 6 postes de scaneamento, para obter uma impressão digital. Um dente de resina acrílica convencional foi scaneado e armazenado no programa e posteriormente unido ao modelo digital. A estrutura foi fabricada em um torno de 5 eixos. Três testes clínicos (degradação a saliva, teste de Sheffield, e resistência do parafuso) foram realizadas para avaliar o ajuste da estrutura. Observou-se um ajuste preciso. O caso apresentado neste relatório propõe um novo protocolo clínico para obtenção digital de impressões de implantes múltiplos precisas.

COGULLUDO et al. (2013) fizeram um estudo com o objetivo de identificar a composição da liga mais adequada e técnica de fusão, com a avaliação da adaptação marginal das coroas metalocerâmicas. Setenta pilares de aço inoxidável padronizadas foram preparados para receber coroas metalocerâmicas e foram aleatoriamente divididos em quatro grupos de liga: Grupo 1: paládio-ouro ( $\mathrm{Pd}-\mathrm{Au})$, Grupo 2: níquel-cromo-titânio (Ni-Cr-Ti), Grupo 3: níquel-cromo (Ni-Cr) e Grupo 4: titânio (Ti). Grupos 1, 2 e 3 foram, por sua vez subdivididas para ser derretido e fundido usando: (a) tocha de oxigénio gás e máquina de fundição centrífuga (CT) ou (b) a indução e máquina de fundição centrífuga (IC). O grupo 4 foi derretido e fundido usando arco elétrico e máquina de vácuo / pressão (EV). Todas as coroas metalocerâmicas foram cimentadas com ionômero de vidro. A adaptação marginal foi medida em microscópio óptico antes e após a cimentação usando software de análise de imagem. A liga de $\mathrm{Ni}-\mathrm{Cr}$-Ti foi o mais previsível em termos de diferenças de desajuste quando uma tocha ou indução foi aplicada antes ou após a cimentação. As coroas de titânio cimentado excederam o limite clinicamente 
aceitável de $120 \mathrm{~mm}$. A combinação de composição da liga, técnica de fusão, fundição método e processo de cimentação influencia o vedante vertical de coroas metal-cerâmico fundido. A uso preciso da tocha de oxigênio gás pode superar os resultados alcançados com a indução sistema relativo à adaptação marginal de próteses dentárias fixas.

CASTRO et al. (2013) A falta de passividade tem sido associada com problemas biomecânicos em prótese implanto-suportada. O objetivo deste estudo foi avaliar a passividade de três técnicas para fabricar uma estrutura de implante a partir de uma liga de Co-Cr por Fotoelasticidade. O modelo foi obtido a partir de uma matriz de aço simulando uma mandíbula edêntula com 4 análogos de implantes, hexágono externo plataforma padrão. Neste modelo, cinco estruturas foram fabricadas para cada grupo: grupo monobloco (controle), grupo solda a Laser e grupo solda TIG. O modelo fotoelástico foi feito a partir de uma resina epoxi flexível. $\mathrm{Na}$ análise fotoelástica, as estruturas foram aparafusadas no modelo para a verificação da tensão máxima de cisalhamento em 34 pontos selecionados em torno dos implantes e 5 pontos no meio do modelo. As tensões foram comparadas em todo o modelo fotoelástico, entre a direita, esquerda e centro, e entre as regiões cervical e apical. Os valores foram submetidos a duas vias análise de variância e Tukey $(\mathrm{a}=0,05)$. Não houve diferença significativa entre os grupos e áreas estudadas ( $p>0,05)$. Concluiu-se que as tensões geradas em torno os implantes foram semelhantes para todas as técnicas.

DE SANTIS et al. (2014) investigaram os efeitos dos implantes de titânio e diferentes configurações de próteses de arco completo sobre a biomecânica de mandíbulas desdentadas. Engenharia reversa, resina, anisotrópia, mandíbulas desdentadas feitas de um poli(metilmetacrilato), pinos e uma fibra de vidro reforçada foram o protótipo e mensurados com a strain gauges. Implantes de plataforma regular de Brånemark em conjunto com Procera, produziram estruturas de uma peça ou duas peças que foram utilizadas para simular reabilitações orais. Uma carga lateral foi utilizada para testar os efeitos biomecânicos. Como comparação foram produzidas estruturas no método convencional com ouro como material de escolha. As estruturas de uma peça feita pelo CAD/CAM tiveram uma adaptação melhor do que as produzidas pelo método convencional em ouro. Sobre a distribuição de forças as estruturas de uma peça tiveram os piores resultados em relação as de duas peças. Na forma convencional houve uma concentração de stress nos molares 
e na região de sínfise, já nas peças realizadas pelo método mais moderno houve grande melhora na distribuição do stress.

ABDUO em 2014 fez uma revisão na literatura com o objetivo de examinar o efeito do processamento CAD/CAM e o efeito de materiais sobre o ajuste final da estrutura do implante. As hipóteses nulas são de que CAD/CAM não produz estruturas de implantes com melhor adaptação do que as outras técnicas, e não há nenhum efeito de alterando materiais CAD/CAM. Inicialmente, 303 artigos foram extraídos pela pesquisa eletrônica. Após a análise dos títulos, 272 artigos foram excluídos. Triagem dos resumos excluídos 14 artigos, deixando 17 artigos adequado para análise de texto completo. Após a aplicação da inclusão critérios, foram selecionados 13 artigos. Procura manual e revisão de listas de referência nos artigos selecionados revelou um artigo adicional adequado para a inclusão. Portanto, um total de 14 artigos foram considerados para essa avaliação. Dos artigos selecionados, a relevante informação foi extraída. Onde quer que identificado, os valores de ajuste vertical foram registrados. As medições dimensionais visam quantificar o grau de desajuste ou a distorção entre a estrutura e a infraestrutura. As seguintes medições foram aplicadas pelos estudos: Avaliação por Microscopia, Fotometria e Scanner de Contato. Os estudos selecionados foram realizados medições em diferentes condições sendo elas: Sem apertar o parafuso, Apertando o parafuso mais distal, Apertando todos os parafusos. Dentro das limitações desta revisão, pode-se concluir que: (1) CAD / CAM é capaz de produzir estruturas de implante com uma precisão de ajuste que supera a fundição de uma peça e soldadas a laser. Confiabilidade e consistência do CAD/CAM no ajuste das estruturas foi observado pelos estudos incluídos. A precisão do CAD/CAM não é influenciada pelo mecanismo de retenção. (2) Estruturas de titânio e de zircônia podem ser fabricados com um elevado grau de precisão como auxílio de CAD/CAM. Para arco completo e próteses arco parciais, estruturas produzidas em titânio por CAD / CAM são confiáveis no fornecimento de um ajuste aceitável. No entanto, as estruturas de zircônia foram confirmadas para expor um ajuste preciso para próteses parciais arco total.

BUZZAYAN e YUNUS (2014) realizaram uma revisão da literatura onde estudaram alguns aspectos do ajuste passivo para atingir e melhorar os métodos. A revisão da literatura foi realizada através Science Direct, Pubmed, e banco de dados do Google. Eles foram pesquisados em Inglês utilizando as seguintes combinações 
de palavras-chave: ajuste passivo, desajuste implante e desajuste estrutura. Os artigos foram selecionados com base em se eles tinham informação suficiente como fatores relacionados desajuste de estruturas, ajuste passivo e as suas técnicas de realização, alteração do osso marginal com o desajuste, técnicas de moldagem de implantes e conceito de esplintagem. As referências relacionadas foram selecionadas, a fim de enfatizar a importância da realização ajuste passivo e a minimização desajuste. Apesar do fato de que a literatura apresenta informações consideráveis sobre desajuste de estrutura, não havia consistência na literatura sobre um determinado número ou mesmo uma faixa para ser o nível aceitável de desajuste. Por outro lado, uma revisão da literatura revelou que o ajuste passivo total continua a ser uma meta difícil de ser alcançada pelo protético.

BHERING et al. (2015) avaliaram o efeito do desajuste e perda de torque do parafuso de retenção de unidades múltiplas de próteses dentárias implanto suportadas, após fundição de um cilindro protético, sob simulação mastigatória. Próteses fixas de 3 elementos e de arco total aparafusadas, foram enceradas usando cilindros calcináveis (plástico) ou sobrefundição (pré-usinados) sobre os pilares de implantes dentários. Os cilindros foram fundidos em liga de Co-Cr para obter quatro grupos de acordo com o tipo de cilindro e tipo de prótese $(n=10)$. Os parafusos foram apertados com $20 \mathrm{~N} / \mathrm{cm}$ (pilar) e N/cm de torque $10 \mathrm{~N} / \mathrm{cm}$ (prótese) de acordo com a recomendação do fabricante. Após 24 horas, analisou-se o torque de desaperto inicial. As mensurações das desadaptações iniciais foram realizadas de acordo com o teste Schiffleger. Os parafusos foram apertados novamente, e os espécimes foram submetidos a 106 ciclos mecânicos $(2 \mathrm{~Hz} / 280$ N). Perda de de torque e desajuste foram reavaliados (medições finais), e os dados foram submetidos à análise de variância, HSD de Tukey, e os testes de correlação de Pearson $(A=0,05)$. Nas fixas de 3 elementos, os cilindros calcináveis demonstraram maior desajuste (inicial: 107,53 \pm 40,36 | iM; final: 99,00 \pm 40,85 mm) do que os sobrefundidos (inicial: $51,50 \pm 22,98 \mathrm{~m}$; final: 44,33 $\pm 14,14 \mathrm{~mm}$ ) (inicial: $\mathrm{p}$ $=0,0005$; final: $p=0,0007)$. Nenhuma diferença estatística foi observada entre 0 calcinável e sobrefundida $(p>0,05)$ nas estruturas de arco total. A simulação mastigatória não afetou o desajuste $(p>0,05)$. As estruturas sobrefundidas de arco total, apresentaram uma perda de torque menor do parafuso do pilar $(12,05 \pm 1,80 \mathrm{~N}$ / cm) do que os calcináveis $(14,75 \pm 1,72 \mathrm{~N} / \mathrm{cm})$ na medição final $(p=0,0024)$. Os grupos calcináveis apresentaram perda de toque menor do parafuso da prótese do 
que os grupos de sobrefundição na avaliação final $(P<0,05)$. Após a simulação mastigatória, o torque do parafuso protético diminuiu nas próteses fixas de 3 elementos (inicial: 5,49 $\pm 1,07 \mathrm{~N} / \mathrm{cm}$; final: $3,73 \pm 1,15 \mathrm{~N} / \mathrm{cm} ; \mathrm{p}=0,0044$ ). Correlação entre desajuste e afrouxamento só foi observado para os parafusos protéticos $(p<0,05)$. Os componentes sobrefundidos proporcionaram um melhor ajuste nas estruturas de 3 elementos, mas não influenciou o ajuste das estruturas de arco completo. Os parafusos protéticos de estruturas sobrefundidas apresentaram maior estabilidade, enquanto que a simulação mastigatória não influenciou desajuste, mas não reduziu a perda de torque dos cilindros calcináveis das próteses de3 elementos.

BERRENDERO et al. (2015) compararam o ajuste de coroas totais de cerâmica pura fabricadas com impressões de silicone convencionais e fabricadas a partir de impressões digitais intra-orais. Trinta pacientes com 30 dentes posteriores com uma foram selecionados. Coras cerâmicas à base de zircônia foram feitas usando uma impressão digital de intraoral sistema (tecnologia Seccionamento Optical Ultrafast) (digital grupo D) e a técnica de impressão com silicone de 2 passos (Grupo convencional, C). Para replicar a interface entre a coroa e o preparo, cada coroa foi cimentada na sua correspondente clínica preparado utilizando silicone ultra-fluido. Os espécimes foram seccionados na orientação vestíbulo-lingual, e desajuste interna foi medido em diferentes áreas usando lupa estereoscópica (x 40). Os dados foram analisados pelo teste $t$ de Student e Mann Whitney $(\alpha=0,05)$. Resultados: Não houve diferenças estatisticamente significativas foram encontradas $(P>0,05)$ entre os dois grupos. O desajuste interna média e significa desajuste marginal foram 170,9 mm $(D P=119,4) / 106,6 \mathrm{~mm}(\mathrm{DP}=69,6)$ no grupo $\mathrm{D}$ e 185,4 $\mathrm{mm}(\mathrm{DP}=112,1) / 119.9 \mathrm{~mm}(\mathrm{DP}=59,9)$ para o grupo $\mathrm{C}$. Conclusão As coroas cerâmicas fabricadas usando um scanner intraoral são comparáveis com elastômero impressões convencionais em termos dos seus ajustes marginais e internos.

MATOS et al. (2015) avaliaram o comportamento de corrosão de juntas unidas por tungstênio gás inerte (TIG) brasagem e soldadura convencional em amostras feitas de comercial Ni-Cr liga em Fusayama saliva artificial a 37? C (pH 2,5 e 5,5). Material e métodos. Dezoito amostras de metais $\mathrm{Ni}-\mathrm{Cr}$ foram fundidas e soldadas por brasagem ou tungstênio métodos de gás inerte. Os espécimes foram divididos em 3 grupos (metal base, 2 soldados espécimes), e a composição e microestrutura foram avaliados qualitativamente. Os resultados de potencial de 
corrosão e de corrosão densidade de corrente foram analisados com uma análise de uma maneira de variância e teste de Tukey para comparações de pares $(a=.05)$. Resultados: Metais comuns com solda TiG mostraram resultados equivalentes em eletroquímica, testes de corrosão, enquanto os espécimes fundidos com ao ar exibiram baixa resistência à corrosão. O desempenho foi pior em $\mathrm{pH} 2.5$. Conclusões. Estes resultados sugerem que o gás inerte de tungsténio é um processo de soldadura adequado para uso em odontologia, porque a microestrutura final não reduz a resistência à corrosão em saliva artificial a $37 \mathrm{C}$, mesmo num meio de ensaio de corrosão, que facilita processos de corrosão galvânica. Além disso, a densidade de corrente de corrosão de juntas de liga de $\mathrm{Ni}-\mathrm{Cr}$ soldadas foi significativamente maior $(P<0,001)$ do que o metais comuns e tungstênio gás inerte juntas soldadas.

YOSHINARI et al. (2016) pesquisaram a resistência de união à tração e à corrosão de ligas de $\mathrm{CoCr}$ com cilindros de ouro por um sistema de solda em comparação com o sistema de fundição convencional. Ligas de CoCr foram unidos a cilindros de ouro por um sistema de solda de alta fusão e outro grupo ligas de ouro foram unidas a cilindros de ouro pelo método da fundição. Foram realizados testes de tração e resistência a corrosão e avaliadas no MEV Nos resultados encontramos que as forças de união foram semelhantes nos 2 grupos. Essas estruturas híbridas com liga de cobalto-cromo e cilindro de ouro são promissoras para superestruturas de implante com o baixo custo e propriedades mecânicas favoráveis em relação as de ouro.

FASBINDER e NEIVA (2016) realizaram um estudo com objetivo de medir a rugosidade de superfície de restaurações produzidas no CAD/CAM usando vários sistemas de polimento. Materiais e Métodos: 100 onlays foram usinadas a partir de blocos de CAD/CAM monolíticas, sendo 30 de resina de nano-cerâmica (Lava Ultimate, 3M ESPE), 30 híbridos de cerâmica (Enamic, Vita) e 40 de cerâmica reforçada com leucita (EmpressCAD, Ivoclar). Um único grupo de onlays EmpressCAD foi glaseado no forno de porcelana (Programat CS2, Ivoclar). Sistemas de acabamento e polimento consistiram de uma técnica abrasiva/polimento. Valores de rugosidade foram medidos utilizando um microscópio de laser de medição tridimensional (OLS4000 LEXT pela Olympus). Resultados: Houve uma diferença significativa na rugosidade da superfície da linha de base dos materiais de CAD/CAM ( $p \leq 0,05)$, com o nano-cerâmico (Lava Ultimate) de resina ser mais suave 
do que o híbrido de cerâmica (Enamic), e sendo ambas suave do que a cerâmica reforçada com leucita (EmpressCAD). Todas as técnicas de polimento resultaram em uma superfície mais lisa em comparação com a superfície da linha de base para o cerâmico reforçado com leucita ( $p \leq 0,05)$, com ambas as técnicas resultando numa superfície significativamente mais suave do que um forno de vitrificação em porcelana $(p \leq 0,05)$.

ZARAUZ et al. (2016) compararam o ajuste de coroas totais cerâmicas fabricadas a partir de impressões de silicone convencionais com coroas fabricadas a partir de impressões digitais intra-orais. Vinte pacientes com 26 dentes posteriores foram selecionados para o estudo. Duas coroas (Straumann-Zerion) foram feitas para cada preparo. Uma coroa foi fabricada a partir de um sistema de impressão digital de intraoral (IDI group; Cadent-iTero), e a outra coroa foi fabricado a partir de um silicone de impressão de uma etapa convencional $(\mathrm{Cl}$ group; Express Penta Putty and Body Light). Para replicar a interface entre a coroa e a preparo, cada coroa foi cimentada no seu preparo clínica correspondente com silicone ultra-flow (Express Ultra Light Body) cada coroa foi incorporado na resina para estabilizar a interface registada, cortar em fatias de $2 \mathrm{~mm}$ de espessura em uma orientação bucolingual. $\mathrm{O}$ desajuste foi medido em microns usando lupa estereoscópica com uma ampliação de $\times$ 40. As medidas foram tomadas em diferentes marcos: margem, ângulo do chanfro, axial, crista, e fossa oclusal. Depois de verificar a normalidade, os dados foram analisados e emparelhado por meio do teste $t$ de Student $(\alpha=0,05)$. Resultados: valores foram significativamente afetadas pela técnica de impressão ( $p$ $=0,000)$. A média de desajuste interna e média desajuste marginal foram 111,40 $\mathrm{mm}(\mathrm{DP}=54,04) / 80.29 \mathrm{~mm}(\mathrm{DP}=26,24)$ para as coroas do grupo IDI e 173,00 mm $(\mathrm{DP}=92,65) / 133.51 \mathrm{~mm}(\mathrm{DP}=48,78)$ para o grupo $\mathrm{Cl}$. Conclusão coroas em cerâmica pura fabricadas por impressões com tecnologia confocal paralela de digital intraoral demonstraram um ajuste interno e marginal clinicamente aceitável, convencional impressão. 
PROPOSIÇÃO 



\section{ProposiçÃo}

O objetivo deste trabalho foi avaliar, por meio de microscopia óptica e microscopia confocal a laser, a adaptação marginal de barras metálicas tipo protocolo de Branemark, de ligas de niquel-cromo ( $\mathrm{NiCr}$ ) em monobloco e soldadas (solda convencional e solda TIG) confeccionadas a partir de enceramento convencional. 

MATERIALEMÉTODOS 



\section{Material e Métodos}

\subsection{Materiais, Instrumentos e Aparelhos}

Para o presente estudo foram usados os seguintes materiais:

- Modelo de mandíbula em Resina Acrílica (Nacional Ossos, Jaú, SP, Brasil)

- Resina Acrílica

- Duralay (Reliance Dental Co, Illinois, EUA)

- Pattern Bright (KOTA, SP, Brasil)

- Gesso Tipo IV (Durone tipo IV, Dentsply, EUA)

- Gesso Tipo III (Asfer, São Caetano do Sul, SP, Brasil)

- Liga NiCr (Fit Cast-V Plus, Talmax, Curitiba, PR, Brasil)

- Fluxo (Fluxo Fit, Talmax, Curitiba, PR, Brasil)

- Solda (Bordente, SP, Brasil)

- Componentes Protéticos (Conexão, Arujá, São Paulo, Brasil)

- Análogos Microunit

- Transferentes Quadrados Microunit

- Cilindros plásticos do Microunit (UCLA plástica)

- Parafuso sextavados do Cilindro do Microunit

- Brocas e Discos

- Broca Carbide 170L

- Disco (Ninja Gold, TALMAX, Curitiba, Brasil)

- Espatuladora a vácuo (Twister Evolution, Renfert, Alemanha)

- Forno Elétrico (EDG 3000 3P, São Carlos, Brasil)

- Maçarico (EDG, São Paulo, SP, Brasil)

- Centrífuga para fundição (EDG, São Carlos, Brasil)

- Aparelho de solda TIG (modelo PUK D2, Lampert, Alemanha)

- Microscópio Óptico, Lupa estereoscópica S8AP0 (Leica, Leica Microsystems, Hurbrugg, Suíça)

- Microscópio Confocal a Laser 3D (Olympus LEXT OLS4000®, Japão) 


\subsection{Delineamento Experimental}

Para o estudo da variável adaptação marginal por meio de dois métodos, microscopia Confocal a laser e microscopia Óptica, foi realizado o plano piloto, no qual foram determinados os fatores de estudo, estabelecidas as condições essenciais para cada um dos métodos de medição utilizados, além de identificar e controlar os fatores não interessantes para o estudo proposto.

Os fatores com seus níveis e respectivas siglas são:

1) Fator Método de medida, com 2 níveis:

CF - Microscópio Confocal a laser

MO - Microscópio Óptico

2) Fator Técnica de solda, com 3 níveis:

MNB - Monobloco

CNV - Solda Convencional

TIG - Solda TIG

3) Fator Secção, com 3 níveis:

S1 - 1 Secção

S3 - 3 Secções

SOL - Soldada

4) Fator Implante, com 4 níveis:

I1 - Implante posterior

12 - Implante anterior direito

I3 - Implante anterior esquerdo

14 - Implante posterior

\subsection{Delineamento Estatístico}

A variável de estudo adaptação marginal $(\mu \mathrm{m})$ é uma variável continua. Para a realização do estudo foi determinado o número de repetições $n=5$ para cada condição experimental. Totalizando um total de 60 implantes.

Para melhor avaliação do efeito dos fatores de estudo sobre a adaptação marginal na condição estática, utilizando os dois métodos de medições, Microscopia 
Confocal a laser e Microscopia Óptica, foram realizadas diferentes análises estatísticas.

Assim, foram realizadas as seguintes análises:

1. Fatores Método e Técnica

a. Modelo fatorial $2 \times 3$

2. Microscopia Confocal - Fatores Secção e Técnica

a. Modelo fatorial $3 \times 2$

3. Microscopia Óptica - Fatores Secção e Técnica

a. Modelo fatorial $3 \times 2$

4. Microscopia Confocal - Fatores Técnica e Implante

a. Modelo fatorial $3 \times 4$

5. Microscopia Óptica - Fatores Técnica e Implante

a. Modelo fatorial $3 \times 4$

Quando utilizado o Método de Microscopia Confocal a laser foram realizadas 3 leituras na face vestibular, por cada corpo de prova, totalizando um total de 180 leituras. Foi obtida a média das 3 leituras por cada corpo de prova, que resultaram em 60 número de dados.

Quando utilizado o Método de Microscopia Óptica foram realizadas 6 leituras na fase vestibular e lingual, por cada corpo de prova, totalizando um total de 360 leituras. Foi obtida a média das 6 leituras por cada corpo de prova, que resultaram em 60 número de dados.

Para cada uma das análises realizadas foi determinada a aplicação do Teste de Normalidade (Shapiro-Wilk ou Kolmogorov-Smirnov (alfa $=5 \%$ )) para determinação da distribuição da amostra. Para a amostra com distribuição normal foi determinada a utilização do teste paramétrico, Análise de Variância, enquanto que a amostra com distribuição não normal, determinou-se a utilização do teste não paramétrico de Kruskal Wallis. Foi utilizado o Programa Estatístico Assistat. 7.7.

\subsection{Métodos}

4.4.1 Modelo mestre e Modelo de trabalho

4.4.1.1 Confecção do modelo mestre

O modelo mestre foi obtido a partir de um modelo de mandíbula em resina acrílica (Nacional Ossos, Jaú, SP, Brasil). Utilizando perfurações já existentes foram 
adaptados quatro análogos de microunit (Conexão, Arujá, São Paulo, Brasil) com diâmetro de 4,1 $\mathrm{mm}$ para simular um caso de prótese fixa tipo protocolo de Branemark, com quatro implantes (Fig.1) inter forames mentuais. Os análogos foram adaptados nas perfurações, de modo a ficarem paralelos entre si. Da esquerda para a direita, os componentes protéticos foram numerados de 1 a 4 (Fig. 2).

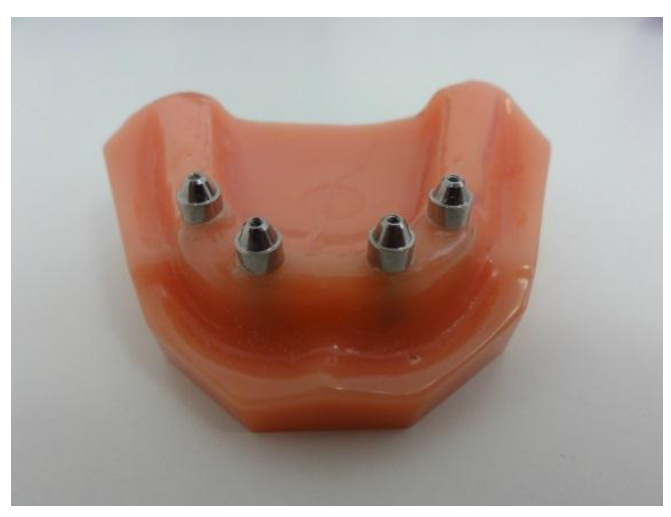

Figura 1 - Modelo mestre e os análogos em posição.

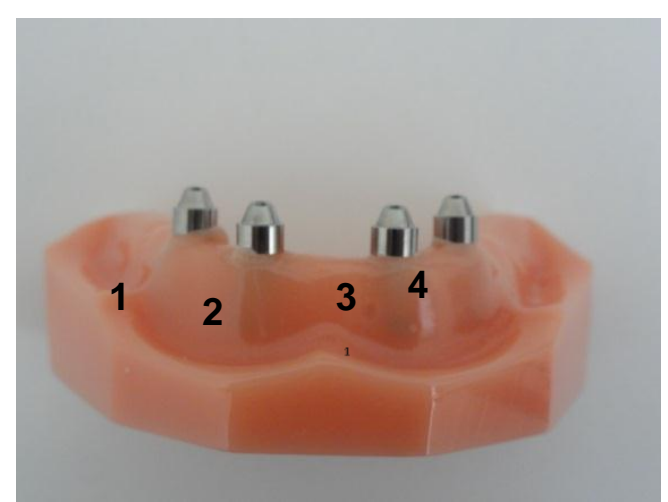

Figura 2 - Numeração dos análogos e paralelismo entre eles.

\subsubsection{Transferência da posição dos análogos dos minipilares}

Quatro transferentes quadrados do microunit (Conexão, Arujá, São Paulo, Brasil) foram adaptados nos análogos de microunit no modelo mestre, unidos com fio dental (Sanifill, São Paulo, SP, Brasil) (Fig. 3) e resina acrílica (Duralay, Reliance Dental Co, Illinois, EUA) (Fig. 4). Após a polimerização da resina, a tensão gerada por ela, foi eliminada pelo seccionamento do conjunto resina/fio dental, entre os transferentes com broca tipo carbide 170L (Fig. 5). Em seguida, as partes foram novamente unidas, com resina Duralay, tendo o cuidado de realizar uma união de cada vez (Fig. 6). 


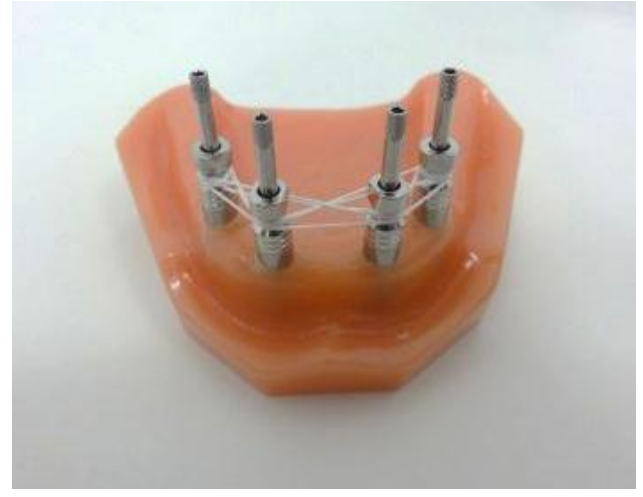

Figura 3 - Transferentes unidos com fio dental.

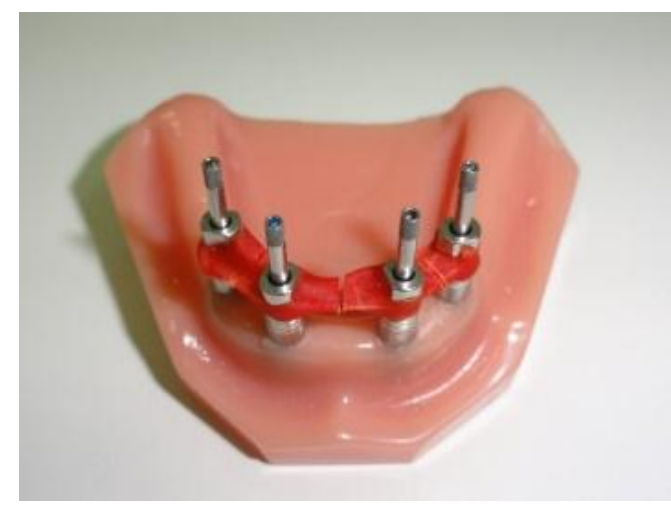

Figura 5 - Seccionamento com broca Carbide.

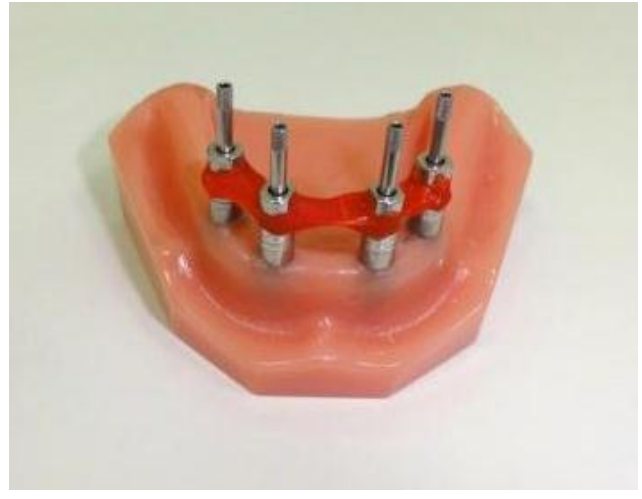

Figura 4 - Transferentes unidos com Resina Duralay.

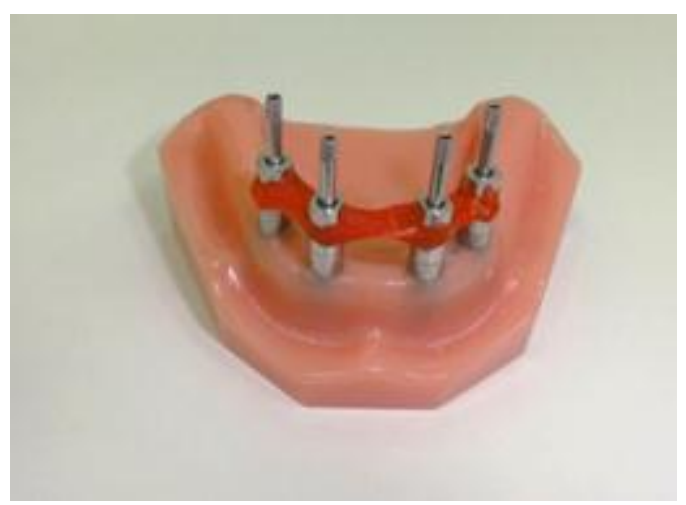

Figura 6 - União após seccionamento com resina Duralay.

\subsubsection{Moldagem com moldeira aberta}

Uma moldeira de estoque, de plástico (Morelli, Sorocaba, SP, Brasil) foi selecionada e perfurações foram realizadas para abrir espaço para os transferentes quadrados. Foi utilizado como material de moldagem a silicone de condensação (Zetaplus System, Zhermack, Itália), sendo que o material leve foi injetado com uma seringa para elastômero, diretamente sobre os transferentes ferulizados com resina e fio dental e, o material pesado, na moldeira (Fig. 7 A e B). No molde ficaram inseridos os transferentes. 

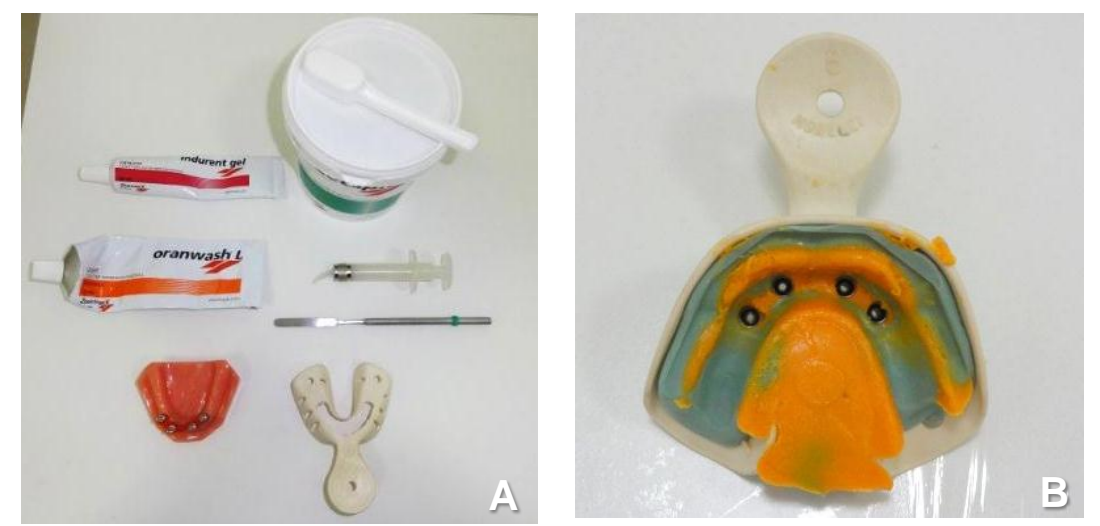

Figura 7- A - Material de Moldagem Silicone de Condensação; B- Molde.

Análogos foram adaptados nos transferentes para a confecção do modelo de gesso.

Vinte gramas de gesso pedra tipo IV (Durone tipo IV, Dentsply, EUA) foram manipulados, manualmente, na proporção água/pó recomendada pelo fabricante, e, posteriormente, vazado no molde e mantido sobre a bancada, por uma hora, aguardando a presa do gesso para depois ser complementado com gesso tipo III (Asfer, São Caetano do Sul, SP, Brasil) (Fig. 8).

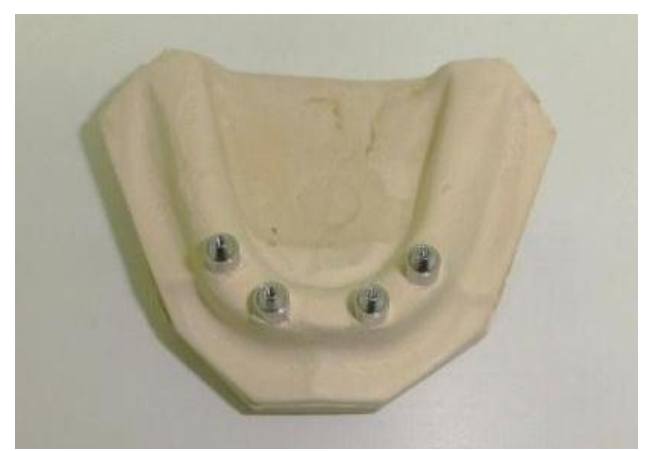

Figura 8 - Modelo de gesso com análogos em posição.

Todo o processo foi repetido para a confecção de novo modelo de gesso, perfazendo 15 modelos para a realização do projeto. Esses modelos $(n=15)$ foram divididos de maneira que, 5 modelos foram utilizados para monobloco, 5 modelos para a técnica de soldagem com maçarico e 5 modelos para a técnica de soldagem TIG. 


\subsubsection{Confecção da barra:}

\subsubsection{Técnica convencional (Enceramento)}

Sobre os modelos $(n=15)$ foram adaptados cilindros plásticos do microunit (Conexão, Arujá São Paulo, Brasil) (Fig. 9). Foram confeccionados os padrões das barras em resina acrílica autopolimerizavel (Pattern Bright, KOTA, SP, Brasil) medindo $4 \mathrm{~mm}$ de altura por $4 \mathrm{~mm}$ de largura, e unidas aos cilindros calcináveis com a própria resina acrílica (Fig. 10), onde nos implantes distais o cantilever foi de $15 \mathrm{~mm}$. Estes foram seccionados $2 \mathrm{~mm}$ acima do parafuso do cilindro do microunit. Em seguida, uma fina camada de cera foi aplicada por todo o conjunto, com a finalidade de obter uma padronização nos padrões (Fig. 11).

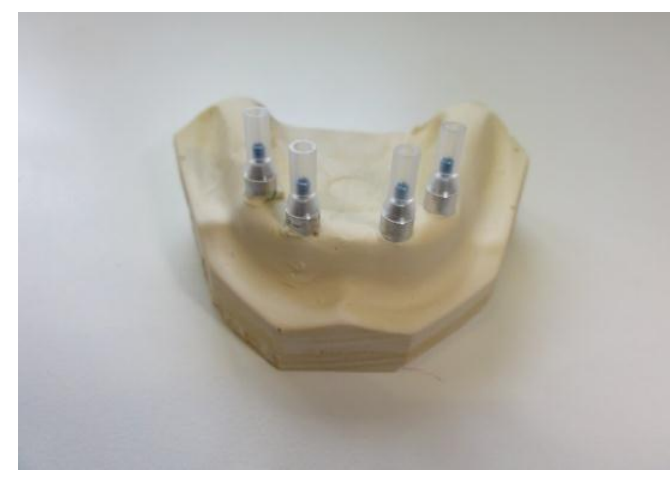

Figura 9 - Cilindros plásticos adaptados no análogo do microunit

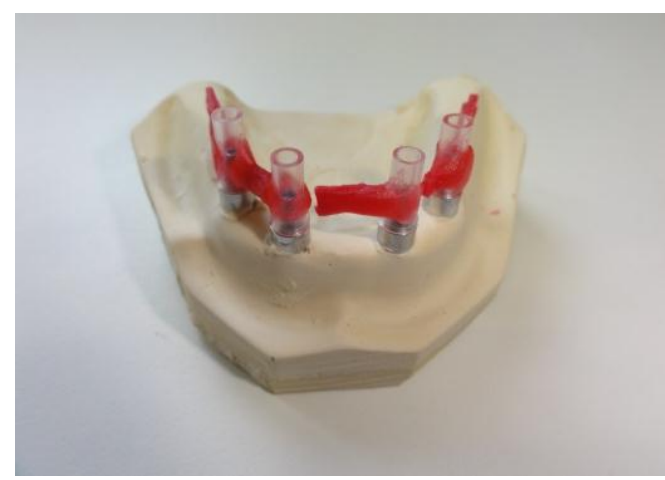

Figura 10 - Barras em resina acrílica unidas aos cilindros plásticos

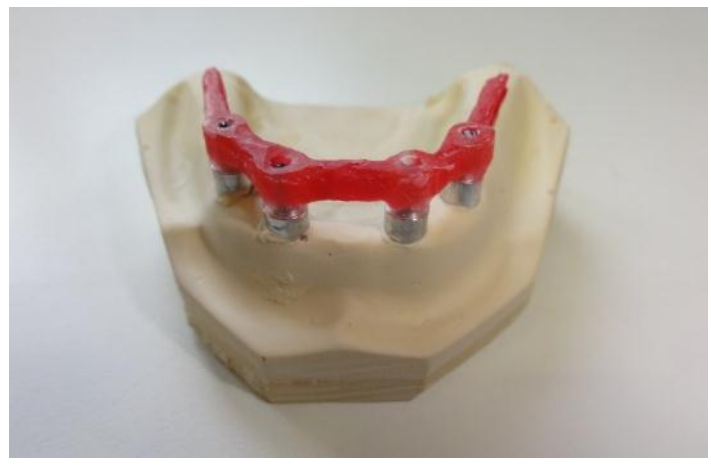

Figura 11 - Enceramento da barra finalizado.

Após o enceramento, 5 padrões foram incluídos em monobloco, sem secção, formando o grupo Monobloco. Os outros 10 padrões foram seccionados (Secção 1) na metade da distância entre os cilindros calcináveis dos implantes 2 e 3 , com o disco de Oxido de Alumínio de 25x0,6 mm (Ninja Gold, Talmax, Curitiba, Brasil) (Fig. 12 A e B). 

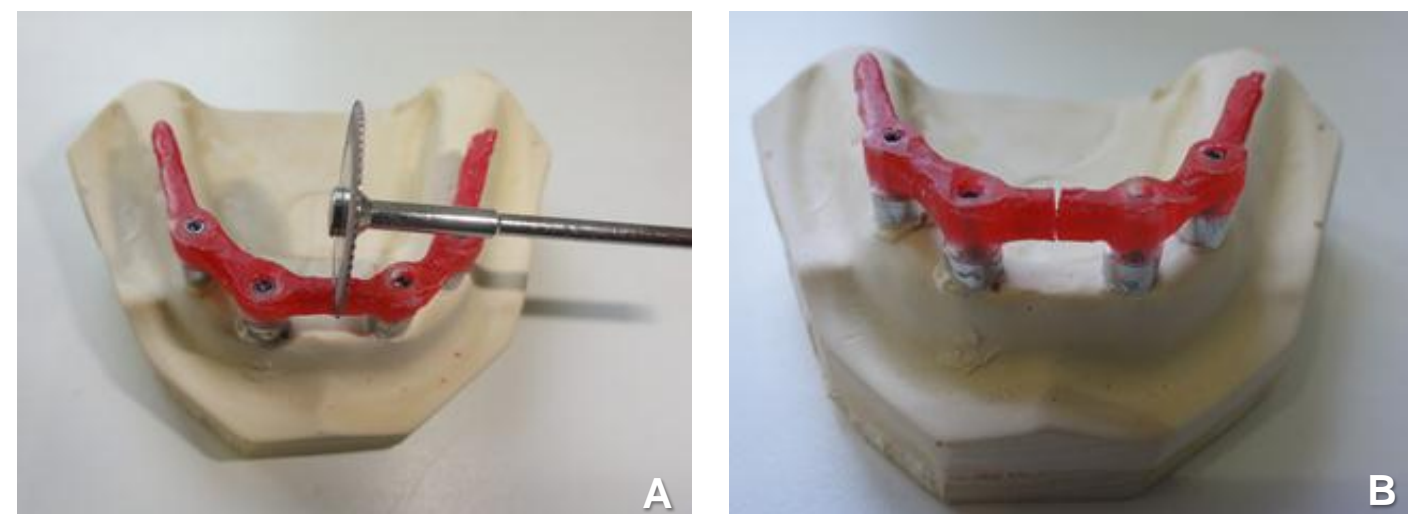

Figura 12- A - Secção da barra após encerada, para alivio de tensão; B - Barra seccionada entre os implantes 2 e 3 .

\subsubsection{Inclusão em revestimento}

Em todos os conjuntos foram aplicados, com pincel, um líquido umectante anti-bolhas (Expansor, VIPI, Pirassununga, Brasil) para diminuir a tensão superficial. Os anéis de inclusão de silicone foram adaptados à base e preenchidos, sob vibração e pincel, com revestimento fosfatado para alta fusão (Calibra Express, VIPI, Pirassununga, Brasil), na proporção de $20 \mathrm{ml}$ de líquido para 1 envelope de $90 \mathrm{~g}$ (Fig. 13). Para evitar a formação de bolhas, o revestimento foi espatulado, manualmente, por 10 segundos e, mecanicamente a vácuo, por 60 segundos (Twister Evolution, Renfert, Alemanha), de acordo com as especificações do fabricante (Fig. 14).

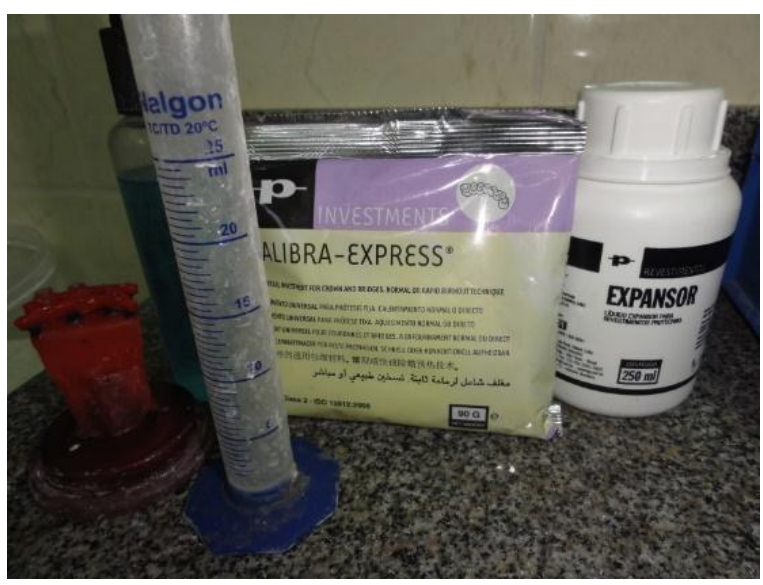

Figura 13 - Revestimento Fosfatado.

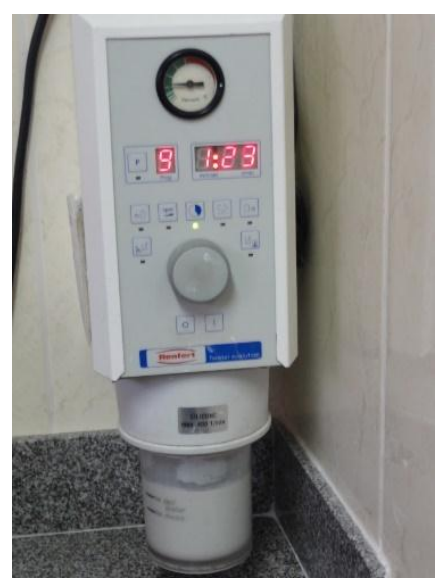

Figura 14 - Espatulador a vácuo.

Para o grupo monobloco foi incluído um padrão por anel de inclusão de silicone, com capacidade para 120g (OGP, Bragança Paulista, SP, Brasil). A partir da base formadora do cadinho foi colocado um conduto de alimentação, em cera utilidade (Wilson, Polidental, Brasil) em forma piramidal, sobre o qual foi fixado o 
padrão de cera por meio de 4 condutos de alimentação, com 2,5mm de diâmetro (Fio de cera, Dentaurum, Alemanha) (Fig. 15 A e B).

Para os grupos solda Convencional e TIG foram incluídos 2 padrões de cera (seccionados) por anel de inclusão de silicone, com capacidade para $90 \mathrm{~g}$ (OGP, Bragança Paulista, SP, Brasil). A partir da base formadora do cadinho foi colocado um conduto de alimentação, em cera utilidade (Wilson, Polidental, Brasil), em forma piramidal, sobre o qual foram fixados os padrões de cera por meio de 8 condutos de alimentação com 2,5mm de diâmetro (Fio de cera, Dentaurum, Alemanha) (Fig.16 A e B).
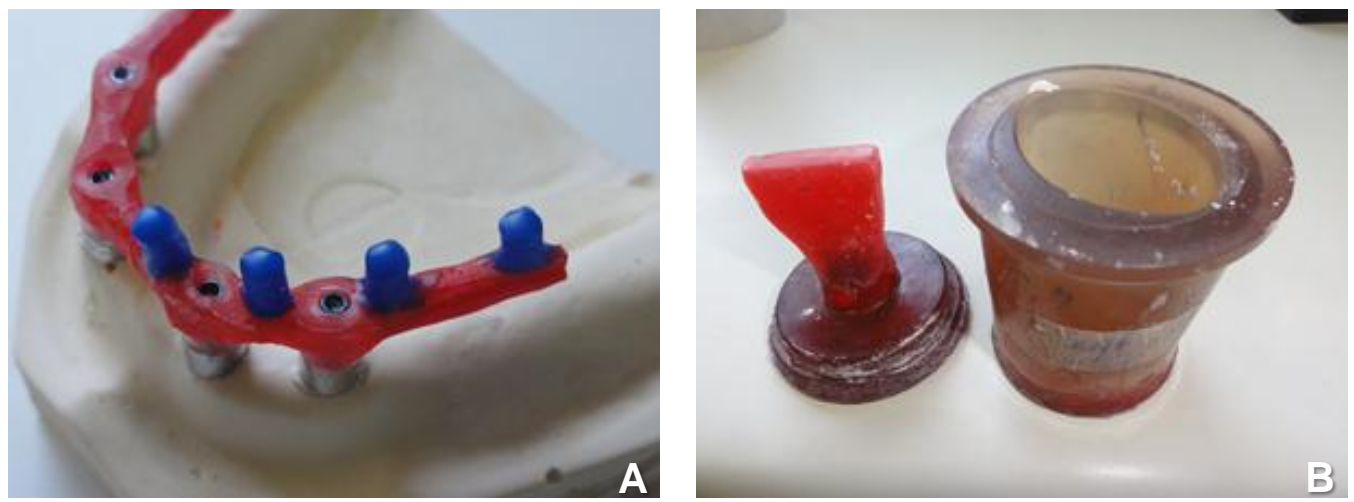

Figura 15- A- Condutos de alimentação; B - Anel de inclusão de silicone.

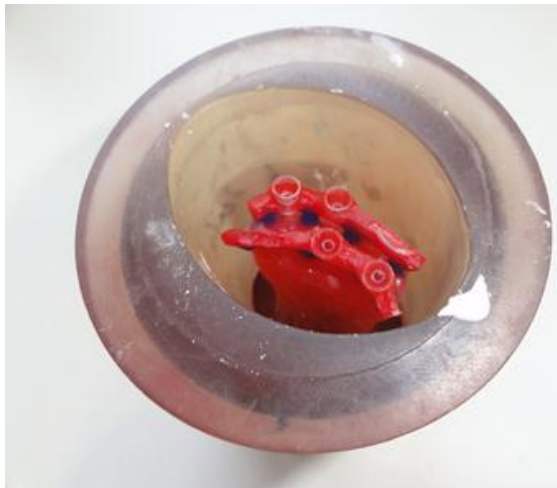

A

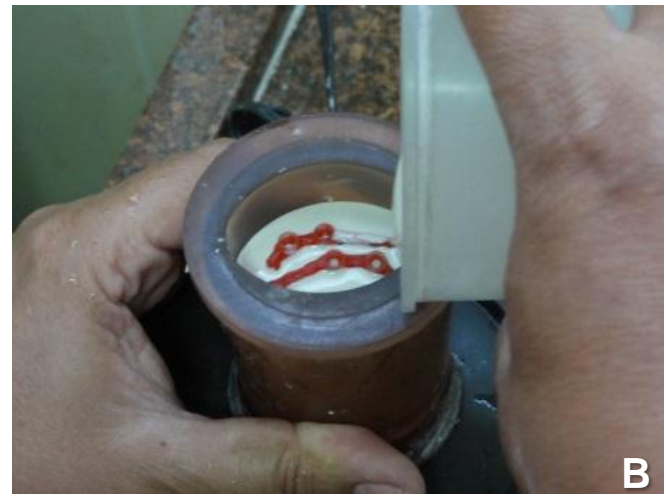

Figura 16- A- Padrão de cera posicionado dentro do anel de fundição em 2 partes; B Preenchimento com revestimento fosfatado.

\subsubsection{Processo de fundição}

Decorrido o tempo de uma hora de cristalização do revestimento, a base formadora do cadinho e o anel de silicone foram cuidadosamente removidos para a colocação do cilindro de revestimento no interior do forno elétrico (EDG 3000 3P, São Carlos, Brasil) para a expansão do revestimento, eliminação da cera e do 
plástico calcinável, seguindo o seguinte ciclo de aquecimento: 1. Elevação da temperatura do forno, a uma velocidade de $5^{\circ} \mathrm{C}$ por minuto, até $350^{\circ} \mathrm{C}$ e manutenção nesta temperatura por 60 minutos. 2. Aumento da velocidade de aquecimento para $7^{\circ} \mathrm{C}$ por minuto, elevação da temperatura do forno até $750^{\circ} \mathrm{C}$ e manutenção nesta temperatura por 30 minutos. 3. Aumento da velocidade de aquecimento do forno para $12^{\circ} \mathrm{C}$ por minuto, elevação da temperatura até $940^{\circ} \mathrm{C}$ e manutenção nesta temperatura por 15 minutos e em seguida, realização da fundição (Fig. 17 A e B).
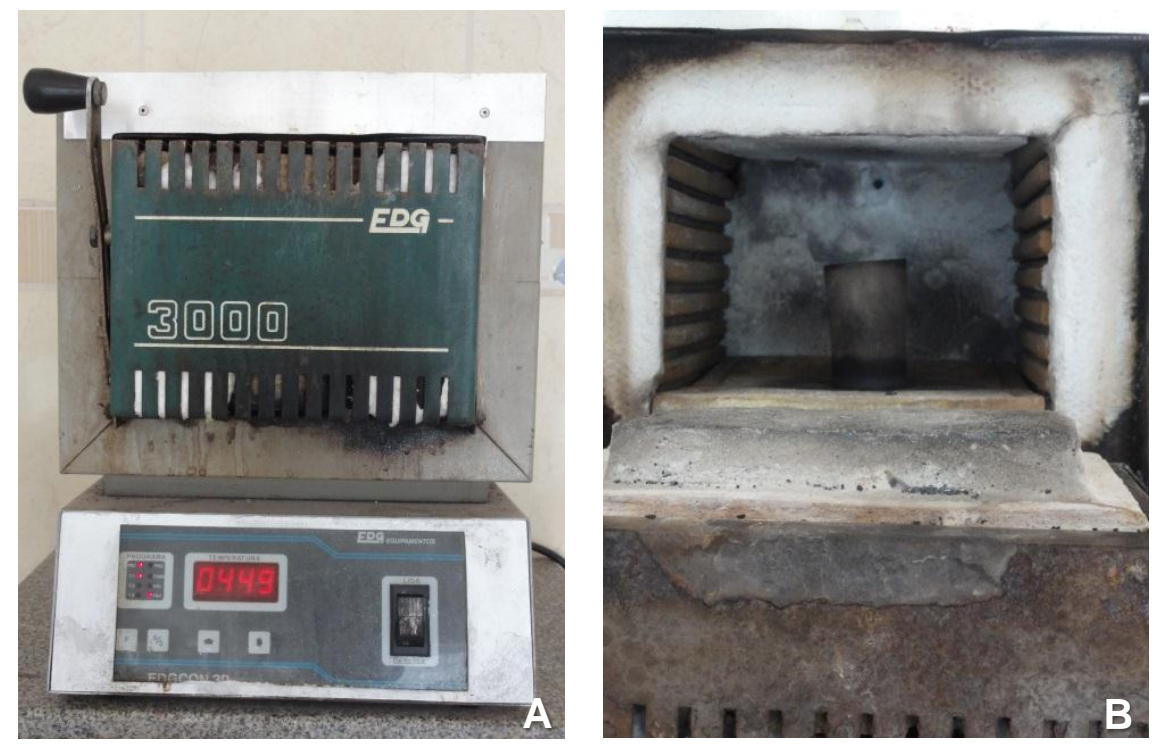

Figura 17- A- Forno para Anel EDG 3000; B - Cilindro de revestimento no interior do forno.

O cadinho cerâmico para Níquel tamanho 2,5 (Daufenbach, Santa Catarina Brasil), previamente aquecido, foi posicionado no braço da centrífuga para fundição (EDG, São Carlos, Brasil) que foi ativada, sempre com 2 voltas (Fig. 18). Em seguida, uma porção de liga de 22g, à base de níquel-cromo (Fit Cast-V Plus, Talmax, Curitiba, PR, Brasil) foi posicionada no cadinho e liquefeita, gradualmente, utilizando a chama redutora de um maçarico (EDG, São Paulo, SP, Brasil), com proporções adequadas de gás/oxigênio (Fig. 19). 


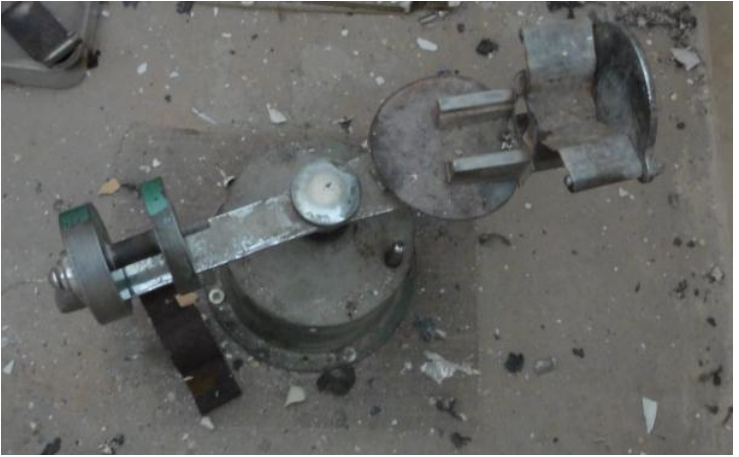

Figura 18 - Centrifuga para fundição.

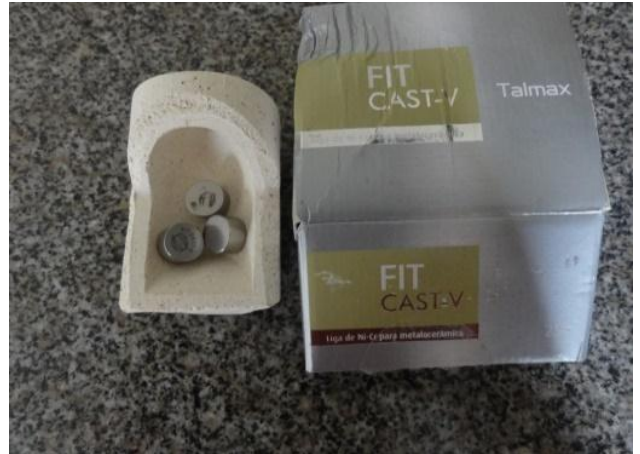

Figura 19 - Liga Fit Cast V - NiCr.

Após a fundição, os corpos-de-prova foram mantidos sobre a bancada em temperatura ambiente, por 1 hora, antes da desinclusão, pois, o resfriamento muito rápido poderia provocar alterações dimensionais nas estruturas metálicas. Em seguida, os corpos-de-prova fundidos foram desincluídos, os condutos de alimentação removidos com disco de carburundum e jateados com óxido de alumínio de granulação 100 e pressão de $60 \mathrm{lb} / \mathrm{pol}^{2}$, tendo-se o cuidado de preservar as interfaces protéticas (Fig. 20 A, B, C e D).
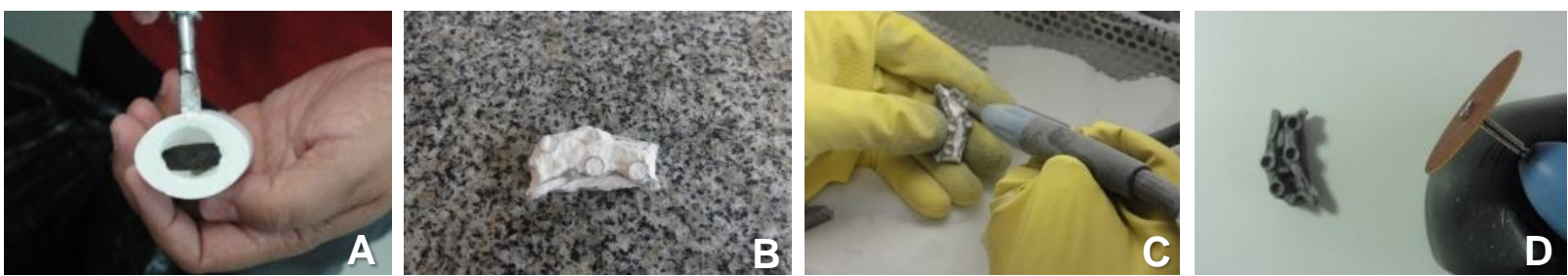

Figura 20 - A, B - Desinclusão; C - Jateamento com óxido de alumínio; D - Separação da peça em 2 partes.

No caso de presença de bolhas positivas, estas foram removidas, cuidadosamente, com brocas carbides 170L. Para remover possíveis irregularidades internas foi utilizado o kit Retificador Manual (Conexão, Arujá, São Paulo, Brasil) (Fig. $21 \mathrm{~A}$ e B) 


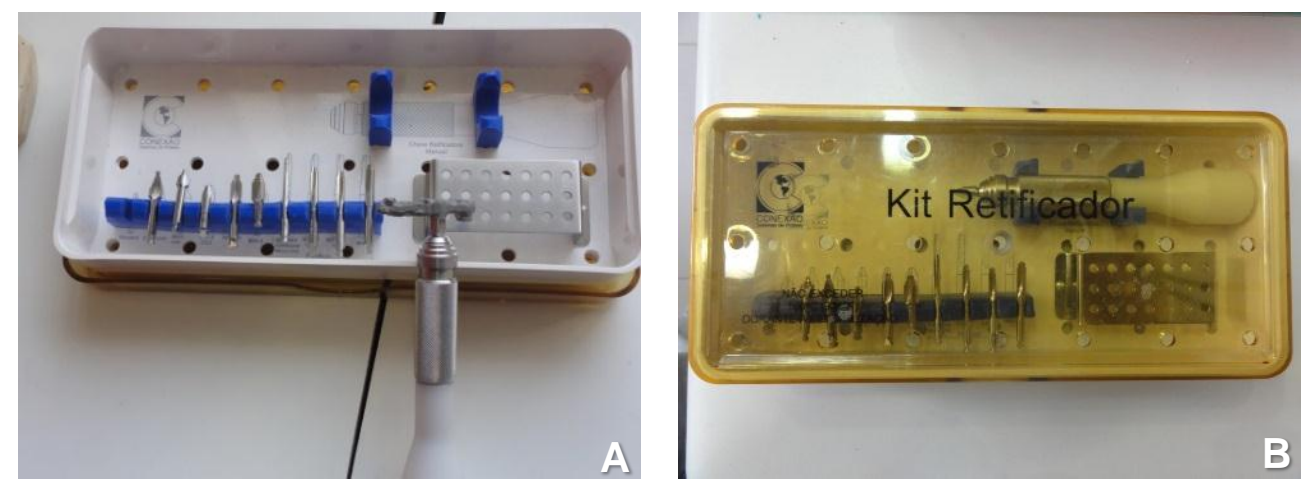

Figura 21 - A e B Kit Retificador Conexão para remoção de irregularidades na base.

Em seguida, os corpos-de-prova $(n=5)$ em monobloco foram adaptados nos respectivos modelos, para a realização das medidas do grau de desadaptação no modelo mestre (Fig. 22.).

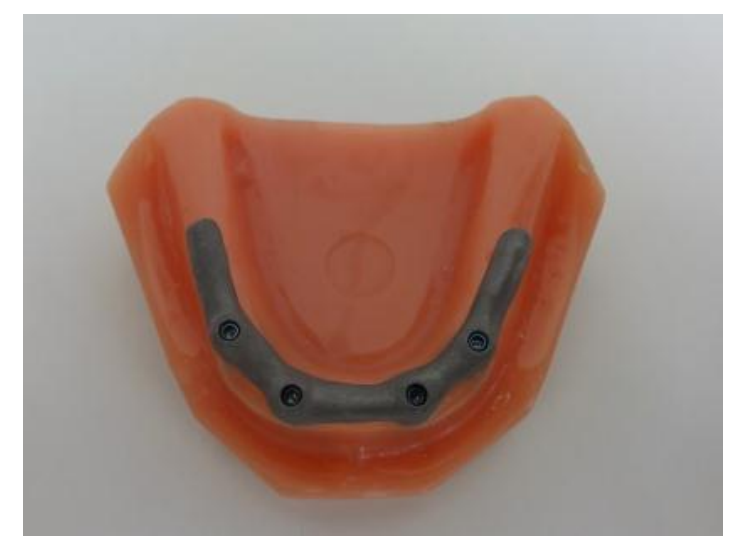

Figura 22 - Estrutura pronta no modelo mestre.

\subsubsection{Técnicas de Soldagem}

\subsubsection{Soldagem Convencional, a maçarico}

Os corpos-de-prova foram reinstalados nos respectivos modelos e unidos com resina acrílica (Duralay, Reliance Dental Co, Illinois, EUA). Após a polimerização da resina, os corpos-de-prova foram incluídos em revestimento (Calibra Express, VIPI, Pirassununga, Brasil) na proporção $20 \mathrm{ml}$ de líquido para 1 envelope de $90 \mathrm{~g}$. Após a presa do revestimento, uma hora após o início da espatulação, foi realizada a soldagem. Inicialmente, a resina acrílica foi eliminada na chama do maçarico para solda (EDG, São Carlos, Brasil) e a região a ser soldada foi aquecida. Sobre o local das soldas foi colocado o fluxo (Fluxo Fit, Talmax, Curitiba, $\mathrm{PR}$, Brasil), para limpar e facilitar o escoamento da liga de solda. Em seguida, foram 
realizadas as soldagens seguindo as orientações do fabricante da solda (Bordente, SP, Brasil) (Fig. 23 A, B, C e D). Logo após, o conjunto peça e revestimento foi aquecido, uniformemente, até que a peça apresentasse uma tonalidade vermelho brilhante. Neste momento, a chama foi posicionada sobre a junta a ser soldada e a vareta de solda, presa por uma pinça mosquito de ponta reta, foi imersa no fluxo e levada para a região a ser soldada, onde recebeu a chama do maçarico. Após a soldagem, o resfriamento dos corpos-de-prova ocorreu sobre a bancada de trabalho, até que atingisse a temperatura ambiente.
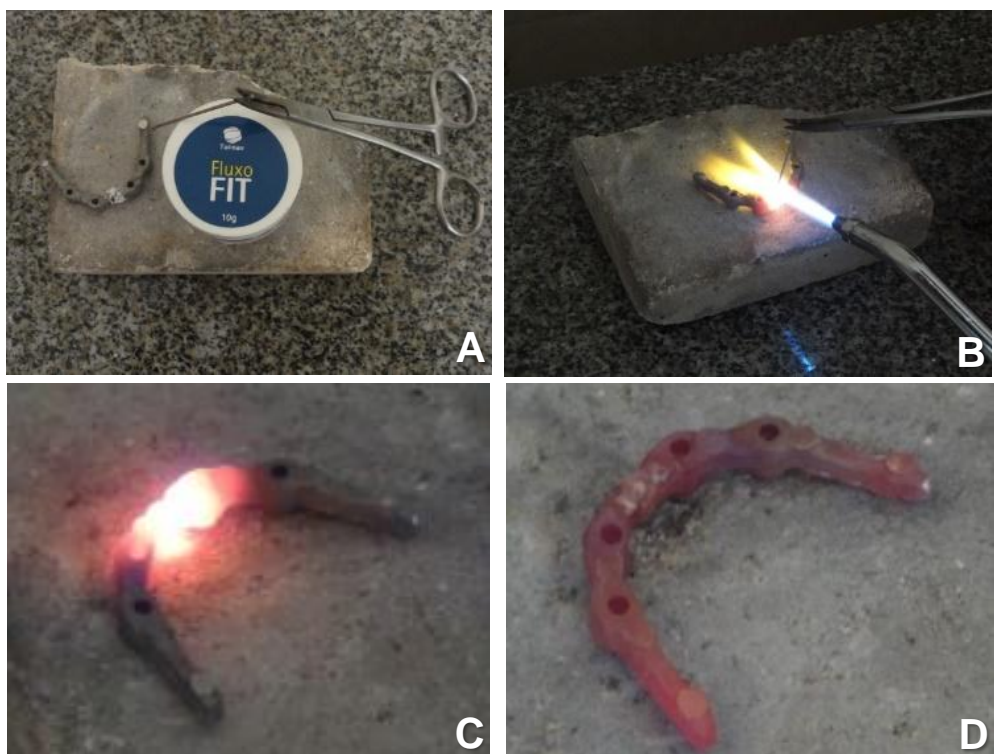

Figura 23- Processo de Solda Convencional a maçarico.

\subsubsection{Soldagem TIG}

A soldagem com arco elétrico foi realizada com aparelho de solda "TIG" (modelo PUK D2, Lampert, Alemanha) e com os corpos-de-prova assentados sobre os respectivos modelos. O aparelho foi regulado em $60 \mathrm{~A}$ e com tempo de $120 \mathrm{~ms}$. Para isso, o aparelho foi montado com eletrodo de tungstênio centralizado no interior do bocal cerâmico, seguindo as recomendações do fabricante: eletrodo posicionado, perpendicularmente à peça a ser soldada e à distância de 0,5 mm; limpeza do eletrodo com lixa de óxido de alumínio, 220 mesh a cada dois disparos; eletrodo sempre afiado, de modo que, a ponta do mesmo se mantivesse extremamente pontiaguda. O tempo de pré-fluxo e pós-fluxo estipulado para vazão de gás argônio foi de $2 \mathrm{~L} / \mathrm{min}$. 
Os modelos com os corpos-de-prova foram posicionados na máquina soldadora. $\mathrm{Na}$ extremidade lateral do corpo de prova foi posicionada uma garra tipo jacaré formando o polo positivo, uma vez que, o pólo negativo foi conectado ao eletrodo de tungstênio da máquina de solda TIG, e assim permaneceu durante a soldagem (Fig. 24 A e B).
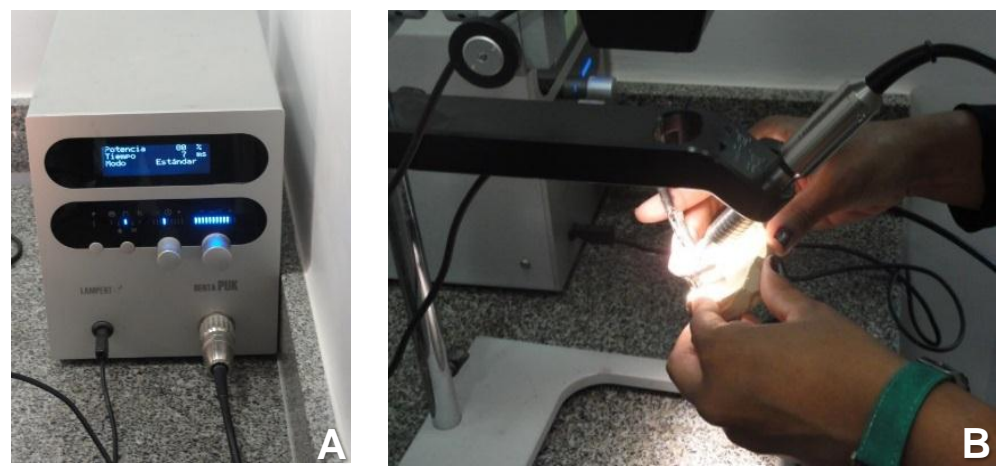

Figura 24- A e B - Processo de Solda TIG.

Após a solda, os modelos com as estruturas metálicas seccionadas foram divididos, aleatoriamente, em grupo da técnica de soldagem TIG $(n=5)$ e grupo da técnica de soldagem com maçarico $(n=5)$.

Nas figuras 25 as barras estão prontas para as medições (Fig. 25 A e B).
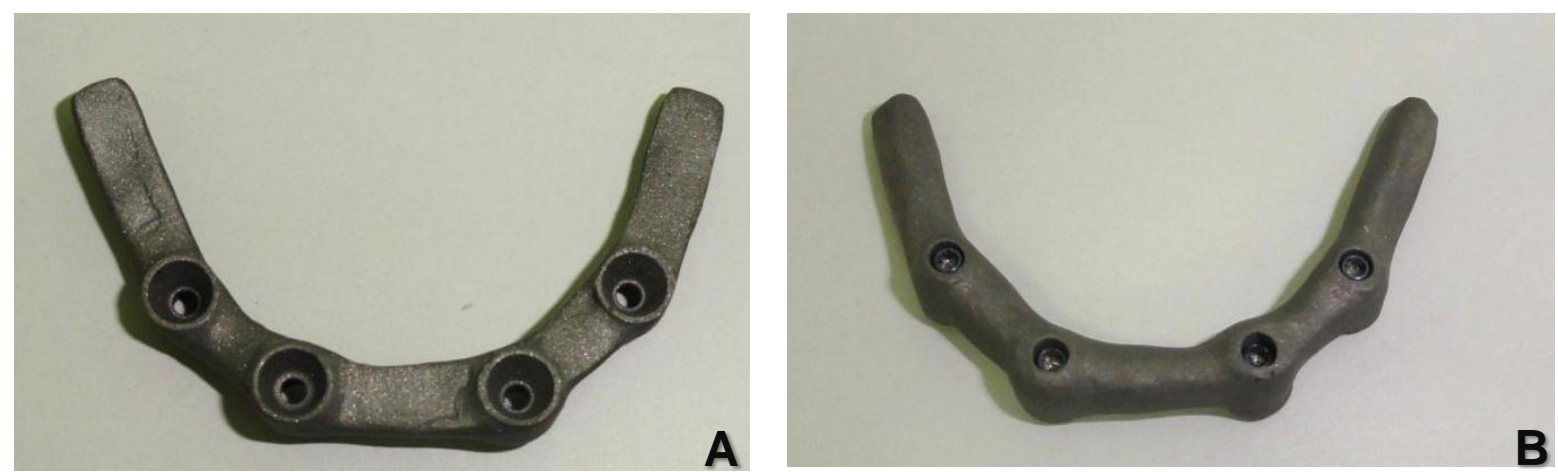

Figura 25- A, B -Barras prontas para a medição.

As medições da adaptação marginal foram obtidas em micrômetro, por meio dos seguintes métodos:

\subsubsection{Microscopia Óptica}

Todas as barras foram analisadas na lupa estereoscópica S8AP0 (Leica, Leica Microsystems, Hurbrugg, Suíça), com aumento de 63X. Para realização das 
mensurações foi utilizado o programa Leica Application Suíte V3 (Leica Microsystems, Hurbrugg, Suíça) (Fig. 26 A e B).
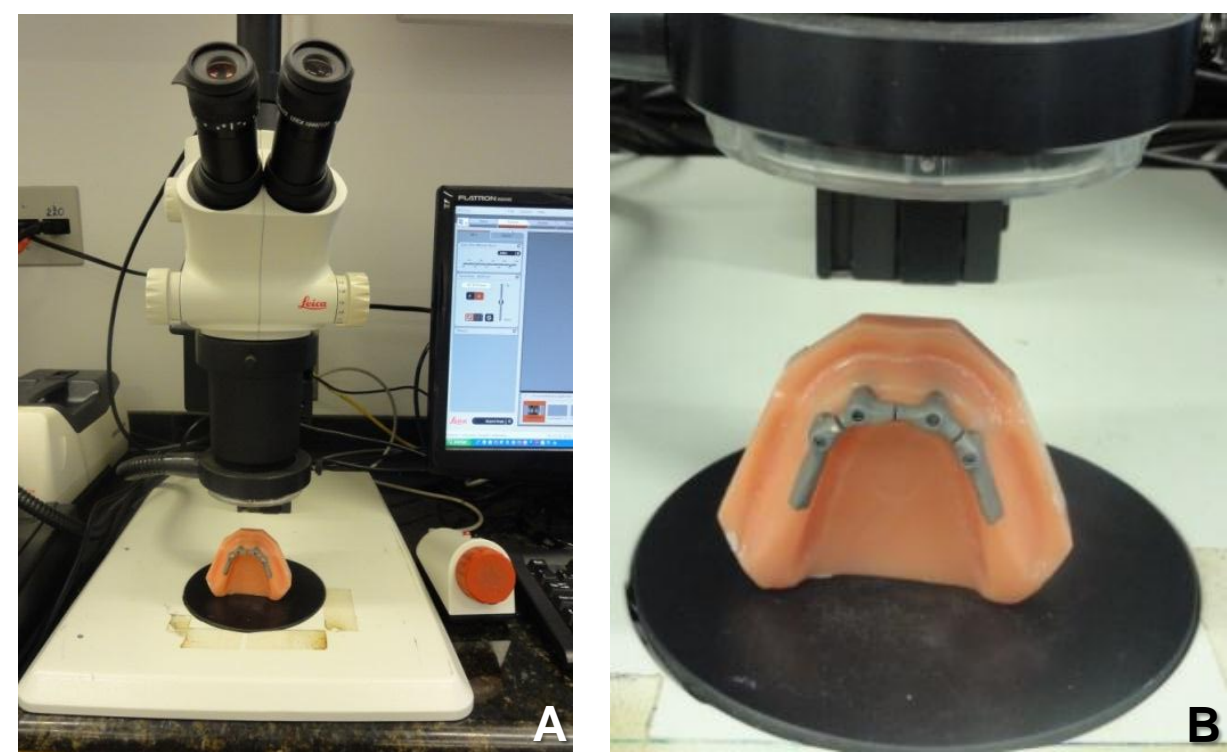

Figura 26- A, B - Leitura no Microscópio Óptico.

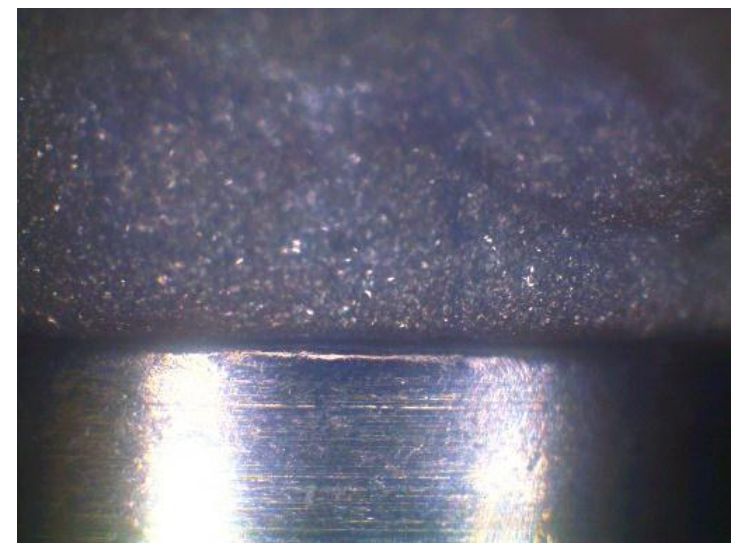

Figura 27 - Imagem da adaptação marginal no MO.

Para a análise da interface, as barras foram transferidas do modelo de gesso para o modelo mestre. A sequência de parafusamento (1-3-2-4) seguiu o mesmo padrão para todas as barras, com torque final de $10 \mathrm{Ncm}$.

Cada implante, foram realizadas três leituras, sempre com o mesmo operador, em duas áreas diferentes (vestibular e lingual), perfazendo um total de 6 medidas por implante. A média aritmética foi calculada para cada implante.

As captações das imagens foram realizadas, onde a primeira medição ocorreu após a fundição, onde a barra foi fundida em 2 partes, denominada Secção 1 (1ª secção entre os implantes 2 e 3$)$. 
Após a primeira medição, foi realizada o segundo momento de secção em mais 2 regiões (secção entre os implantes 1 e 2, 3 e 4), totalizando 3 secções, denominada Secção 3.

Após a segunda medição, todas as secções foram soldadas e a terceira medição foi realizada denominada de Soldada.

Para a mensuração da parte vestibular, nos implantes 2 e 3, o modelo mestre com o corpo de prova, foi posicionado na base do aparelho apoiando-se a parte posterior do modelo na mesa acrílica (Fig. 28). Já para a medição dos implantes distais ( 1 e 4) foram confeccionados guias em silicone de condensação (Zetaplus, Dentsply, Itália) para padronização das medições (Fig. 29 A e B).

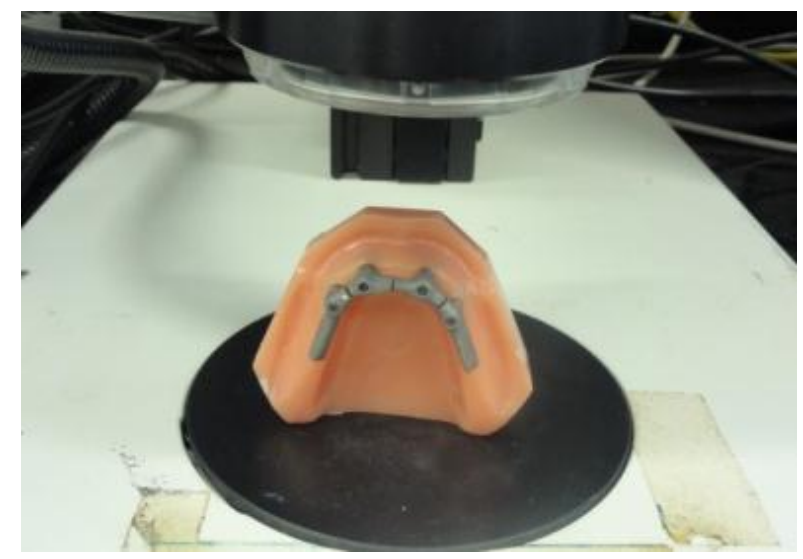

Figura 28 - Modelo mestre posicionado com corpo de prova para medição vestibular dos implantes 2 e 3.
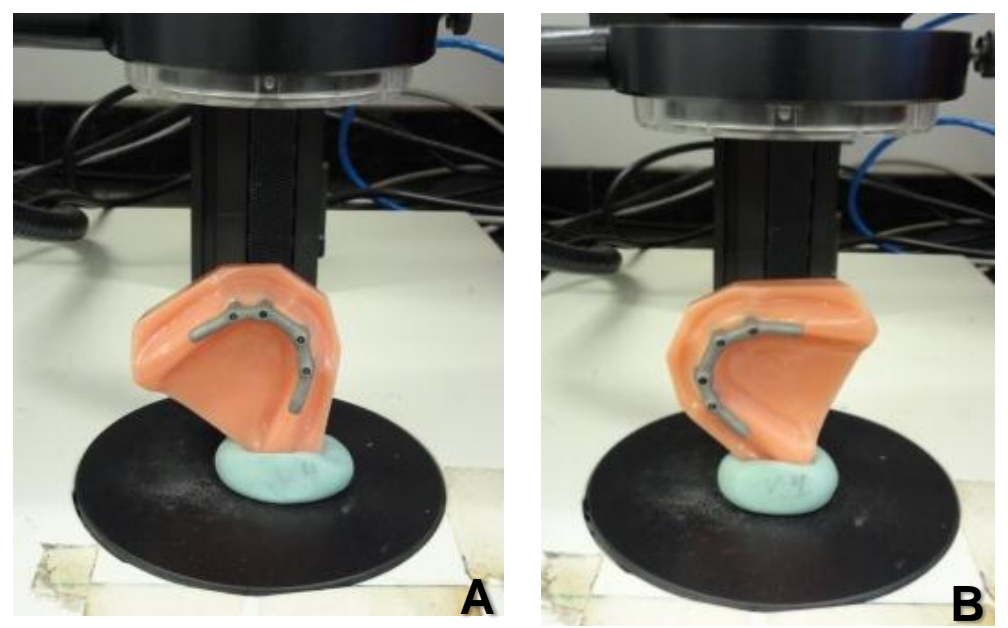

Figura 29- A, B - Guia de Silicone para padronização das medições dos implantes distais (1 e 4) na vestibular. 
Para a mensuração da parte lingual de cada implante, o modelo mestre com o corpo de prova foi posicionado na base do aparelho, apoiando-se na mesa especifica, onde na base do modelo foram realizadas marcações de acordo com a posição do respectivo implante (Fig. 30 A, B e C).
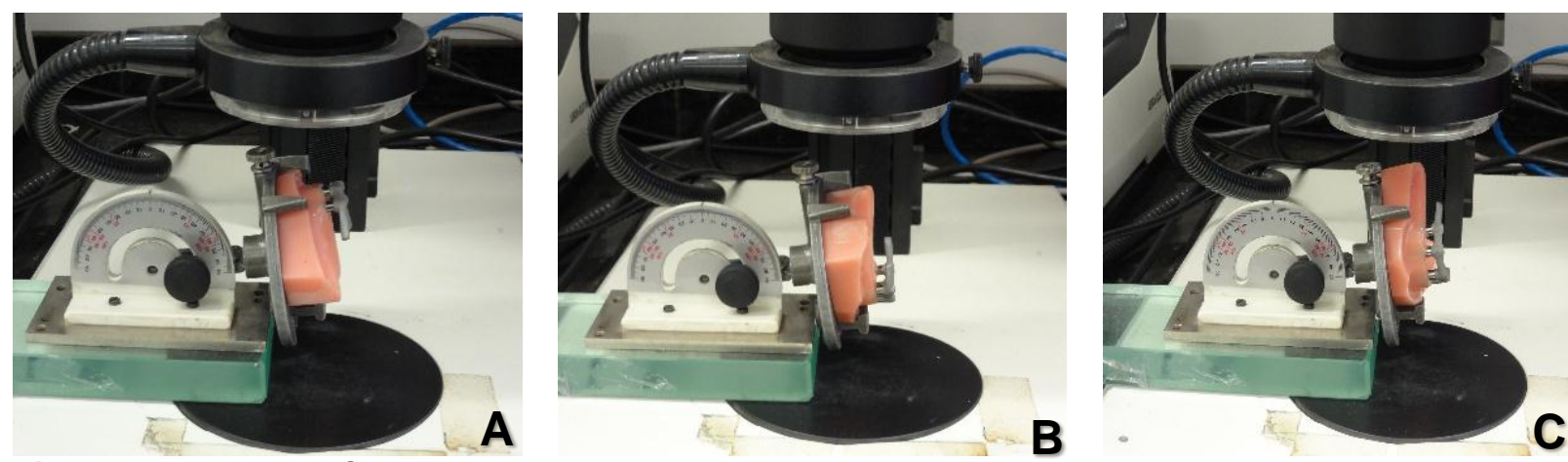

Figura 30- A, B e C - Modelos posicionados na mesa, com corpo de prova em posição, para padronização das medições dos implantes na lingual.

\subsubsection{Microscopia Confocal a laser}

As medições da adaptação marginal também foram realizadas por meio do Microscópio Confocal a Laser 3D (Olympus LEXT OLS4000®, Japão), que permite a análise morfológica da superfície dos espécimes, através de imagens 3D obtidas nas áreas de interface pilar/barra e seus respectivos grupos (Fig. 31).

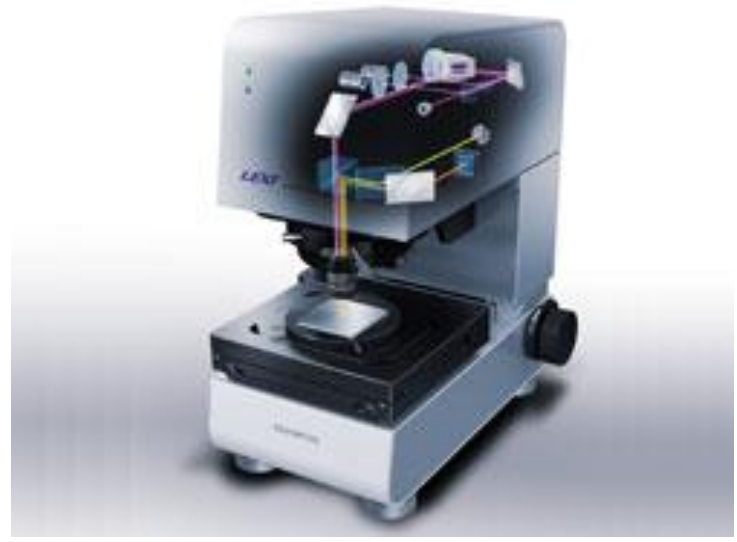

Figura 31 - Microscópio Confocal a Laser.

Para a análise da interface, as barras foram transferidas do modelo de gesso para o modelo mestre. A sequência de parafusamento seguiu o mesmo padrão para todas as barras, com torque final de $10 \mathrm{Ncm}$. 
Cada implante passou por uma leitura, sempre com o mesmo operador, em uma área (vestibular), 3 vezes, perfazendo um total de 3 medidas por implante. A média aritmética foi calculada para cada implante.

As captações das imagens foram realizadas, onde a primeira medição ocorreu após a fundição, onde a barra foi fundida em 2 partes, denominada Secção 1 (1ª secção entre os implantes 2 e 3).

Após a primeira medição, foi realizada o segundo momento de secção em mais 2 regiões (secção entre os implantes 1 e 2, 3 e 4), totalizando 3 secções, denominada Secção 3.

Após a segunda medição, todas as secções foram soldadas e a terceira medição foi realizada denominada de Soldada.

Foram realizadas as aquisições das imagens, onde na parte vestibular, 0 modelo mestre com o corpo de prova foi posicionado na base do aparelho LEXT OLS4000. Após selecionar a interface pilar/barra, foi selecionada a objetiva de 10x. Os dados em $\mu$, foram obtidos por meio do software especifico. (Fig. 32 A e B).

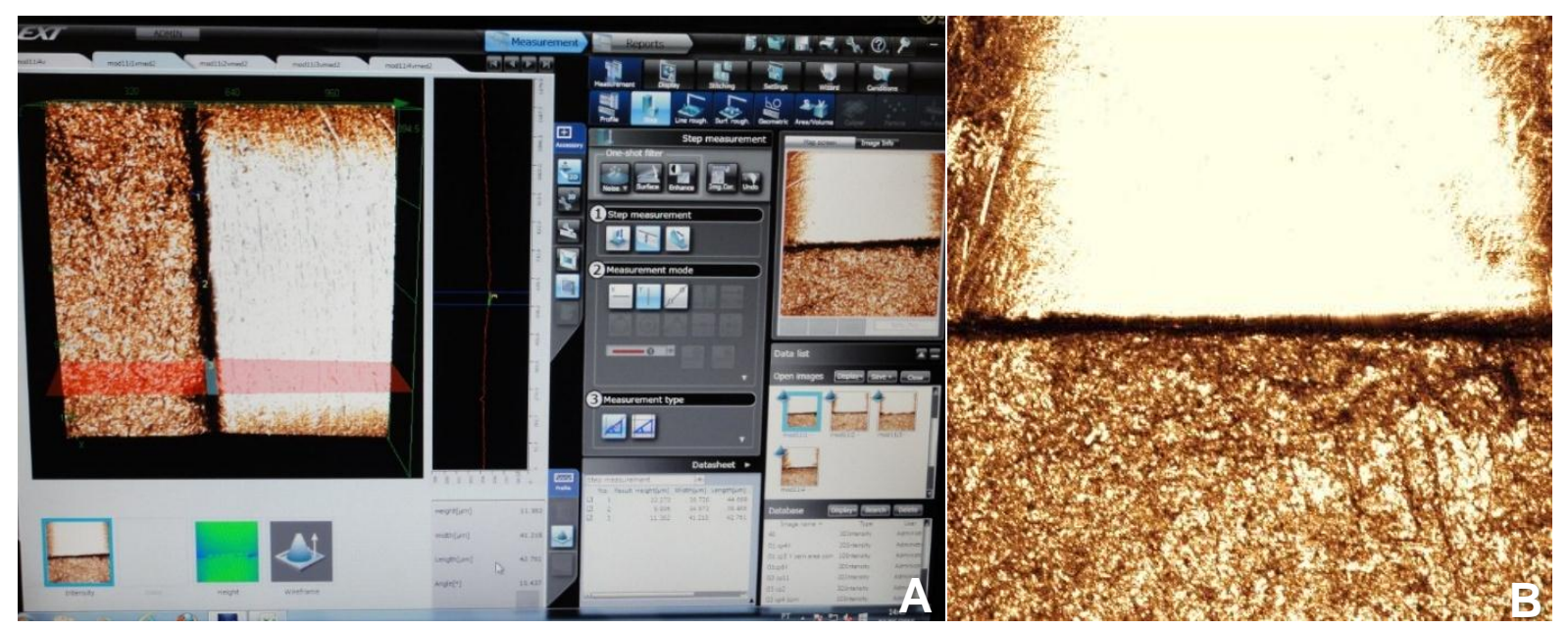

Figura 32- A, B - Leituras realizadas no microscópio Confocal a Laser. 
A medição da face lingual dos implantes não foi realizada devido ao espaço insuficiente para atingir a distância focal necessária para fazer as análises (Fig. 33).

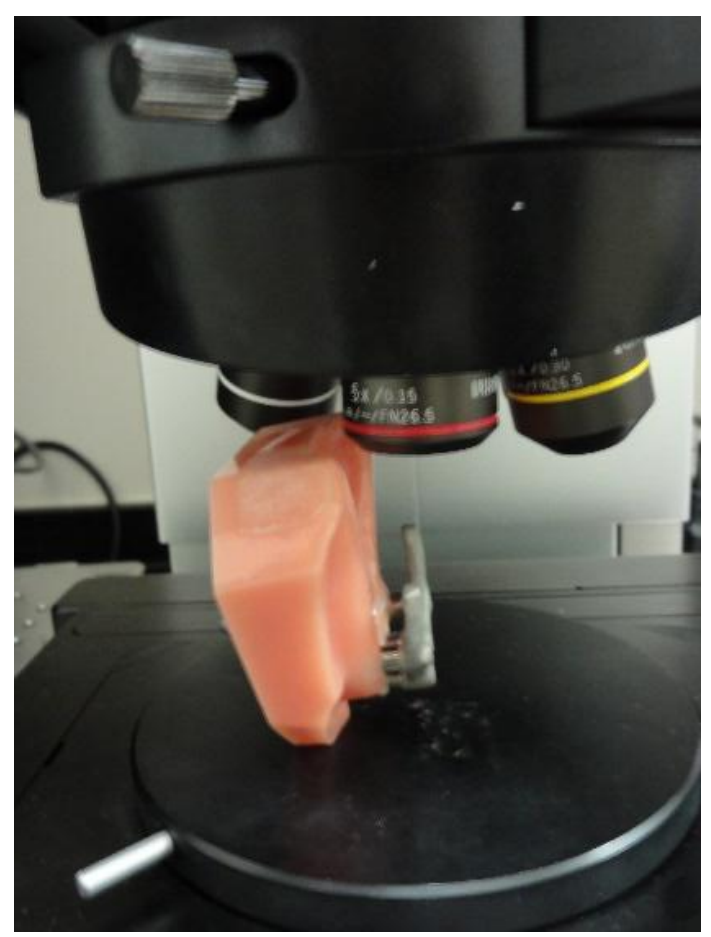

Figura 33- Modelo posicionado, mostrando a inviabilidade da medição por lingual. 

RESULTADOS 



\section{REsultados}

Os dados de adaptação marginal $(\mu \mathrm{m})$ foram agrupados em tabelas (Anexos $1,2,3,4,5$ e 6). Para avaliação do efeito dos fatores estabelecidos, sobre a variável de estudo, foram realizadas as seguintes análises estatísticas:

\section{1- Fatores Método e Técnica}

Foi realizado o teste de Normalidade (Shapiro-Wilk (alfa $=5 \%$ ) para verificar a distribuição da amostra, que foi Normal (Anexo B), para os dados de adaptação marginal $(\mu \mathrm{m})$ contidos no Anexo A. Assim, foi feita a análise de variância (Tabela 1), e demonstrou significância estatística, para os fatores Técnica e Métodos, analisados isoladamente, enquanto que a interação Técnica x Método foi não significante.

Tabela 1- Resumo da Análise de Variância

\begin{tabular}{lcccc}
\multicolumn{1}{c}{ FV } & GL & SQ & QM & F \\
\hline MËTODO (F1) & 1 & 1789.49633 & 1789.49633 & 9.2450 ** \\
TÉCNICA (F2) & 2 & 5929.05374 & 2964.52687 & $15.3154^{* *}$ \\
F1 x F2 & 2 & 870.46993 & 435.23496 & $2.2485 \mathrm{~ns}$ \\
Resíduo & 24 & 4645.55272 & 193.56470 & \\
\hline Tetal & 29 & 13234.57272 & & \\
$\begin{array}{l}\text { ** significativo ao nível de 1\% de probabilidade }(\mathrm{p}<.01) \\
\text { P=0.0056; } \mathrm{P}=<.0001\end{array}$ \\
ns não significativo $(\mathrm{p}>=0.05)$
\end{tabular}

De acordo com o resultado acima e para identificar as diferenças, foi aplicado o Teste de Tukey ao nível de 5\%. Assim, analisando:

\section{a. Fator Técnica}

$\mathrm{Na}$ tabela 2 de médias de adaptação marginal $(\mu \mathrm{m})$ para o fator técnica, isoladamente, verificou-se que a maior média de adaptação marginal foi apresentada pela técnica Monobloco, quando comparada com as condições Convencional e TIG, que por sua vez apresentaram médias estatisticamente iguais entre si (Gráfico 1). 
Tabela 2 - Médias de adaptação marginal $(\mu \mathrm{m})$ para o fator Técnica.

\begin{tabular}{|c|c|c|}
\hline MNB & CONV & TIG \\
\hline $70.21 \mathrm{a}$ & $51.25 b$ & $35.83 \mathrm{~b}$ \\
\hline
\end{tabular}

Desvio padrão $\pm 4,39$

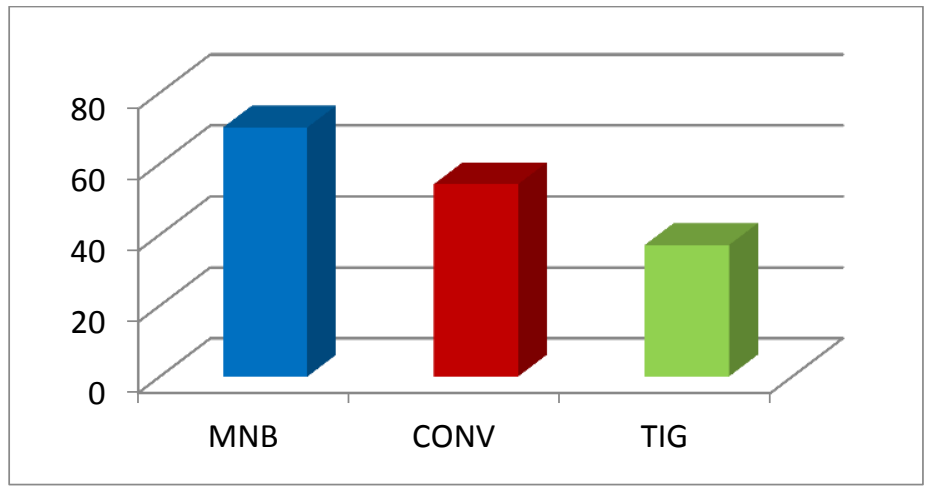

Gráfico 1- Médias de adaptação marginal $(\mu \mathrm{m})$ para o fator Técnica.

\section{b. Fator Método}

A significância deste fator quer dizer que, o Método de medição da adaptação marginal $(\mu \mathrm{m})$ determinou diferenças entre as médias. Isto é, a média das medidas de adaptação marginal realizadas por meio da microscopia óptica (MO) foi estatisticamente menor que a determinada pela microscopia Confocal a laser. Tabela 3 e Gráfico 2 a seguir.

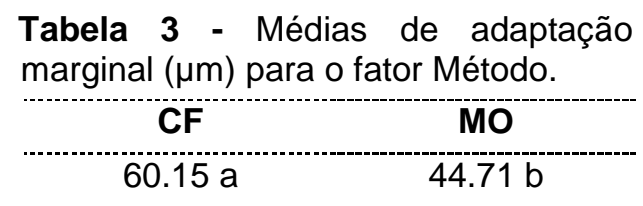

Desvio padrão $\pm 3,59$

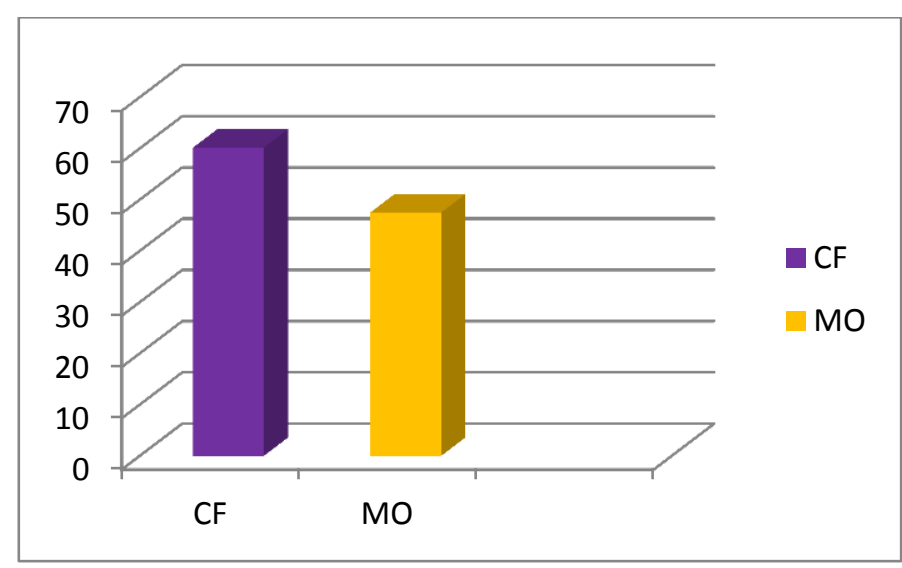

Gráfico 2 - Adaptação marginal $(\mu \mathrm{m})$ para o fator Método. 


\section{c. Interação Método x Técnica}

De acordo com a análise de variância a interação Método x Técnica não teve efeito significante sobre a variável adaptação marginal. Isso torna relevante esta análise. Tabela 4 e Gráfico 3 a seguir.

Tabela 4 - Adaptação margina ( $\mu \mathrm{m})$ para a Interação.

\begin{tabular}{ccc} 
& \multicolumn{2}{c}{ Método $x$ Técnica } \\
\cline { 2 - 3 } & CF & MO \\
\hline MNB & 71.41 & 69.01 \\
COM & 65.64 & 36.86 \\
TIG & 43.41 & 28.26 \\
\hline
\end{tabular}

Desvio padrão $\pm 6,22$

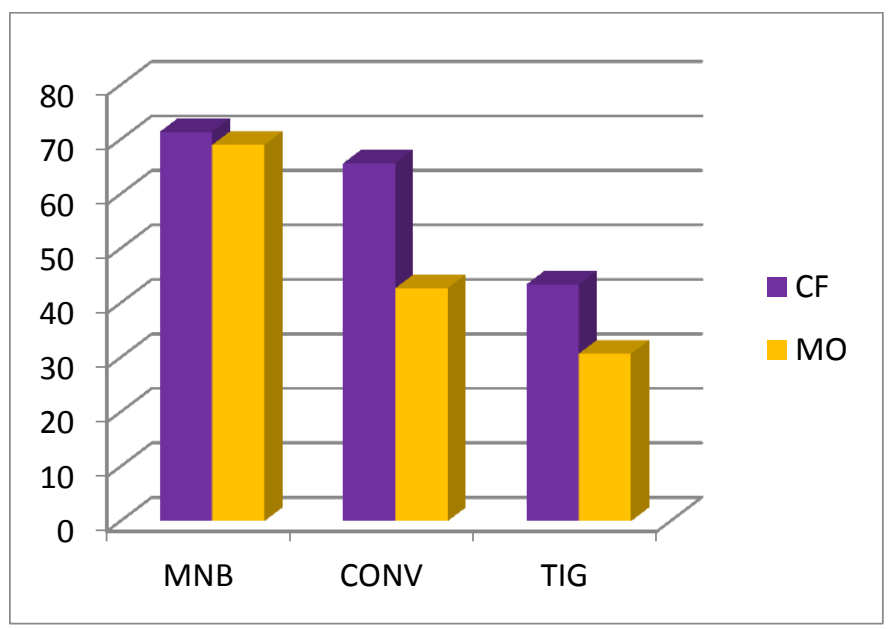

Gráfico 3 - Adaptação marginal $(\mu \mathrm{m})$ para a Interação Método x Técnica.

\section{2- Microscopia Confocal - Fatores Secção e Técnica}

Para análise estatística dos resultados de adaptação marginal, obtidos por meio do Microscópio Confocal na região vestibular(Anexo C), para as condições experimentais determinadas pelos fatores Secção e Técnica, foi aplicado o teste de normalidade Shapiro-Wilk (alfa $=5 \%$ ) e a distribuição foi normal(Anexo D). Assim, foi utilizado o teste paramétrico Análise de Variância(Tabela 5). De acordo com a análise verifica-se que os fatores de estudo Secção de Técnica, isoladamente, tiveram efeito estatisticamente significante sobre a adaptação marginal, enquanto que a interação Secção x Técnica foi não significante, estatisticamente $(p>=.05)$. 
Tabela 5- Resumo da análise de Variância.

\begin{tabular}{lcccc}
\multicolumn{1}{c}{ FV } & GL & SQ & QM & F \\
\hline Secção & 2 & 1161.52658 & 580.76329 & $7.1679^{* *}$ \\
Técnica & 1 & 1825.35600 & 1825.35600 & $22.5288^{* *}$ \\
Sec x Téc & 2 & 170.32329 & 85.16164 & $1.0511 \mathrm{~ns}$ \\
Resíduo & 24 & 1944.55776 & 81.02324 & \\
- Total & 29 & 5101.76363 & &
\end{tabular}

** significativo ao nível de $1 \%$ de probabilidade $(p<.01)$

$P=0.0036 ; P<.0001$

ns não significativo $(p>=.05) \quad P=0.3651$

Foram montadas as tabelas de médias de adaptação marginal e foi aplicado

o Teste de Tukey ao nível de $5 \%$ de probabilidade para verificação das diferenças:

\section{a. Fator Secção}

Analisando a tabela 6 verifica-se que a condição experimental 3 Secções, determinou menor média de adaptação marginal $(\mu \mathrm{m})$ que a de 1 Secção e a Soldada. Enquanto que a de 1 Secção e a soldada apresentaram médias estatisticamente iguais entre si. Gráfico 4 a seguir.

Tabela 6 - Médias de adaptação marginal $(\mu \mathrm{m})$ para o fator SECÇÃO.

\begin{tabular}{|c|c|c|}
\hline 1 Secção & 3 Secção & Soldada \\
\hline $56,46 \mathrm{a}$ & $42,39 \mathrm{~b}$ & $54,52 \mathrm{a}$ \\
\hline
\end{tabular}

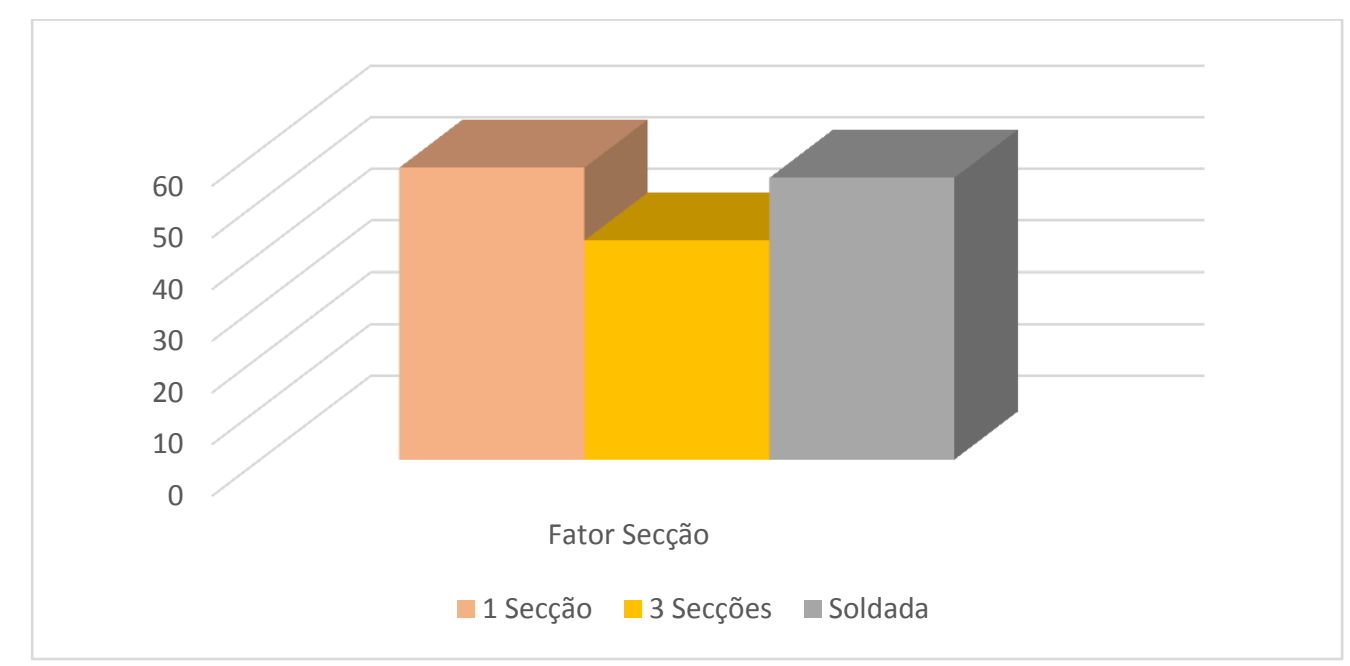

Gráfico 4 - Adaptação marginal $(\mu \mathrm{m})$ para o fator SECÇÃO. 


\section{b. Fator Técnica}

De acordo com a tabela 7 constata-se que a utilização da Técnica convencional determinou maior média de adaptação marginal que a promovida pela Técnica TIG. Gráfico 5 a seguir.

Tabela 7 - Médias de adaptação marginal $(\mu \mathrm{m})$ para o fator Técnica.

\begin{tabular}{c}
\hline CNV \\
\hline $58,92 \mathrm{a}$ \\
\hline
\end{tabular}

Desvio Padrão $\pm 2,32$

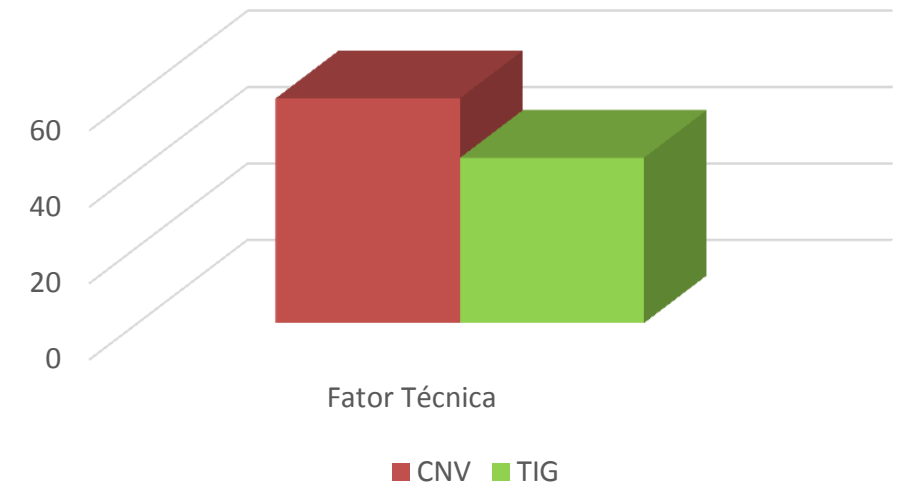

Gráfico 5 - Adaptação marginal $(\mu \mathrm{m})$ para o fator Técnica.

\section{c. Interação Secção x Técnica}

A interação entre os fatores Secção e Técnica não teve efeito estaticamente significante sobre a adaptação marginal, por esse motivo não foi aplicado o teste para comparação das médias. As médias da interação constam na tabela 8 e gráfico 6 a seguir:

Tabela 8 - Médias de adaptação marginal $(\mu \mathrm{m})$ para a Interação.

\begin{tabular}{ccc} 
& \multicolumn{2}{c}{ Seccão x Técnica } \\
\hline 1 Secção & CNV & TiG \\
3 Secção & 63.05 & 49.86 \\
Soldada & 48.07 & 36.72 \\
\hline
\end{tabular}

Desvio padrão $\pm 4,02$ 


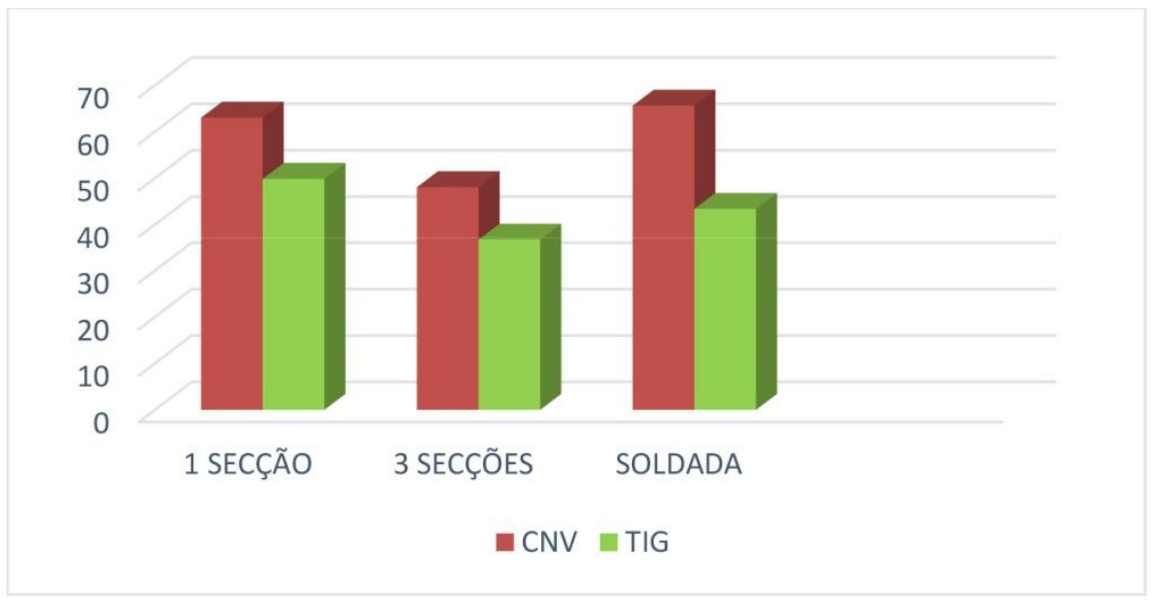

Gráfico 6 - Adaptação Marginal para Interação Secção x Técnica no CF.

\section{3- Microscopia Óptica - Fatores Secção X Técnica}

Para verificação dos resultados foram utilizados os dados de adaptação marginal $(\mu \mathrm{m})$ (Anexo E). Foi aplicado teste de normalidade e a distribuição da amostra foi normal de acordo com o teste Lilliefors (alfa $=5 \%$ ) (Anexo F). Assim foi aplicado o teste paramétrico, a análise de variância(Tabela 9) e verificou-se que os fatores de estudo Secção e Técnica, isoladamente, tiveram efeito significante ao nível de $5 \%$ de probabilidade $(.01=<p<.05)$, e a interação entre os fatores não teve efeito estatisticamente significante sobre a adaptação marginal na vestibular e lingual, medidas por meio do Microscópio Óptico. Para verificação das diferenças foi aplicado o Teste de Tukey ao nível de 5\% de probabilidade.

Tabela 9 - Resumo da análise de Variância.

\begin{tabular}{lcccc}
\multicolumn{1}{c}{ FV } & GL & SQ & QM & F \\
\hline Secção(F1) & 2 & 1259.94093 & 629.97046 & $5.3715^{*}$ \\
Técnica(F2) & 1 & 603.09800 & 603.09800 & $5.1423^{*}$ \\
F1 x F2 & 2 & 282.52761 & 141.26380 & $1.2045 \mathrm{~ns}$ \\
Resíduo & 24 & 2814.74480 & 117.28103 & \\
\hline Total & 29 & 4960.31134 & & \\
* significativo ao nível de 5\% de probabilidade $(.01=<p<.05)$ & & \\
P - 0.0118; -0.0326 & & \\
ns não significativo $(p>=.05)$ & $p-0.3173$
\end{tabular}

\section{a. Fator Secção}

$\mathrm{Na}$ tabela 10 de médias para o fator Secção, verifica-se que a condição 2 Secções apresentaram menor média de adaptação marginal $(\mu \mathrm{m})$ que a de 1 Secção e estatisticamente igual à soldada. Gráfico 7 a seguir. 
Tabela 10 - Médias de adaptação marginal $(\mu \mathrm{m})$ para o fator Secção.

\begin{tabular}{ccc}
1 Secção & 3 Secção & Soldada \\
\hline $43,10 a$ & $27,32 \mathrm{~b}$ & $36,73 \mathrm{ab}$
\end{tabular}

Desvio padrão $\pm 3,42$

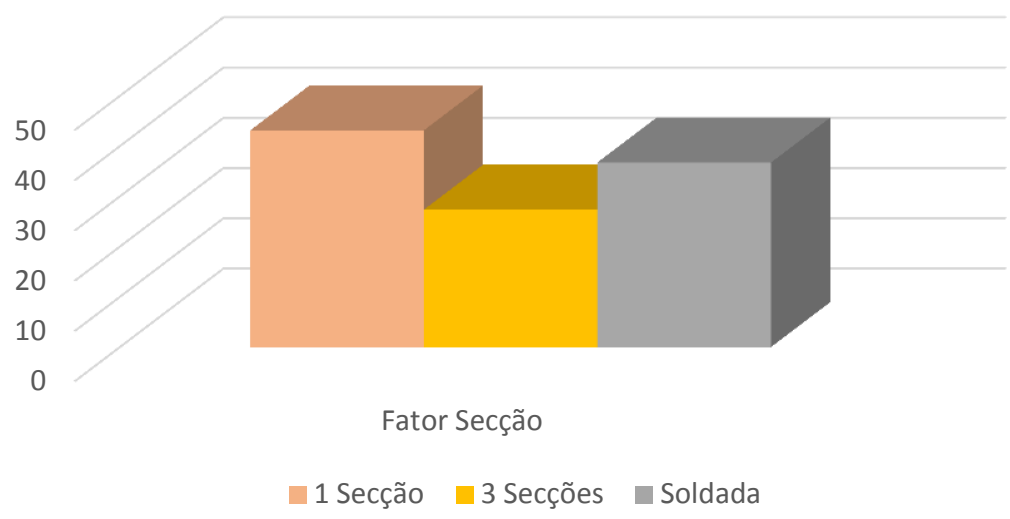

Gráfico 7 - Adaptação marginal $(\mu \mathrm{m})$ para o fator Secção.

\section{b. Fator Técnica}

A significância deste fator quer dizer que, a Técnica de solda utilizada influencia adaptação marginal $(\mu \mathrm{m})$. De acordo com a tabela 11 e gráfico 8 a seguir, constata-se que a Solda Convencional determinou maior média que a Técnica TIG.

Tabela 11 - Médias de adaptação marginal $(\mu \mathrm{m})$ para o fator Técnica.

\begin{tabular}{cc}
\hline CNV & TIG \\
\hline $40.20 \mathrm{a}$ & $31.23 \mathrm{~b}$ \\
\hline
\end{tabular}

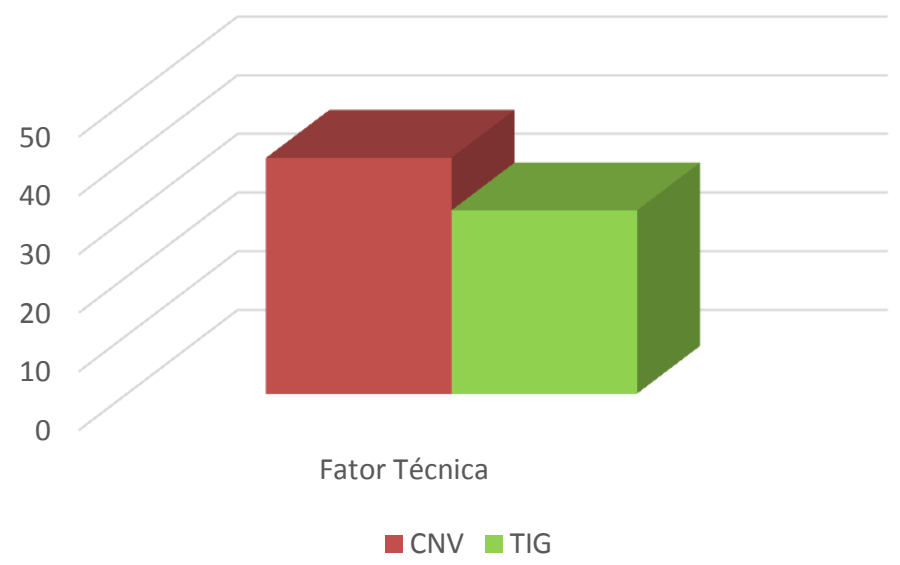

Gráfico 8 - Adaptação marginal $(\mu \mathrm{m})$ para o fator Técnica. 


\section{c. Interação Secção x Técnica}

A interação entre os fatores Secção e Técnica não teve efeito estaticamente significante sobre a adaptação marginal, por esse motivo não foi aplicado o teste para comparação das médias. As médias da interação constam na tabela 12 e gráfico 9 a seguir:

Tabela 12 - Médias de adaptação marginal $(\mu \mathrm{m})$ para a Interação.

\begin{tabular}{ccc} 
& Seccão x Técnica \\
\hline 1 Secção & CNV & TíG \\
3 Secçóes & 50.32 & 35.87 \\
Soldada & 27.52 & 27.12 \\
\hline-32.75 & 30.70 \\
\hline
\end{tabular}

Desvio padrão $\pm 4,84$

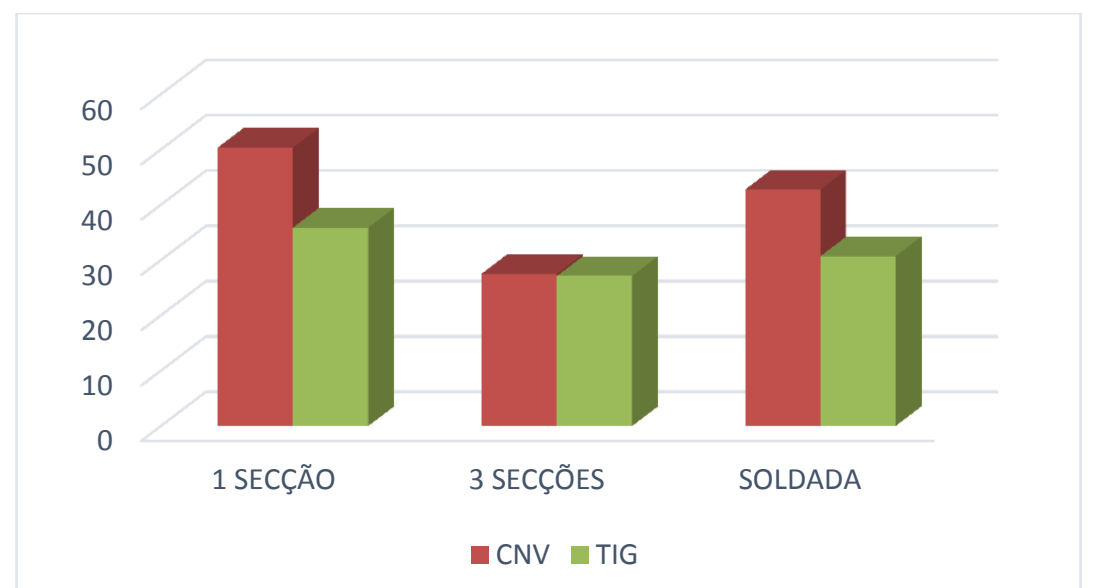

Gráfico 9 - Adaptação Marginal para a Interação Secção x Técnica - MO.

\section{4- Microscopia Confocal - Técnica e Região do Implante}

Foi realizado o teste de Normalidade Kolmogorov-Smirnov (alfa $=5 \%$ ) (Anexo $\mathrm{H}$ ), com os dados de adaptação marginal $(\mu \mathrm{m})($ Anexo $\mathrm{G}$ ) para verificar a distribuição da amostra, que foi não Normal. Assim, foi feita utilizado o Teste não paramétrico Kruskal Wallis(Anexo I), e demonstrou não haver significância estatística, entre os postos das médias das condições experimentais propostas, Técnica x Implante(Tabela 13). 
Tabela 13 - Resumo do Teste Kruskal Wallis para adaptação marginal - Técnica x Implante.

\begin{tabular}{|c|c|c|c|c|}
\hline Condiçôes & Repetiçôes & Soma Dos Postos & Média & alfa-5\% \\
\hline $11 \times \mathrm{MBL}$ & 5 & 206.0000 & 41.2000 & $\mathrm{a}$ \\
\hline I1xCNV & 5 & 227.0000 & 45.4000 & a \\
\hline I1x TIG & 5 & 125.0000 & 25.0000 & a \\
\hline I2xMBL & 5 & 199.0000 & 39.8000 & a \\
\hline I2xCNV & 5 & 134.0000 & 26.8000 & a \\
\hline I2x TIG & 5 & 105.0000 & 21.0000 & a \\
\hline I3xMBL & 5 & 63.5000 & 12.7000 & a \\
\hline I3XCNV & 5 & 111.0000 & 22.2000 & a \\
\hline $13 \times \mathrm{TIG}$ & 5 & 79.0000 & 15.8000 & a \\
\hline I4xMBL & 5 & 244.5000 & 48.9000 & a \\
\hline $14 \times C N V$ & 5 & 235.5000 & 47.1000 & a \\
\hline $14 \times T I G$ & 5 & 100.5000 & 20.1000 & a \\
\hline
\end{tabular}

As comparações múltiplas constam em ANEXO I.

\section{5- Microscopia Óptica - Técnica e Região do Implante}

Foi aplicado o teste de Normalidade aos dados de adaptação marginal (Anexo J) e a distribuição da amostra deu não normal. (Anexo K). Por isso foi realizada a transformação dos dados em Logaritmo(Anexo L), aí a distribuição foi normal por meio do teste Shapiro-Wilk (alfa = 5\%) (Anexo M). Assim, foi realizada a análise de Variância, 0 que demonstrou que 0 fator Técnica teve efeito estatisticamente significante ao nível de $1 \%$ de probabilidade $(p<0.01)$, enquanto que o fator Implante e a interação dos fatores Técnica $x$ Implante não tiveram efeito significante sobre a variável de estudo(Tabela 14).

Tabela 14 - Resumo da Análise de Variância

\begin{tabular}{lcccc}
\multicolumn{1}{c}{ FV } & GL & SQ & QM & F \\
\hline Técnica(F1) & 2 & 0.54862 & 0.27431 & $9.8438^{* *}$ \\
Implante(F2) & 3 & 0.14774 & 0.04925 & $1.7673 \mathrm{~ns}$ \\
F1 x F2 & 6 & 0.04914 & 0.00819 & $0.2939 \mathrm{~ns}$ \\
Resíduo & 48 & 1.33759 & 0.02787 & \\
\hdashline Total & 59 & 2.08311 & & \\
\hline ** significativo ao nível de 1\% de probabilidade $(\mathrm{p}<.01)$ & & \\
$\mathrm{P}=0.0002$ \\
ns não significativo $(\mathrm{p}>=.05) \mathrm{p}=0.166 ; \mathrm{p}=0.9369$
\end{tabular}


Para melhor análise dos resultados foram montadas as tabelas de médias dos logaritmos dos dados de adaptação marginal e as tabelas das médias dos dados originais.

\section{a. Fator Técnica}

O fator Técnica teve efeito significante sobre a variável adaptação marginal, assim, para identificar as diferenças foi aplicado o Teste de Tukey ao nível de $5 \%$ de probabilidade. Verificou-se que as médias determinadas pelas Técnicas Convencional e TIG foram estatisticamente iguais entre si. Na tabela 15 de médias para o fator Técnica, dos dados transformados em logaritmo e as médias com os dados originais na Tabela 16 e gráfico 10, encontram - se a seguir:

Tabela 15 - Médias (log) de adaptação marginal para o fator Técnica.

\begin{tabular}{ccc} 
MNB & CNV & TIG \\
\hline $1.70030 \mathrm{a}$ & $1.54025 \mathrm{~b}$ & $1.47217 \mathrm{~b}$ \\
\hline Desvio padrão $\pm 0,03$ & &
\end{tabular}

Tabela 16 - Médias de adaptação marginal $(\mu \mathrm{m})$ para o fator Técnica.

\begin{tabular}{|c|c|c|}
\hline MNB & CNV & TIG \\
\hline $54.53 a$ & $37.76 b$ & $130.70 \mathrm{~b}$ \\
\hline
\end{tabular}

Desvio padrão $\pm 3,91$

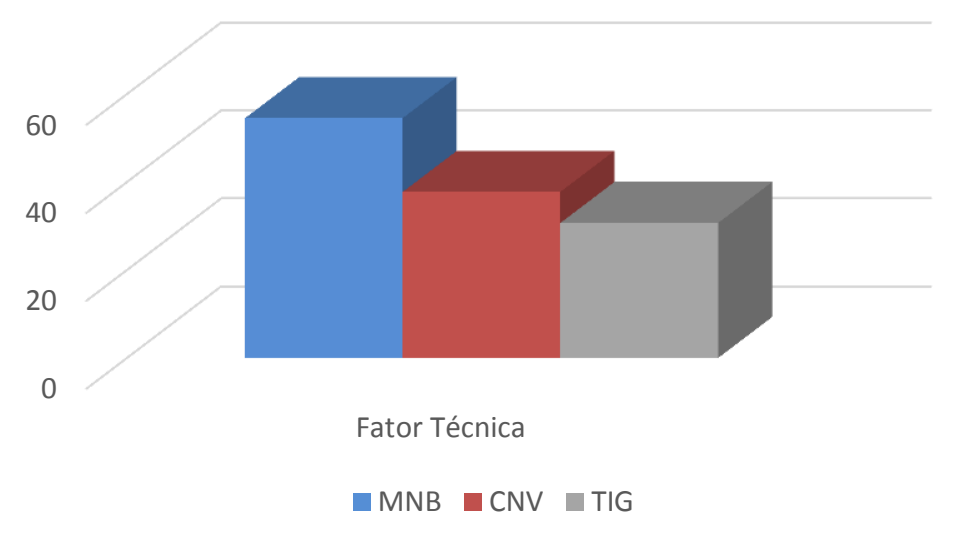

Gráfico 10 - Adaptação marginal $(\mu \mathrm{m})$ para o fator Técnica. 


\section{b. Fator Implante}

Na tabela 17 de médias dos dados transformados, verifica-se que as médias para o fator Implante, isoladamente não apresentou diferença estatisticamente significante. Gráfico 11 a seguir.

Tabela 17 - Médias (log) de adaptação marginal para o fator Implante.

\begin{tabular}{|c|c|c|c|}
\hline I1 & 12 & 13 & 14 \\
\hline $1.61815 \mathrm{a}$ & $1.48939 \mathrm{a}$ & $1.57416 \mathrm{a}$ & $1.60192 \mathrm{a}$ \\
\hline
\end{tabular}

Tabela 18 - Médias de adaptação margina I( $\mu \mathrm{m})$ para o fator Implante.

\begin{tabular}{cccc}
11 & 12 & 13 & 14 \\
\hline $45.80 a$ & $34.10 a$ & $39.86 a$ & $44.25 a$ \\
\hline-
\end{tabular}

Desvio padrão $\pm 4,52$

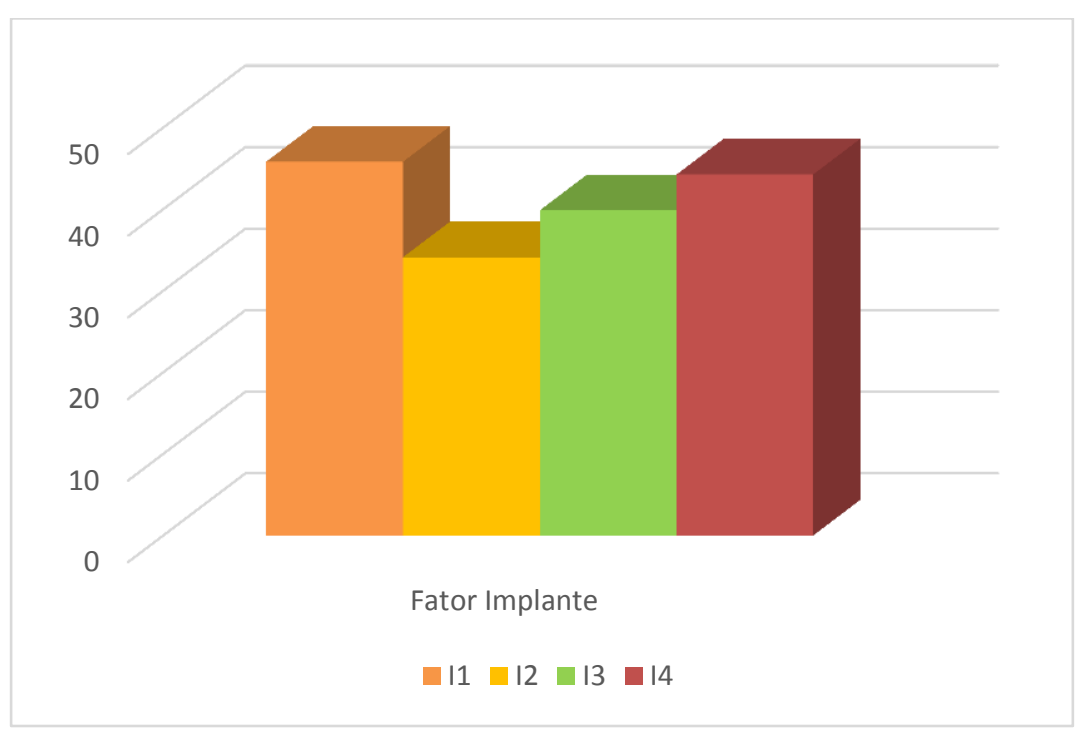

Gráfico 11 - Adaptação marginal $(\mu \mathrm{m})$ para o fator Implante.

\section{c. Interação Técnica X Implante}

$\mathrm{Na}$ tabela 20 constam as médias de adaptação marginal para a interação Técnica x Implante. De acordo com a análise de variância, esta interação não teve efeito estatisticamente significante sobre a variável de estudo. Para melhor visualização foi confeccionado o Gráfico 12 com as médias originais. 
Tabela 19 - Médias (log) de adaptação marginal para a Interação Técnica x Implante.

\begin{tabular}{lcccc} 
& $\mathbf{I 1}$ & $\mathbf{1 2}$ & $\mathbf{1 3}$ & $\mathbf{1 4}$ \\
\hline MNB & 1.7323 & 1.6614 & 1.6606 & 1.7469 \\
CON & 1.6000 & 1.4030 & 1.5707 & 1.5873 \\
TIG & 1.5222 & 1.4038 & 1.4911 & 1.4715
\end{tabular}

Desvio padrão $\pm 0,07$

Tabela 20 - Médias de adaptação marginal $(\mu \mathrm{m})$ para a Interação Técnica x Implante.

\begin{tabular}{lcccc} 
& $\mathbf{I 1}$ & $\mathbf{1 2}$ & $\mathbf{1 3}$ & $\mathbf{1 4}$ \\
\hline MNB & 61.96 & 49.02 & 47.39 & 59.82 \\
CON & 41.36 & 26.72 & 40.06 & 42.89 \\
TIG & 34.09 & 26.56 & 32.13 & 30.02 \\
\hline
\end{tabular}

Desvio padrão $\pm 7,83$

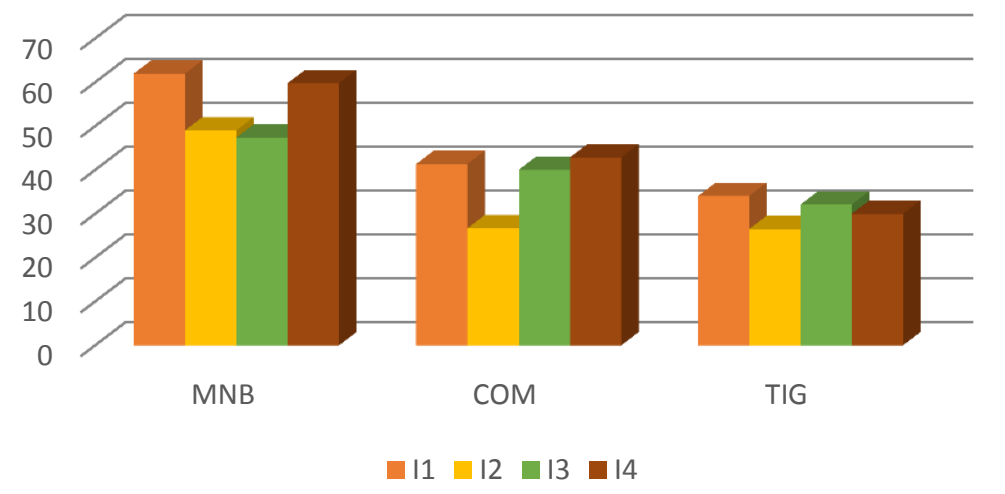

Gráfico 12 - Adaptação marginal $(\mu \mathrm{m})$ para Interação Técnica x Posição do implante MO. 
DISCUSSÃO 



\section{DIscussÃo}

Este estudo, in vitro, foi realizado para analisar a adaptação marginal de barras, em níquel-cromo, confeccionadas em monobloco e soldadas pelas técnicas TIG e convencional a maçarico, por meio de leituras feitas no microscópio óptico e no microscópio confocal a laser.

Um dos critérios mais importantes para que uma restauração se mantenha em função, por longo tempo, é a adaptação marginal aliada à resistência à fratura (ZARAUZ et al., 2016). A adaptação marginal relacionada à passividade da barra, favorece que sobrecargas funcionais não sejam incidentes diretamente sobre os implantes.

A passividade é definida como ausência de qualquer estresse sobre os componentes do implante, bem como o osso circundante, na ausência de carga externa (BRANEMARK,1983; BYRNE, 1991). É esta passividade que garante o sucesso e a longevidade clínica.

Pequenos desajustes são tolerados pelo organismo, porém, o nível desse desajuste ainda é bem controverso na literatura. Branemark (1983) foi o primeiro a definir conceito de passividade e adotou um nível máximo de $10 \mu \mathrm{m}$ para permitir a maturação óssea e remodelação em resposta às cargas oclusais. Outros autores, como Klineberg e Murray (1985), sugeriram que discrepâncias maiores que 30 4 m, ao longo de mais do que $10 \%$ da circunferência do pilar, eram inaceitáveis. No entanto, em 1991, Jemt definiu ajuste passivo como sendo o nível que não resultaria em quaisquer complicações clínicas de longo prazo, tornando as desadaptações marginais abaixo de $120 \mu \mathrm{m}$ aceitáveis (MARTINEZ-RUS et al, 2011).

Apesar de haver uma variedade de medidas descritas na literatura, tem-se adotado como valor máximo aceitável um espaço marginal de $120 \mu \mathrm{m}$ entre o dente preparado e a estrutura protética (MCLEAN e VON FRAUNHOFER, 1971), entretanto estudos clínicos utilizando moldagem intraoral, o desajuste marginal encontrado ser menor que $100 \mu \mathrm{m}$ (ZARAUZ et al., 2016). Deve-se salientar que todas as medições de desadaptações obtidas neste trabalho, estão dentro dos parâmetros aceitáveis do ponto de vista biológico (JEMT e BOOK, 1996).

Para avaliação clínica da desadaptação/passividade alguns métodos têm sido utilizados como a avaliação visual, o uso da ponta do explorador percorrendo toda a interface pilar/estrutura $(60 \mu \mathrm{m})$, radiografia e torque de 1 parafuso no qual 
verifica-se a adaptação simultânea de toda a estrutura (KAN et al 1999; BUZAYAN e YUNUS, 2014). Porém, nenhum desses métodos é confiável, se utilizado separadamente, devendo ser aplicada a combinação dos mesmos.

Além disso, há várias outros métodos para verificar a precisão da adaptação de estruturas metálicas sobre implantes. Podem ser utilizados materiais de impressão, microscópio óptico, microscópio eletronico de varredura, microscópio confocal a laser (JEMT et al, 2012) e dentro desta variedade, ou mesmo em um só tipo, podem ser encontradas grandes variações nos resultados. A busca pela precisão tem levado a pesquisadores a lançar mão de métodos tais como microscopia eletrônica de varredura e microscopia confocal a laser, pois é importante verificar quanto de detalhes podem informar, de tal forma a melhorar a adaptação marginal. A microscopia Confocal a laser é uma técnica utilizada para aumentar o contraste da imagem microscópica e construir imagens tridimensionais através da utilização de um orifício de abertura, que permite uma grande definição de imagem em amostras mais espessas que o plano focal (PALMER, 1999). Além disso, pode ser utilizada para ensaios in-vivo em tempo real (time series). Já a microscopia óptica é utilizada, para visualização de materiais a serem analisados, onde a luz atravessa e que passa por lentes de vidro para chegar ao olho do observador. A imagem observada é colorida e o objeto pode ou não ser vivo (dependendo da preparação).

A investigação de sistemas de confecção de estruturas da prótese e de técnicas de soldagem é importante na busca pela produção de próteses sobre dente ou sobre implante com precisão no ajuste marginal que possa ser comprovado visual e numericamente utilizando-se desses recursos tecnológicos, como será discutido a seguir.

Com relação ao tipo de liga utilizada na confecção das estruturas metálicas, as ligas de metais não nobres, como a de $\mathrm{NiCr}$, têm sido muito utilizadas devido ao menor custo e às propriedades mecânicas adequadas como dureza e módulo de Young $(\mathrm{ROACH}, 2007$, MATOS et al., 2015), apesar das ligas de metal nobre apresentarem vantagens com relação à biocompatibilidade, adaptação marginal e manuseio após a fundição (YOSHIDA e ATSUTA, 1997; OYAGU et al., 2009). A fundição das ligas não nobres é um processo mais sensível devido ao maior ponto de fusão e potencial de oxidação que podem ocasionar imprecisão das estruturas (BEZZON et al., 2001; ROACH, 2007), razão pela qual considera-se importante que 
se analise a adaptação marginal de estruturas confeccionadas em liga $\mathrm{NiCr}$, em monobloco e em estruturas que passaram pelo processo de soldagem.

Atualmente, várias técnicas são usadas para soldagem e cada uma delas tem suas vantagens e desvantagens. A escolha por um método de soldagem vai depender do fato de a técnica produzir calor suficiente para unir os materiais sem distorção e conservar as suas propriedades (ROCHA et al, 2006). As técnicas mais utilizadas para solda são: solda convencional à maçarico, solda TIG (Tungstein Gas Inert) e solda a Laser. No presente trabalho, foram utilizadas as duas primeiras e os resultados em relação a elas sugeriram que a escolha por uma delas está na dependência de fatores como disponibilidade de equipamentos, custos, número de procedimentos e domínio da técnica e, não especificamente quanto à adaptação marginal.

Como diferentes métodos podem ser utilizados para a medição do desajuste nas barras de protocolo, no presente estudo optou-se por comparar 2 métodos sendo eles microscopia óptica e microscopia confocal a laser e medir a adaptação marginal determinado pelas técnicas de estudo. De acordo com a análise do fator técnica, comparando as medições em Monobloco, Solda Convencional e Solda TIG (somente para a vestibular), mostraram resultado estatisticamente significante. Os corpos de prova, confeccionados em Monobloco, mostraram leituras da adaptação marginal, com média maior que os confeccionados pela técnica de solda convencional que, por sua vez, foi estatisticamente igual à média dos soldados pela técnica TIG. Isso demonstra a falta de adaptação marginal determinada pela técnica de Monobloco, onde encontraram-se os piores resultados. Nas estruturas fundidas em monobloco, tem-se a vantagem de o processo ser mais simples, mais rápido, com menor custo e que por ser uma peça única a resistência é maior (SHIFFLEGER, 1985). Por outro lado, a chance de distorção aumenta, o que pode levar à desadaptação da peça (BYRNE et al, 1986; SHILLIINGBURG, 1997; COSTA et al, 2004; ANUSAVICE, 2005). Há de se considerar que a soldagem realizada com Solda Convencional (maçarico de gás e oxigênio), apresenta a dificuldade técnica no controle da temperatura utilizada, havendo a possibilidade de superaquecimento e alteração da composição da liga (GOMEZ-COGOLLUDO et al., 2013) por adição de diferentes metais e incorporação de oxigênio no material fundido (MATOS et al., 2015). Entretanto, neste estudo não houve diferença estatisticamente significante de adaptação marginal determinada pelas técnicas e ambas as médias ficaram bem 


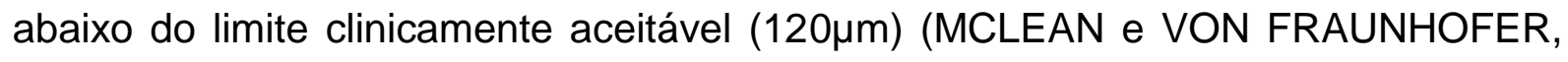
1971; JEMT, 1991). Provavelmente, como o sucesso da técnica convencional pode estar relacionado com a experiência do operador em controlar os parâmetros críticos desta técnica, pode-se considerar que a experiência tenha sido um fator importante na obtenção de médias menores. A técnica TIG tem como vantagens a facilidade da técnica, menor tempo, menor custo, o que pode ser considerado na escolha das técnicas. O fato de a soldagem TIG ter resultado em peças com menor desadaptação marginal pode estar relacionado com o próprio processo que possibilita a união de partes da estrutura com e sem a utilização de metal adicional, que pode ser do mesmo metal que o da estrutura a ser soldada (MATOS et al., 2015), além de permitir o controle das condições operacionais, com precisão, qualidade no acabamento e ser aplicável em espaços de solda pequenos (MODENESI et al., 2000) como foi no presente estudo, em que os padrões de resina (barra) foram seccionados com disco de dimensões 25 diâmetro $\times 0.6 \mathrm{~mm}$ de espessura.

Em relação à precisão dos aparelhos, encontramos diferença significante, onde o método Confocal a laser aferiu as maiores medidas, o que significa maior precisão nas medições. Isso pode ser explicado, pois a forma de medição é bem diferente. No microscópio óptico analisamos somente, a medição por 3 pontos aleatórios medidos após a fotografia do corpo de prova, obtendo dessa forma uma imagem em 2D. Já na microscopia confocal a laser, é realizado uma varredura, por toda a extensão determinada, e selecionados 3 pontos sempre na mesma posição para obter os resultados, sendo esta em 3D, (FASBINDER e NEIVA, 2016).

Já para a interação Método x Técnica não teve efeito significante sobre a variável adaptação marginal. A relevância desta interação de um fator com o outro está em não ter um efeito significante sobre a variável analisada. Isso, permite deduzir, que poderia ser utilizada qualquer um dos métodos para análise da adaptação marginal. No entanto, a microscopia Óptica, além de ser um método mais econômico, permite a verificação da adaptação marginal nas faces vestibular e lingual do implante, o que é uma limitação apresentada pela microscopia Confocal a laser, que permite a leitura somente na região vestibular.

Quando a adaptação adequada não for atingida, o seccionamento da estrutura pode ser necessário seguido da solda para nova união, no posicionamento correto (MCCARTNEY e DOUD, 2000; WATANABE et al, 2000). Solda é definida 
como a união de componentes de metal, utilizando o próprio metal base ou outra liga como um material de preenchimento, o qual é fundido em cada uma das peças a serem unidas (SHILLINGBURG, 1997; ALADAG et al 2011). No entanto, com relação a ser uma estrutura em monobloco ou soldada, há uma controvérsia na literatura sobre as vantagens e desvantagens das mesmas quanto à adaptação marginal e a outros fatores (SCHIFFLEGER et al., 1985; ZIEBERT et al., 1986). Nas estruturas seccionadas e soldadas, tem-se como principal vantagem a melhor adaptação (CHAY e CHOU, 1998, BYRNE, 2011), entretanto, há desvantagens como maior número de seções, maior custo, ponto de fragilidade da estrutura na região da solda.

A avaliação dos diferentes fatores, Secção e Técnica, para o método de medição por microscopia Confocal, apresentou diferença estatística para o fator Secção, onde foi encontrado para 3 secções os melhores resultados (menores valores de adaptação marginal), porém igualdade entre 1 secção e a soldada, concordante com Schiffleger et al. (1985), cujos resultados indicaram menor desadaptação marginal após secção da estrutura. Isso mostra que 1 secção e posterior solda, já é suficiente para garantir uma boa adaptação da peça minimizando-se tempo, número de procedimentos e custo. A realização de 3 secções e posterior solda, não atingiu melhoras na adaptação marginal da infraestrutura, de acordo com os resultados desta análise. Para o fator técnica, a Solda Convencional apresentou maior média de adaptação marginal em relação a solda TIG. Isso nos mostra que a solda TIG é a técnica de solda mais precisa que a solda convencional a maçarico. Já a interação secção x técnica, não apresentou resultados estatisticamente significante. (HART et al 2006, LYRA e SILVA et al, 2012).

Outra análise realizada foi a interação de Secção x Técnica, para o método de medição por microscopia Óptica. No fator secção, 3 secções apresentaram as menores medidas de desadaptação, do que soldada e 1 secção, que apresentaram igualdade estatística nos valores encontrados. No fator técnica, a solda TIG apresentou os melhores resultados. Os 2 fatores tiveram resultados semelhantes aos da Microscopia Confocal, o que nos mostra que com um aparelho mais simples e com menor custo, podemos fazer medições e análises com precisão.

A análise dos resultados considerando as estruturas em monobloco, soldadas pela técnica convencional e soldadas pela técnica TIG para 4 implantes 
para o método de microscopia Confocal a laser, mostraram resultado estatisticamente não significante. Não houve diferença entre os implantes anteriores e posteriores. Esse resultado pode sugerir, que a estrutura está adaptada de forma uniforme nos pilares, o que garante uma ótima distribuição de forças, resultado semelhante ao encontrado por CHESHIRE e HOBKIRK (1996) onde avaliaram in vivo, as discrepâncias verticais e horizontais de estruturas protéticas múltiplas instaladas sobre 5 implantes com torque padronizado de $10 \mathrm{Ncm}$ e concluíram que 0 aperto manual máximo dos parafusos pode reduzir desajustes no sentido vertical. Já outro estudo com resultados diferentes (ZIEBERG et al, 1986), onde encontraram valores de desadaptação maiores nos pilares distais.

Pela microscopia Óptica, se confirmou o mesmo padrão, onde o fator implante não apresentou resultado estatisticamente significante, o que pode sugerir, que se tivéssemos conseguido realizar as medições por lingual no confocal, iriamos atingir o mesmo resultado, já que no microscópio Óptico utilizamos as médias das medições por vestibular e lingual.

Também podemos analisar no método de microscopia Óptica o fator Técnica, onde encontramos valores estatisticamente significante para Monobloco e igualdade para as soldas, o que confirma os resultados anteriores apresentados.

É importante salientar que todas as medições foram realizadas sem aplicação de forças, ou seja, somente foram avaliadas as desadaptações existentes com a barra em posição no modelo mestre. 
CONCLUSÕES 



\section{Conclusões}

Dentro das limitações de metodologia empregados no presente estudo e com base nos resultados obtidos, pode concluir que:

- A técnica de Monobloco deve ser evitada, pois apresenta os maiores níveis de desadaptação.

- As secções melhoram a adaptação da estrutura, e 1 secção e posterior solda já é suficiente para atingir excelentes resultados, para ambos os métodos de medição.

- Não houve diferença estatísticas na adaptação entre os tipos de solda, Convencional e TIG, onde ambas podem ser utilizadas.

- O método de medição por microscopia Confocal a laser é mais precisa, do que a microscopia Óptica.

- A posição dos implantes não influenciou na adaptação marginal. 

REFERÊNCIAS BIBLIOGRÁFICAS 



\section{REFERÊNCIAS BIBLIOGRÁFICAS}

1. Adell R; Lekholm U, Rockler B, Branemark, PI. A 15-years study of osseointegrated implants in the treatment of the edentulous jaw. Int J Oral Surg $1981 ; 10: 387-416$.

2. Aladağ $A$, Cömlekoğlu $M E$, Dündar $M$, Güngör MA, Artunç $C$. Effects of soldering and laser welding on bond strength of ceramic to metal. $\mathrm{J}$ Prosthet Dent. 2011 Jan;105(1):28-34

3. American Dental Association. Guide to dental materials and devices: specification no5 for dental casting gold alloy. 6.ed. Chicago: ADA, 1972.

4. Anusavice KJ Phillips: materiais dentários. 11. ed. Rio de Janeiro: Elsevier, 2005.

5. Anusavice KJ, Okabe T, Galloway SE, Hoyt DJ, Morse PK. Flexure test evaluation of pre soldered base metal alloys. J Prosthet Dent. 1985; 54(4):50717.

6. Atoui, JA. Resistência mecânica e desajuste marginal do titânio comercialmente puro submetido a dois métodos de soldagem: TIG e Laser. Tese Doutorado, Faculdade do Odontologia de Ribeirão Preto, Universidade de São Paulo, 2008.

7. Barbi FCL, Camarini ET, Silva RS, Endo EH, Pereira JR. Comparative analysis of different joining techniques to improve de passive fit of cobalt-chromium superstructures. J Prosthet Dent. 2012;108(6):377-85.

8. Barbosa GA, Bernardes SR, das Neves FD, Fernandes Neto AJ, de Mattos Mda G, Ribeiro RF. Relation between implant/abutment vertical misfit and torque loss of abutment screws. Braz Dent J. 2008;19(4):358-63.

9. Barbosa GAS, Simamoto Júnior PC, Fernandes Neto AJ, Mattos MGC, Neves FD. Prosthetic laboratory influence on the vertical misfit at the implant/UCLA abutment interface. Braz Dent J 2007, 18(2): 139-143.

10. Bertrand C, Le Petitcorps $Y$, Albingre L, Dupuis V. The laser welding technique applied to the non precious dental alloys procedure and results. Brit Dent J. 2001;190(5):255-7.

11. Beuer F, Schweiger J, Edelhoff D. Digital dentistry: an overview of recent developments for CAD/CAM generated restorations. $\mathrm{Br}$ Dent J. 2008; 204(9):505-11. 
12. Bezzon OL, Ribeiro RF, Rollo JM, Crosara S. Castability and resistance of ceramometal bonding in $\mathrm{Ni}-\mathrm{Cr}$ and $\mathrm{Ni}-\mathrm{Cr}-\mathrm{Be}$ alloys. Journal of Prosthetic Dentistry 2001;85:299-304.

13. Bhering CL, Marques ID, Takahashi JM, Barão VA, Consani RL, Mesquita MF. Fit and Stability of Screw-Retained Implant-Supported Frameworks Under Masticatory Simulation: Influence of Cylinder Type. J Prosthodont. 2015 Oct 14. doi: 10.1111/jopr.12349.

14. Bhering CL, Takahashi JM, Luthi LF, Henriques GE, Consani RL, Mesquita MF Influence of the casting technique and dynamic loading on screw detorque and misfit of single unit implant-supported prostheses. Acta Odontol Scand. 2013 May-Jul;71(3-4):404-9.

15. Bianchini MA, Souza JG, Souza DC, Magini RS, Benfatti CA, Cardoso AC. Are sectioning and soldering of short-span implant-supported prostheses necessary procedure?. 2011;24(1):21-8.

16. Branemark PI: Osseointegration and its experimental background. J Prosthet Dent 1983;50:399-410

17. Brunski JB, Skalak, R. Biomechanics of osseointegration and dental prostheses. In Naert, I.; Steenberg, D.V.; Worthington, P. Quintessence Osseointegration in oral reabilitation; 1993. p.133-56.

18. Buzayan MM, Yunus NB. Passive Fit in Screw Retained Multi-unit Implant Prosthesis Understanding and Achieving: A Review of the Literature. J Indian Prosthodont Soc. 2014 Mar;14(1):16-23.

19. Byrne G, Goodacre CJ, Dykema RW, Moore BK. Casting accuracy of highpalladium alloys. J Prosthet Dent. 1986 Mar;55(3):297-301.

20. Byrne G. Soldering in Prosthodontics - An Overview, Part I. J Prosthodont v. 20, 233-243, 2011.

21. Carr AB, Stewart RB. Full-arch implant framework casting accuracy. Preliminary in vitro observation for in vivo testing. J Prosthodont 1993;2:2-8.

22. Cattaneo G, Wagnild G, Marshall G, Watanabe L. Comparison of tensile strength of solder joints joined by infrared and conventional torch technique. $J$ Prosthet Dent 1992;68:33-7.

23. Chai T, Chou CK. Mechanical properties of laser welded cast titanium joint under different conditions. J Prosthet Dent 1998; 70:477-83. 
24. Cheshire PD, Hobkirk JA.An in vivo quantitative analysis of the fit of Nobel Biocare implant superstructures. J Oral Rehabil. 1996 Nov;23(11):782-9

25. Costa EMV, Neisser MP, Bottino MA. Multiple-unit implant frames: one-piece casting vs. laser welding and brazing J Appl Oral Sci 2004; 12(3): 227-31.

26. Costa HM, Rodrigues RC, Mattos Mda G, Ribeiro RF. Evaluation of the adaptation interface of one-piece implant-supported superstructures obtained in Ni-Cr-Ti and Pd-Ag alloys. Braz Dent J 2003;14:197-202.

27. Davidowitz G, Kotick PG. The use of CAD/CAM in dentistry. Dent Clin North Am 2011;55: 559-570.

28. De Santis R, Gloria A, Russo T, D'Amora U, Varriale A, Veltri M, Balleri P, Mollica F, Riccitiello F, Ambrosio L. Reverse engineering of mandible and prosthetic framework: Effect of titanium implants in conjunction with titanium milled full arch bridge prostheses on the biomechanics of the mandible. $J$ Biomech. 2014 Dec 18;47(16):3825-9

29. Drago C, Saldarriaga RL, Domagala D, Almasri R. Volumetric determination of the amount of misfit in CAD/CAM and cast implant frameworks: A multicenter laboratory study. Int J Oral Maxillofac Implants 2010;25:920-929.

30. Eliasson A, Wennerberg A, Johansson A, Örtorp A, Jemt T. The Precision of Fit of Milled Titanium Implant Frameworks (I-Bridge $\left.{ }^{\circledR}\right)$ in the Edentulous Jaw. Clin Implant Dent and Related Research 2010;12(2):81-90.

31. Fasbinder DJ, Neiva GF. Surface Evaluation of Polishing Techniques for New Resilient CAD/CAM Restorative Materials. J Esthet Restor Dent. 2016 JanFeb;28(1):56-66. doi: 10.1111/jerd.12174. Epub 2015 Jul 14.

32. Gómez-Cogolludo P, Castillo-Oyagüe R, Lynch CD, Suárez-García MJ. Effect of electric arc, gas oxygen torch and induction melting techniques on the marginal accuracy of cast base-metal and noble metal-ceramic crowns. J Dent. 2013 Sep;41(9):826-31. doi: 10.1016/j.jdent.2013.06.007. Epub 2013 Jun 25

33. Gordon TE, Smith DL. Laser welding of prostheses - an initial report. J Prosthet Dent. 1970;24(4):472-6.

34. Hart CN, Wilson PR. Evaluation of welded titanium joints used with cantilevered implant-supported prostheses. J Prosthet Dent. 2006;96(1):25-32. 
35. Hedkvist L, Mattsson T, Helldén LB. Clinical performance of a method for the fabrication of implant-supported precisely fitting titanium frameworks: a retrospective 5- to 8-year clinical follow-up study. Clin Implant Dent Relat Res. 2004;6(3):174-80.

36. Henriques GE, Consani S, Rollo JM, Andrade e Silva F. Soldering and remelting influence on fatigue strength of cobalt-chromium alloys. J Prosthet Dent. 1997 Aug;78(2):146-52.

37. Jameson LM. Mechanical properties of laser welded titanium joints. J Prosthet Dent 1993;69:103-9. Back to cited text no. 5

38. Jemt $\mathrm{T}$, Book K. Prosthesis misfit and marginal bone loss in edentulous implant patients. Int J Oral Maxillofac Implants. 1996 Sep-Oct;11(5):620-5.

39. Jemt $T$, Hjalmarsson $L$. In vitro measurements of precision of fit of implantsupported frameworks. A comparison between "virtual" and "physical" assessments of fit using two different techniques of measurements. Clin Implant Dent Relat Res. 2012 May;14 Suppl 1:e175-82.

40. Jemt $T$, Rubenstain JE, Carlsson L, Lang BR. Measuring fit at the implant prosthodontic interface. J Prosthet Dent 1996;75:314-325.

41. Jemt $T$. In vivo measurements of precision of fit involving implant-supported prosthesis in the edentulous jaw. Int J Oral Maxillofac Implants. 1996;11:151-8.

42. Jemt T: Failures and complications in 391 consecutively inserted fixed prostheses supported by Branemark implants in edentulous jaws: a study of treatment from the time of prosthesis placement to the first annual checkup. Int $\mathrm{J}$ Oral Maxillofac Implants 1991;6:270-276.

43. Kallus $T$, Bessing $C$. Loose gold screws frequently occur in full-arch fixed prosthesis supported by osseointegrated implants after 5 years. Int $\mathrm{J}$ Oral Maxillofac Implants. 1994;9:169-78.

44. Kan JY, Rungcharassaeng K, Bohsali K, Goodacre CJ, Lang BR. Clinical methods for evaluating implant framework fit. J Prosthet Dent 1999:81:7-13

45. Kayatt FE, Neves FD. Aplicação dos sistemas CAD/CAM na odontologia restauradora. $1^{\underline{a}}$ ed. Rio de Janeiro: Elsevier Editora Ltda, 2013. 295p.

46. Klineberg IJ, Murray GM. Design of superstructures for osseointegrated fixtures. Swed Dent J Suppl. 1985;28:63-9. 
47. Lin W, Harris BT, DMD, Zandinejad A, Morton D. Use of digital data acquisition and CAD/CAM technology for the fabrication of a fixed complete dental prosthesis on dental implants J Prosthet Dent 2014;111:1-5.

48. Lyra e Silva JP, Fernandes Neto AJ, Raposo LH, Novais VR, de Araujo CA, Cavalcante Lde A, Simamoto Júnior PC. Effect of plasma welding parameters on the flexural strength of Ti-6Al-4V alloy. Braz Dent J. 2012;23(6):686-91.

49. Ma T, Nicholls JI, Rubenstein JE (1997) Tolerance measurements of various implant components. Int J Oral Maxillofac Implants 12:371-375

50. Machha S, Kumar MV, Rangarajan V. Microstructure, mechanical performance and corrosion properties of base metal solder joints. Indian J Dent Res. $2011 ; 22(4): 614-20,2011$.

51. Marques PV. Tecnologia da soldagem. Belo Horizonte: ESAB, 1991.

52. Martínez-Rus F, Suárez MJ, Rivera B, Pradíes G. Evaluation of the absolute marginal discrepancy of zirconia-based ceramic copings. J Prosthet Dent. 2011 Feb;105(2):108-14.

53. Matos, IC; Bastos, IN; Diniz, MG, Miranda, MS. Corrosion in artificial saliva of a Ni-Cr-based dental alloy joined by TIG welding and conventional brazing. J Prosthet Dent 2015;114:278-285.

54. McCartney JW, Doud R. Passive adaptation of the prosthesis-implant interface by soldering gold cylinders to the framework casting. J Prosthet Dent. 1993 Jul;70(1):17-20.

55. McLean JW, von Fraunhofer JA. The estimation of cement film thickness by an in vivo technique. Br Dent J. 1971 Aug 3;131(3):107-11.

56. Menini M, Dellepiane E, Pera P, Bevilacqua M, Pesce P, Pera F, Tealdo T. A Luting Technique for Passive Fit of Implant-Supported Fixed Dentures. J Prosthodont. 2016 Jan;25(1):77-82. doi: 10.1111/jopr.12281

57. Mericske-Stern RD, Taylor TD, Belser U. Management of the edentulous patient. Clin Oral Implants Res 2000;11(suppl 1):108-25.

58. Michaels GC, Carr AB, Larsen PE: Effect of prosthetic superstructure accuracy on the osseointegrated implant bone interface. Oral Surg Oral Med Oral Pathol Oral Radiol Endod 1997;83:198-205.

59. Misch CE. Implantes dentais contemporâneos. 3ª. Ed., Mosby-Elsevier, 2009. $1102 p$. 
60. Modenesi PJ, Apolinário ER, Pereira IM. TIG welding with single-component fluxes. J Mat Proces Tech. 2000;99:260-5, 2000.

61. Moreno A, Giménez B, Özcan M, Pradíes G. A clinical protocol for intraoral digital impression of screw-retained CAD/CAM framework on multiple implants based on wavefront sampling technology. Implant Dent 2013;22(4): 320-325.

62. Nikellis I, Levi A, Zinelis S. Effect of soldering on the metal-ceramic bond strength of an Ni-Cr base alloy. J Prosthet Dent 2005;94:435-9.

63. Oyagu" e RC, Turrión AS, Toledano M, Monticelli F, Osorio R. In vitro vertical misfit evaluation of cast frameworks for cement-retained implant-supported partial prostheses. Journal of Dentistry 2009;37:52-8.

64. Palmer RJ Jr, Sternberg C. Modern microscopy in biofilm research: confocal microscopy and other approaches.Curr Opin Biotechnol. 1999 Jun;10(3):263-8. Review.

65. Riedy SJ, Lang BR, Lang BE. Fit of implant frameworks fabricated by different techniques. J Prosthet Dent 1997;78:596-604.

66. Roach M. Base metal alloys used for dental restorations and implants. Dental Clinics of North America 2007;51: 603-27.

67. Rocha R, Pinheiro ALB, Villaverde AB. Flexural Strength of Pure Ti, Ni-Cr and Co-CrAlloys Submitted to Nd:YAG Laser or TIG Welding. Braz Dent J. 2006;17(1):20-23.

68. Romero GG, Engelmeier R, Powers JM, Canterbury AA. Accuracy of three corrective techniques for implant bar fabrication. J Prosthet Dent. 2000 Dec;84(6):602-7.

69. Rosenstiel SF, Land MF, Fujimoto J. Contemporary fixed prosthodontics. 3rd. Ed. St. Louis: Mosby, 2001

70. Sahin S, Çehreli MC. Significance of passive framework fit in implant prosthodontics: Current status. Implant Dent. 2001;10:85-92.

71. Sarfati E, Harter JC. Comparative accuracy of fixed partial dentures made as one-piece castings or joined by solder. Int J Prosthod.1992;5:377-83.

72. Schiffleger BE, Ziebert GJ, Dhuru VB, Brantley WA, Sigaroud K. Comparison of accuracy of multiunit one-piece castings. J Prosthet Dent. 1985;54(6):770-6.

73. Shillingburg HT Jr, Hobo S, Whitsett LD, Jacobi R, Brackett SE. Fundamentals of fixed prosthodontics. 3rd ed. Chicago: Quintessence; 1997. p. 509-35. 
74. Silva J, Hotta TH, Matsumoto W. Avaliação da resistência flexural entre diferentes métodos de soldagem. Implant News. 2012;9(6):803-9.

75. Silva J, Matsumoto W, Souza RF. Avaliação da resistência flexural entre diferentes métodos de soldagem: Chama direta, TIG e Laser. In: IX Congresso Interno De Pesquisa, 2007. Anais... Ribeirão Preto: Faculdade de Odontologia de Ribeirão Preto, 2007.

76. Silva, F. de A. S. e. \& Azevedo, C. A. V. de. A New Version of The AssistatStatistical Assistance Software. In: WORLD CONGRESS ON COMPUTERS IN AGRICULTURE, 4, Orlando-FL-USA: Anais... Orlando: American Society of Agricultural and Biological Engineers, 2006. p.393-396.

77. Silva, F. de A. S. e. \& Azevedo, C. A. V. de. Principal Components Analysis in the Software Assistat-Statistical Attendance. In:WORLD CONGRESS ON COMPUTERS IN AGRICULTURE, 7, Reno-NV-USA: American Society of Agricultural and Biological Engineers, 2009.

78. Silva, F. de A. S. e. \& Azevedo, C. A. V. de. Versão do programa computacional Assistat para o sistema operacional Windows. Revista Brasileira de Produtos Agroindustriais, Campina Grande, v.4,n.1, p71-78,2002.

79. Silva, F.de A.S.e. The ASSISTAT Software: statistical assistance. In: INTERNATIONAL CONFERENCE ON COMPUTERS IN AGRICULTURE, 6, Cancun, 1996. Anais... Cancun: American Society of Agricultural Engineers, 1996. p.294-298.

80. Skalak R: Biomechanical considerations in osseointegratedprostheses. J Prosthet Dent 1983;49:843-848

81. Souza PCRD, Dinato JC, Bottino, MA, Guastaldi, AC. Brazing and laser welding of a Ni-Cr alloys. Pós-Grad Rev Fac Odontol. 2000;3:7-16.

82. Stade $\mathrm{EH}$, Reisbick MH, Preston JD. Preceramic and postceramic solder joints. J Prosthet Dent. 1975;34(5):527-32.

83. Swallow ST. Technique for achieving a passive framework fit: a clinical case report. J Oral Implantol. 2004;30(2):83-92.

84. Teigen K, Jokstad A. Dental implant suprastructures using cobalt-chromium alloy compared with gold alloy framework veneered with ceramic or acrylic resin: a retrospective cohort study up to 18 years. Clin Oral Implants Res. 2012 Jul;23(7):853-60. 
85. Ueno $\mathrm{AH}$. Avaliação da resistência ao dobramento de juntas soldadas por dois métodos: arco elétrico em atmosfera de argônio e convencional a maçarico, em liga de metal não nobre à base de NiCr. 1994, 124f. Dissertação (Mestrado) Faculdade de Odontologia de Bauru, Universidade de São Paulo, Bauru, 1994.

86. Vallittu PK. Brazing joints of gold alloys used in porcelain-fused-to-metal restorations and their resistence to deflection fatigue. $\mathrm{J}$ Oral Rehabil. 1997;24:444-8.

87. Wang RR, Welsch GE. Joining titanium materials with tungstein inert gas welding, laser welding, and infrared brazing. J Prosthet Dent. 1995;74(5):521-30.

88. Watanabe F, Uno I, Hata Y, Neuendorff G, Kirsch A. Analysis of stress distribution in a screw-retained implant prosthesis. Int J Oral Maxillofac Implants. 2000 Mar-Apr;15(2):209-18.

89. Wee AG, Aquilino SA, Schneider RL. Strategies to achieve fit in implant prosthodontics: a review of the literature. Int J Prosthodont.1999;12(2):167-78.

90. Yoshida K, Atsuta M. Effects of adhesive primers for noble metals on shear bond strengths of resin cements. Journal of Dentistry 1997;25:53-8.

91. Yoshinari M, Uzawa S, Komiyama Y. Hybrid framework with cobalt-chromium alloy and gold cylinder for implant superstructure: Bond strength and corrosion resistance. J Prosthodont Res. 2016 Feb 11. pii: S1883-1958(16)00013-X

92. Zarauz C, Valverde A, Martinez-Rus F, Hassan B, Pradies G.Clinical evaluation comparing the fit of all-ceramic crowns obtained from silicone and digital intraoral impressions. Clin Oral Investig. 2016 May;20(4):799-806.

93. Ziebert GJ, Hurtado A, Glapa C, Schiffleger BE. Accuracy of one-piece castings, preceramic and postceramic soidering. J Prosthet Dent. 1986;55(3):312-7. 
ANEXOS 



\section{ANEXOS}

1 - DADOS GERAIS DE ADAPTAÇAO MARGINAL ( $\mu$ M) PARA MONOBLOCO - MICROSCOPIA CONFOCAL

\begin{tabular}{|c|c|c|c|c|c|}
\hline & & \multicolumn{4}{|c|}{ VESTIBULAR } \\
\hline & & L1 & L2 & L3 & LM \\
\hline & 11 & 59,95 & 38,72 & 46,21 & 47,46 \\
\hline \multirow[t]{4}{*}{ M6 } & 12 & 83,68 & 49,96 & 71,19 & 68,27 \\
\hline & 13 & 37,47 & 24,98 & 19,98 & 27,47 \\
\hline & 14 & 56,2 & 37,47 & 48,71 & 47,46 \\
\hline & 11 & 168,62 & 146,13 & 138,64 & 151,13 \\
\hline \multirow[t]{4}{*}{ M7 } & 12 & 158,62 & 108,66 & 112,41 & 126,56 \\
\hline & 13 & 44,96 & 32,47 & 18,73 & 32,05 \\
\hline & 14 & 84,93 & 97,42 & 94,92 & 92,42 \\
\hline & 11 & 138,64 & 131,14 & 126,15 & 131,97 \\
\hline \multirow[t]{4}{*}{ M8 } & 12 & 44,96 & 56,2 & 58,7 & 53,28 \\
\hline & 13 & 37,47 & 26,22 & 38,72 & 34,13 \\
\hline & 14 & 131,14 & 113,66 & 101,17 & 115,32 \\
\hline & 11 & 56,2 & 39,96 & 44,96 & 47,04 \\
\hline \multirow[t]{4}{*}{ M9 } & 12 & 54,95 & 51,21 & 44,96 & 50,37 \\
\hline & 13 & 69,94 & 72,44 & 63,7 & 68,69 \\
\hline & 14 & 101,17 & 81,18 & 81,18 & 87,84 \\
\hline & 11 & 48,71 & 39,96 & 56,2 & 48,29 \\
\hline \multirow[t]{3}{*}{ M10 } & 12 & 73,69 & 39,96 & 27,47 & 47,04 \\
\hline & 13 & 38,72 & 41,21 & 24,98 & 34,97 \\
\hline & 14 & 137,39 & 111,16 & 101,17 & 116,57 \\
\hline
\end{tabular}


2- DADOS GERAIS DE ADAPTAÇAO MARGINAL $(\mu \mathrm{m})$ para MONOBLOCO - MICROSCOPIA OPTICA

\begin{tabular}{|c|c|c|c|c|c|c|c|c|c|}
\hline & & \multicolumn{4}{|c|}{ VESTIBULAR } & \multicolumn{4}{|c|}{ LINGUAL } \\
\hline & & L1 & $\mathrm{L} 2$ & L3 & LM & $\mathrm{L} 1$ & L2 & L3 & LM \\
\hline & 11 & 47 & 42 & 44 & 44,33 & 11 & 6 & 11 & 9,33 \\
\hline \multirow[t]{4}{*}{ M6 } & 12 & 83 & 114 & 78 & 91,66 & 30 & 19 & 22 & 23,66 \\
\hline & 13 & 39 & 42 & 33 & 38 & 36 & 28 & 22 & 28,66 \\
\hline & 14 & 25 & 30 & 25 & 26,66 & 36 & 28 & 28 & 30,66 \\
\hline & 11 & 141 & 141 & 147 & 143 & 94 & 53 & 50 & 65,66 \\
\hline \multirow[t]{4}{*}{ M7 } & 12 & 111 & 141 & 139 & 130,33 & 14 & 19 & 39 & 24 \\
\hline & 13 & 64 & 75 & 61 & 66,66 & 94 & 58 & 25 & 59 \\
\hline & 14 & 72 & 64 & 80 & 72 & 50 & 30 & 30 & 36,66 \\
\hline & 11 & 86 & 105 & 97 & 96 & 122 & 75 & 80 & 92,33 \\
\hline \multirow[t]{4}{*}{ M8 } & 12 & 33 & 25 & 33 & 30,33 & 19 & 20 & 22 & 20,33 \\
\hline & 13 & 42 & 30 & 45 & 39 & 42 & 25 & 33 & 33,33 \\
\hline & 14 & 119 & 111 & 122 & 117,33 & 36 & 33 & 42 & 37 \\
\hline & 11 & 28 & 25 & 19 & 24 & 64 & 33 & 44 & 47 \\
\hline \multirow[t]{4}{*}{ M9 } & 12 & 58 & 47 & 55 & 53,33 & 33 & 42 & 36 & 37 \\
\hline & 13 & 92 & 80 & 67 & 79,66 & 50 & 47 & 33 & 43,33 \\
\hline & 14 & 33 & 28 & 42 & 34,33 & 80 & 75 & 53 & 69,33 \\
\hline & 11 & 61 & 50 & 75 & 62 & 36 & 36 & 36 & 36 \\
\hline \multirow[t]{3}{*}{ M10 } & 12 & 67 & 67 & 55 & 63 & 14 & 14 & 22 & 16,66 \\
\hline & 13 & 47 & 69 & 61 & 59 & 30 & 30 & 22 & 27,33 \\
\hline & 14 & 105 & 127 & 97 & 109,66 & 72 & 72 & 50 & 64,66 \\
\hline
\end{tabular}


3- DADOS GERAIS DE ADAPTAÇAO MARGINAL $(\mu \mathrm{m})$ para SOLDA CONVENCIONAL - MICROSCOPIA CONFOCAL

\begin{tabular}{|c|c|c|c|c|c|c|c|c|c|c|c|c|c|}
\hline & & \multicolumn{4}{|c|}{ 1SECÇÃO } & \multicolumn{4}{|c|}{2 SECÇÃO } & \multicolumn{4}{|c|}{ SOLDADAS } \\
\hline & & L1 & L2 & L3 & LM & L1 & L2 & L3 & LM & L1 & L2 & L3 & LM \\
\hline & I1 & 134,89 & 92,42 & 93,67 & 106,97 & 98,67 & 72,44 & 74,94 & 82,01 & 167,37 & 138,64 & 136,14 & 147,38 \\
\hline \multirow[t]{4}{*}{ M1 } & 12 & 38,72 & 23,73 & 32,47 & 31,64 & 36,22 & 36,22 & 32,47 & 34,97 & 49,96 & 37,47 & 43,71 & 43,71 \\
\hline & 13 & 62,45 & 48,71 & 34,97 & 48,71 & 33,72 & 33,72 & 26,22 & 31,22 & 43,71 & 49,96 & 38,72 & 44,13 \\
\hline & 14 & 81,18 & 96,17 & 109,91 & 95,75 & 82,43 & 91,17 & 122,4 & 98,66 & 78,68 & 82,43 & 112,41 & 91,17 \\
\hline & 11 & 131,14 & 109,91 & 98,67 & 113,24 & 41,21 & 24,98 & 21,23 & 29,14 & 76,19 & 58,7 & 42,46 & 59,11 \\
\hline \multirow[t]{4}{*}{ M2 } & 12 & 49,96 & 53,7 & 46,21 & 49,95 & 27,47 & 36,22 & 36,22 & 33,3 & 52,45 & 46,47 & 63,7 & 54,2 \\
\hline & 13 & 79,93 & 71,19 & 63,7 & 71,6 & 78,68 & 78,68 & 58,7 & 72,02 & 88,68 & 103,67 & 77,44 & 89,93 \\
\hline & 14 & 58,7 & 71,19 & 62,45 & 64,11 & 38,72 & 54,95 & 38,72 & 44,13 & 71,19 & 64,94 & 68,69 & 68,27 \\
\hline & 11 & 56,2 & 53,2 & 64,94 & 58,11 & 36,22 & 29,97 & 29,97 & 32,05 & 48,71 & 48,71 & 39,96 & 45,79 \\
\hline \multirow[t]{4}{*}{ M3 } & 12 & 44,96 & 22,48 & 22,48 & 29,97 & 44,96 & 38,72 & 36,22 & 39,96 & 53,7 & 39,96 & 37,47 & 43,71 \\
\hline & 13 & 97,67 & 81,18 & 86,18 & 88,34 & 31,22 & 33,72 & 27,47 & 30,8 & 44,96 & 47,46 & 26,22 & 39,54 \\
\hline & 14 & 96,17 & 43,71 & 38,72 & 59,53 & 61,2 & 39,96 & 36,22 & 45,79 & 96,17 & 78,68 & 76,19 & 83,68 \\
\hline & 11 & 84,93 & 71,19 & 69,94 & 75,35 & 64,94 & 48,71 & 51,21 & 54,95 & 96,17 & 87,43 & 71,19 & 84,93 \\
\hline \multirow[t]{4}{*}{ M4 } & 12 & 43,71 & 22,48 & 36,22 & 34,13 & 41,21 & 59,95 & 57,45 & 52,87 & 47,46 & 39,96 & 58,7 & 48,7 \\
\hline & 13 & 29,97 & 16,23 & 16,23 & 20,81 & 51,21 & 32,47 & 31,22 & 38,3 & 44,96 & 58,7 & 26,22 & 43,29 \\
\hline & 14 & 64,94 & 57,45 & 48,71 & 57,03 & 43,71 & 51,21 & 42,46 & 45,79 & 84,93 & 78,68 & 83,68 & 82,43 \\
\hline & 11 & 93,67 & 89,93 & 69,94 & 84,51 & 67,44 & 62,45 & 52,45 & 60,78 & 104,91 & 93,67 & 76,19 & 91,59 \\
\hline \multirow[t]{3}{*}{ M14 } & 12 & 39,96 & 56,2 & 48,71 & 48,29 & 32,47 & 37,47 & 37,47 & 35,8 & 44,96 & 44,96 & 42,46 & 44,12 \\
\hline & 13 & 62,45 & 51,21 & 42,46 & 52,04 & 73,69 & 66,19 & 51,21 & 63,69 & 41,21 & 39,96 & 21,23 & 34,13 \\
\hline & 14 & 76,19 & 76,19 & 61,2 & 71,19 & 42,46 & 41,21 & 22,48 & 35,38 & 74,94 & 84,93 & 59,95 & 73,27 \\
\hline
\end{tabular}


4 - DADOS GERAIS DE ADAPTAÇAO MARGINAL $(\mu \mathrm{m})$ para SOLDA CONVENCIONAL - MICROSCOPIA OPTICA

\begin{tabular}{|c|c|c|c|c|c|c|c|c|c|c|c|c|c|c|c|c|c|c|c|c|c|c|c|c|c|}
\hline & & \multicolumn{8}{|c|}{ 1SECÇÃO } & \multicolumn{8}{|c|}{ 2SECÇÕES } & \multicolumn{8}{|c|}{ SOLDADAS } \\
\hline & & \multicolumn{4}{|c|}{ VESTIBULAR } & \multicolumn{4}{|c|}{ LINGUAL } & \multicolumn{4}{|c|}{ VESTIBULAR } & \multicolumn{4}{|c|}{ LINGUAL } & \multicolumn{4}{|c|}{ VESTIBULAR } & \multicolumn{4}{|c|}{ LINGUAL } \\
\hline & & $\mathrm{L} 1$ & L2 & L3 & LM & $\mathrm{L} 1$ & L2 & L3 & LM & L1 & L2 & L3 & LM & L1 & $\mathrm{L} 2$ & L3 & LM & L1 & $\mathrm{L} 2$ & L3 & LM & L1 & L2 & L3 & LM \\
\hline & 11 & 91 & 83 & 97 & 90,33 & 100 & 30 & 75 & 68,33 & 58 & 47 & 42 & 49 & 17 & 19 & 14 & 16,66 & 86 & 97 & 36 & 73 & 36 & 28 & 30 & 31,33 \\
\hline \multirow{4}{*}{$\mathrm{M} 1$} & 12 & 80 & 69 & 64 & 71 & 22 & 19 & 22 & 21 & 17 & 22 & 20 & 19,66 & 19 & 25 & 19 & 21 & 22 & 19 & 22 & 21 & 8 & 19 & 11 & 12,66 \\
\hline & 13 & 128 & 125 & 129 & 127,33 & 58 & 19 & 25 & 34 & 30 & 22 & 36 & 29,33 & 28 & 30 & 44 & 34 & 19 & 19 & 25 & 21 & 55 & 42 & 42 & 46,33 \\
\hline & 14 & 125 & 111 & 130 & 122 & 30 & 67 & 17 & 38 & 39 & 47 & 58 & 48 & 17 & 22 & 19 & 19,33 & 50 & 75 & 53 & 59,33 & 8 & 6 & 8 & 7,33 \\
\hline & 11 & 69 & 67 & 56 & 64 & 55 & 58 & 58 & 57 & 17 & 19 & 14 & 16,66 & 17 & 25 & 19 & 20,33 & 44 & 19 & 22 & 28,33 & 28 & 14 & 22 & 21,33 \\
\hline \multirow[t]{4}{*}{ M2 } & 12 & 72 & 75 & 78 & 75 & 33 & 28 & 28 & 29,66 & 36 & 42 & 22 & 33,33 & 19 & 19 & 39 & 25,66 & 22 & 22 & 22 & 22 & 14 & 19 & 25 & 19,33 \\
\hline & 13 & 103 & 80 & 105 & 96 & 80 & 25 & 25 & 43,33 & 69 & 44 & 64 & 59 & 14 & 14 & 22 & 16,66 & 80 & 69 & 75 & 74,66 & 22 & 22 & 25 & 23 \\
\hline & 14 & 47 & 36 & 22 & 35 & 19 & 14 & 25 & 19,33 & 14 & 19 & 22 & 18,33 & 25 & 17 & 22 & 21,33 & 14 & 14 & 19 & 15,66 & 17 & 11 & 36 & 21,33 \\
\hline & 11 & 69 & 47 & 55 & 57 & 22 & 14 & 36 & 24 & 22 & 17 & 19 & 19,33 & 25 & 19 & 28 & 24 & 19 & 19 & 22 & 20 & 58 & 33 & 67 & 52,66 \\
\hline \multirow[t]{4}{*}{ M3 } & 12 & 58 & 61 & 61 & 60 & 14 & 11 & 11 & 12 & 44 & 28 & 42 & 38 & 14 & 14 & 25 & 17,66 & 33 & 25 & 25 & 27,66 & 17 & 22 & 33 & 24 \\
\hline & 13 & 75 & 69 & 75 & 73 & 50 & 47 & 47 & 48 & 25 & 14 & 6 & 15 & 30 & 17 & 22 & 23 & 25 & 25 & 22 & 24 & 39 & 28 & 17 & 28 \\
\hline & 14 & 9 & 14 & 14 & 12,33 & 80 & 78 & 92 & 83,33 & 22 & 28 & 19 & 23 & 19 & 47 & 30 & 32 & 53 & 64 & 69 & 62 & 67 & 91 & 122 & 93,33 \\
\hline & 11 & 53 & 50 & 55 & 52,66 & 69 & 61 & 64 & 64,66 & 22 & 22 & 17 & 20,33 & 39 & 44 & 44 & 42,33 & 83 & 67 & 47 & 65,66 & 39 & 44 & 47 & 43,33 \\
\hline \multirow[t]{4}{*}{ M4 } & 12 & 22 & 14 & 25 & 20,33 & 14 & 17 & 22 & 17,66 & 28 & 36 & 31 & 31,66 & 11 & 17 & 11 & 13 & 28 & 17 & 22 & 22,33 & 36 & 25 & 28 & 29,66 \\
\hline & 13 & 53 & 49 & 37 & 46,33 & 39 & 42 & 44 & 41,66 & 25 & 28 & 22 & 25 & 22 & 14 & 19 & 18,33 & 39 & 28 & 17 & 28 & 19 & 19 & 28 & 22 \\
\hline & 14 & 21 & 31 & 30 & 27,66 & 30 & 42 & 30 & 34 & 30 & 28 & 22 & 26,66 & 30 & 25 & 19 & 24,66 & 44 & 58 & 61 & 54,33 & 30 & 33 & 33 & 32 \\
\hline & 11 & 67 & 64 & 69 & 66,66 & 11 & 11 & 25 & 15,66 & 89 & 36 & 39 & 54,66 & 25 & 28 & 47 & 33,33 & 69 & 58 & 33 & 53,33 & 30 & 33 & 11 & 24,66 \\
\hline \multirow[t]{3}{*}{ M14 } & 12 & 25 & 19 & 33 & 25,66 & 17 & 19 & 25 & 20,33 & 22 & 19 & 19 & 20 & 19 & 17 & 25 & 20,33 & 17 & 14 & 22 & 17,66 & 69 & 72 & 72 & 71 \\
\hline & 13 & 47 & 42 & 47 & 45,33 & 69 & 69 & 31 & 56,33 & 17 & 17 & 31 & 21,66 & 39 & 28 & 53 & 40 & 17 & 8 & 11 & 12 & 127 & 133 & 105 & 121,66 \\
\hline & 14 & 36 & 28 & 89 & 51 & 69 & 69 & 61 & 66,33 & 25 & 22 & 22 & 23 & 42 & 53 & 50 & 48,33 & 47 & 28 & 31 & 35,33 & 238 & 252 & 255 & 248,33 \\
\hline
\end{tabular}




\begin{tabular}{|c|c|c|c|c|c|c|c|c|c|c|c|c|c|}
\hline & & \multicolumn{4}{|c|}{ 1SECÇÃO } & \multicolumn{4}{|c|}{2 SECÇÃO } & \multicolumn{4}{|c|}{ SOLDADAS } \\
\hline & & L1 & L2 & L3 & LM & L1 & L2 & L3 & LM & L1 & L2 & L3 & LM \\
\hline \multirow{4}{*}{ M5 } & 11 & 58,7 & 64,94 & 58,7 & 60,78 & 49,96 & 38,72 & 21,23 & 36,63 & 58,7 & 38,72 & 37,47 & 44,96 \\
\hline & 12 & 36,22 & 21,23 & 12,49 & 23,31 & 39,96 & 42,46 & 21,23 & 34,55 & 42,46 & 39,96 & 38,72 & 40,38 \\
\hline & 13 & 82,43 & 59,95 & 42,46 & 61,61 & 77,44 & 73,69 & 41,21 & 64,11 & 27,47 & 39,96 & 16,23 & 27,88 \\
\hline & 14 & 78,68 & 78,68 & 69,94 & 75,76 & 64,94 & 69,94 & 51,21 & 62,03 & 48,71 & 52,45 & 28,72 & 43,29 \\
\hline \multirow{4}{*}{ M11 } & 11 & 59,95 & 64,94 & 56,2 & 60,36 & 38,72 & 34,97 & 41,2 & 38,29 & 67,44 & 33,72 & 46,21 & 49,12 \\
\hline & 12 & 41,21 & 31,22 & 29,97 & 34,13 & 27,68 & 23,93 & 22,11 & 24,57 & 54,95 & 41,21 & 38,72 & 44,96 \\
\hline & 13 & 38,27 & 31,45 & 30,2 & 33,3 & 19,98 & 8,74 & 11,24 & 13,32 & 84,93 & 84,93 & 42,46 & 70,77 \\
\hline & 14 & 49,96 & 47,46 & 38,72 & 45,38 & 56,2 & 34,97 & 42,46 & 44,54 & 57,45 & 51,21 & 47,46 & 52,04 \\
\hline \multirow{4}{*}{ M12 } & 11 & 51,21 & 53,7 & 48,71 & 51,2 & 31,22 & 33,72 & 22,48 & 29,14 & 48,71 & 38,72 & 37,47 & 41,63 \\
\hline & 12 & 58,7 & 57,45 & 62,45 & 59,53 & 36,22 & 36,22 & 28,72 & 33,72 & 44,96 & 41,21 & 38,72 & 41,63 \\
\hline & 13 & 56,2 & 47,46 & 56,2 & 53,28 & 36,22 & 38,72 & 36,22 & 37,05 & 39,96 & 44,96 & 22,48 & 35,8 \\
\hline & 14 & 53,7 & 47,46 & 31,22 & 44,12 & 42,46 & 42,46 & 36,22 & 40,38 & 37,47 & 41,21 & 26,22 & 34,96 \\
\hline \multirow{4}{*}{ M13 } & 11 & 48,71 & 62,45 & 53,7 & 54,95 & 39,96 & 24,98 & 19,98 & 28,3 & 48,71 & 36,22 & 31,22 & 38,71 \\
\hline & 12 & 53,7 & 49,96 & 41,21 & 48,29 & 39,96 & 46,21 & 42,46 & 42,87 & 44,96 & 36,22 & 44,96 & 42,04 \\
\hline & 13 & 57,45 & 37,47 & 51,21 & 48,71 & 38,72 & 39,96 & 81,75 & 53,47 & 41,21 & 42,46 & 28,72 & 37,46 \\
\hline & 14 & 57,45 & 44,96 & 49,96 & 50,79 & 57,88 & 62,91 & 55,36 & 58,71 & 58,7 & 52,45 & 51,21 & 54,12 \\
\hline \multirow{4}{*}{ M15 } & 11 & 73,69 & 64,94 & 44,96 & 61,19 & 49,96 & 37,47 & 16,23 & 34,55 & 87,43 & 56,2 & 38,72 & 60,78 \\
\hline & 12 & 41,21 & 73,69 & 76,19 & 63,69 & 24,98 & 24,98 & 24,98 & 24,98 & 58,7 & 39,96 & 52,45 & 50,37 \\
\hline & 13 & 76,19 & 39,96 & 42,46 & 52,87 & 31,22 & 17,48 & 11,24 & 19,98 & 51,21 & 42,46 & 23,73 & 39,13 \\
\hline & 14 & 16,23 & 11,24 & 14,98 & 14,15 & 13,73 & 13,73 & 12,49 & 13,31 & 27,47 & 13,73 & 13,73 & 18,31 \\
\hline
\end{tabular}


6 - DADOS GERAIS DE ADAPTAÇAO MARGINAL $(\mu \mathrm{m})$ para SOLDA TIG - MICROSCOPIA OPTICA

\begin{tabular}{|c|c|c|c|c|c|c|c|c|c|c|c|c|c|c|c|c|c|c|c|c|c|c|c|c|c|}
\hline & & \multicolumn{8}{|c|}{ 1SECÇ̃̃̃O } & \multicolumn{8}{|c|}{2 SECÇÕES } & \multicolumn{8}{|c|}{ SOLDADAS } \\
\hline & & \multicolumn{4}{|c|}{ VESTIBULAR } & \multicolumn{4}{|c|}{ LINGUAL } & \multicolumn{4}{|c|}{ VESTIBULAR } & \multicolumn{4}{|c|}{ LINGUAL } & \multicolumn{4}{|c|}{ VESTIBULAR } & \multicolumn{4}{|c|}{ LINGUAL } \\
\hline & & $\mathrm{L} 1$ & $\mathrm{~L} 2$ & $\angle 3$ & LM & $\mathrm{L} 1$ & $\mathrm{~L} 2$ & L3 & LM & $\mathrm{L} 1$ & $\mathrm{~L} 2$ & L3 & LM & $\mathrm{L} 1$ & $\mathrm{~L} 2$ & $\mathrm{~L} 3$ & LM & $\mathrm{L} 1$ & $\mathrm{~L} 2$ & L3 & LM & $\mathrm{L} 1$ & $\mathrm{~L} 2$ & $\mathrm{~L} 3$ & LM \\
\hline & 11 & 36 & 44 & 42 & 40,66 & 119 & 122 & 67 & 102,66 & 17 & 19 & 19 & 18,33 & 22 & 19 & 22 & 21 & 39 & 33 & 36 & 36 & 25 & 39 & 33 & 32,33 \\
\hline \multirow[t]{4}{*}{ M5 } & 12 & 47 & 44 & 47 & 46 & 30 & 30 & 25 & 28,33 & 22 & 28 & 33 & 27,66 & 30 & 30 & 30 & 30 & 25 & 28 & 25 & 26 & 30 & 22 & 19 & 23,66 \\
\hline & 13 & 78 & 72 & 78 & 76 & 33 & 30 & 30 & 31 & 33 & 39 & 30 & 34 & 28 & 30 & 36 & 31,33 & 44 & 47 & 53 & 58 & 44 & 25 & 42 & 37 \\
\hline & 14 & 30 & 39 & 28 & 32,33 & 78 & 80 & 89 & 82,33 & 36 & 28 & 30 & 31,33 & 55 & 64 & 47 & 55,33 & 22 & 17 & 25 & 21,33 & 22 & 28 & 36 & 28,66 \\
\hline & 11 & 31 & 36 & 36 & 34,33 & 39 & 20 & 25 & 28 & 53 & 30 & 28 & 37 & 19 & 14 & 33 & 22 & 47 & 19 & 44 & 36,66 & 22 & 36 & 25 & 27,66 \\
\hline \multirow[t]{4}{*}{ M11 } & 12 & 28 & 22 & 36 & 28,66 & 17 & 14 & 25 & 18,66 & 17 & 17 & 19 & 17,66 & 22 & 17 & 19 & 19,33 & 28 & 22 & 22 & 24 & 17 & 14 & 14 & 15 \\
\hline & 13 & 14 & 28 & 8 & 16,66 & 25 & 22 & 19 & 22 & 22 & 19 & 14 & 18,33 & 17 & 22 & 25 & 21,33 & 22 & 14 & 25 & 20,33 & 30 & 22 & 22 & 24,66 \\
\hline & 14 & 19 & 11 & 22 & 17,33 & 19 & 8 & 25 & 17,33 & 17 & 17 & 22 & 18,66 & 33 & 22 & 17 & 24 & 56 & 36 & 33 & 41,66 & 42 & 28 & 17 & 29 \\
\hline & 11 & 17 & 22 & 17 & 18,66 & 25 & 17 & 25 & 22,33 & 22 & 19 & 19 & 20 & 22 & 11 & 19 & 17,33 & 22 & 17 & 17 & 18,66 & 28 & 28 & 25 & 27 \\
\hline \multirow[t]{4}{*}{ M12 } & 12 & 50 & 56 & 47 & 51 & 55 & 80 & 36 & 57 & 20 & 33 & 17 & 23,33 & 25 & 36 & 22 & 27,66 & 14 & 14 & 14 & 14 & 25 & 19 & 33 & 25,66 \\
\hline & 13 & 36 & 39 & 20 & 31,66 & 47 & 50 & 44 & 47 & 11 & 14 & 17 & 14 & 28 & 42 & 39 & 36,33 & 22 & 14 & 17 & 17,66 & 19 & 39 & 58 & 38,66 \\
\hline & 14 & 17 & 14 & 11 & 14 & 44 & 42 & 56 & 47,33 & 22 & 17 & 22 & 20,33 & 44 & 36 & 33 & 37,66 & 14 & 14 & 19 & 15,66 & 36 & 30 & 39 & 35 \\
\hline & 11 & 9 & 14 & 19 & 14 & 25 & 17 & 42 & 28 & 19 & 28 & 28 & 25 & 22 & 25 & 25 & 24 & 36 & 22 & 28 & 28,66 & 94 & 22 & 72 & 62,66 \\
\hline \multirow[t]{4}{*}{ M13 } & 12 & 39 & 33 & 42 & 38 & 19 & 14 & 22 & 18,33 & 33 & 22 & 14 & 23 & 20 & 19 & 19 & 19,33 & 30 & 22 & 25 & 25,66 & 22 & 25 & 24 & 24 \\
\hline & 13 & 28 & 30 & 30 & 29,33 & 25 & 19 & 25 & 23 & 22 & 19 & 22 & 21 & 25 & 11 & 30 & 22 & 25 & 25 & 25 & 25 & 25 & 28 & 28 & 27 \\
\hline & 14 & 19 & 18 & 17 & 18 & 53 & 28 & 33 & 38 & 30 & 25 & 19 & 24,66 & 33 & 19 & 22 & 24,66 & 30 & 39 & 33 & 34 & 25 & 55 & 39 & 39,66 \\
\hline & 11 & 33 & 42 & 36 & 37 & 44 & 33 & 33 & 36,66 & 42 & 42 & 39 & 41 & 25 & 47 & 30 & 34 & 39 & 22 & 25 & 28,66 & 50 & 25 & 53 & 42,66 \\
\hline \multirow[t]{3}{*}{ M15 } & 12 & 33 & 28 & 47 & 36 & 33 & 30 & 25 & 29,33 & 36 & 50 & 30 & 38,66 & 22 & 22 & 25 & 23 & 42 & 69 & 22 & 44,33 & 55 & 44 & 31 & 43,33 \\
\hline & 13 & 53 & 42 & 75 & 56,66 & 55 & 33 & 36 & 41,33 & 25 & 61 & 69 & 51,66 & 28 & 28 & 25 & 27 & 25 & 28 & 28 & 26 & 69 & 44 & 28 & 47 \\
\hline & 14 & 33 & 28 & 22 & 27,66 & 58 & 50 & 50 & 52,66 & 28 & 17 & 28 & 24,33 & 80 & 17 & 17 & 38 & 22 & 22 & 25 & 23 & 39 & 25 & 33 & 32,33 \\
\hline
\end{tabular}


ANEXO A - Dados de Adaptação Marginal $(\mu \mathrm{m})$ Técnica $\times$ Método

\begin{tabular}{cc|cc|cc}
\hline \multicolumn{2}{c|}{ MONOBLOCO } & \multicolumn{2}{|c|}{ ONVENCIONAL } & \multicolumn{2}{c}{ TIG } \\
\hline CF & MO & CF & MO & CF & MO \\
47,66 & 50,16 & 81,59 & 43,58 & 39,12 & 35,33 \\
100,54 & 102,99 & 67,87 & 35,16 & 54,22 & 30,66 \\
83,67 & 70,66 & 53,18 & 33,41 & 38,5 & 16,49 \\
63,48 & 47,83 & 64,83 & 42,58 & 43,08 & 28,33 \\
61,71 & 73,41 & 60,77 & 29,58 & 42,14 & 30,49 \\
\hline
\end{tabular}

ANEXO B - Teste de Normalidade dos dados (alfa $=5 \%$ )

\begin{tabular}{cccc}
\hline Teste (Estatística) & Valor & p-valor & Normal \\
\hline Shapiro-Wilk (W) & 0.94589 & 0.13109 & Sim \\
\hline
\end{tabular}

ANEXO C - Dados de Adaptação Marginal $(\mu \mathrm{m})$ pelo método medição CF

\begin{tabular}{ccc|ccc}
\hline \multicolumn{3}{c|}{ CONVENCIONAL CF } & \multicolumn{3}{c}{ TIG CF } \\
\hline 1 SEC & 2 SEC & SOLDADA & 1 SEC & 2 SEC & SOLDADA \\
\hline 70,76 & 61,71 & 81,59 & 55,36 & 49,33 & 39,12 \\
74,72 & 44,64 & 67,87 & 43,29 & 30,18 & 54,22 \\
58,98 & 37,15 & 53,18 & 52,03 & 35,07 & 38,5 \\
46,83 & 47,97 & 64,83 & 50,68 & 45,83 & 43,08 \\
64 & 48,91 & 60,77 & 47,97 & 23,2 & 42,14 \\
\hline
\end{tabular}

ANEXO D - Teste de Normalidade (alfa $=5 \%$ )

\begin{tabular}{cccc}
\hline Teste (Estatística) & Valor & p-valor & Normal \\
\hline Shapiro-Wilk $(\mathrm{W})$ & 0.98936 & 0.98749 & Sim
\end{tabular}


ANEXO E - Dados Adaptação Marginal $(\mu \mathrm{m})$ pelo método MO

\begin{tabular}{c|c|c|c|c|c}
\hline \multicolumn{2}{l|}{ CONVENCIONAL } & \multicolumn{3}{c}{ TIG } \\
\hline 1 SEC & 2 SEC & SOLDADA & 1 SEC & 2 SEC & SOLDADA \\
\hline 71,49 & 29,61 & 33,99 & 54,91 & 31,12 & 32,87 \\
\hline 52,41 & 26,41 & 28,2 & 22,86 & 22,28 & 27,37 \\
\hline 46,2 & 23,99 & 41,45 & 36,12 & 24,57 & 24,03 \\
\hline 38,11 & 25,24 & 37,16 & 25,83 & 22,95 & 33,33 \\
\hline 43,41 & 32,66 & 72,99 & 39,66 & 34,7 & 35,91 \\
\hline
\end{tabular}

ANEXO F - Teste de Normalidade (alfa = 5\%)

\begin{tabular}{ccccc}
\hline Teste (Estatística) & Valor & Vcrit & p-valor & Normal \\
\hline Lilliefors (D) & 0.16077 & 0.16100 & $p>.05$ & Sim \\
\hline
\end{tabular}

ANEXO G - Dados de Adaptação Marginal $(\mu \mathrm{m})$ por implante pelo método CF

\begin{tabular}{|c|c|c|c|}
\hline & MNB & CNV & TIG \\
\hline \multirow[t]{5}{*}{ IMPLANTE 1} & 47,46 & 147,38 & 44,96 \\
\hline & 151,13 & 59,11 & 49,12 \\
\hline & 131,97 & 45,79 & 41,63 \\
\hline & 47,04 & 84,93 & 38,71 \\
\hline & 48,29 & 91,59 & 60,78 \\
\hline \multirow[t]{5}{*}{ IMPLANTE 2} & 68,27 & 43,71 & 40,38 \\
\hline & 126,56 & 54,2 & 44,96 \\
\hline & 53,28 & 43,71 & 41,63 \\
\hline & 50,37 & 48,7 & 42,04 \\
\hline & 47,04 & 44,12 & 50,17 \\
\hline \multirow[t]{5}{*}{ IMPLANTE 3} & 27,47 & 44,13 & 27,88 \\
\hline & 32,05 & 89,93 & 70,77 \\
\hline & 34,13 & 39,54 & 35,8 \\
\hline & 68,69 & 43,29 & 37,46 \\
\hline & 34,97 & 34,13 & 39,13 \\
\hline \multirow[t]{5}{*}{ IMPLANTE 4} & 47,46 & 91,17 & 43,29 \\
\hline & 92,42 & 68,27 & 52,04 \\
\hline & 115,32 & 83,68 & 34,96 \\
\hline & 87,84 & 82,43 & 54,12 \\
\hline & 116,57 & 73,27 & 18,31 \\
\hline
\end{tabular}


ANEXO H - Teste de NORMALIDADE (alfa = 5\%)

\begin{tabular}{ccccc}
\hline Teste (Estatística) & Valor & Vcrit & p-valor & Normal \\
\hline Kolmogorov-Smirnov (D) & 0.22856 & 0.11408 & $\mathrm{p}<.01$ & Não \\
\hline
\end{tabular}

ANEXO I - Teste Kruskal Wallis - Comparações múltiplas

\begin{tabular}{|c|c|c|c|c|}
\hline Comparação & Diferença & DiferençaCrít & alfa & Diferentes \\
\hline $1-2$ & 4.2 & 37.1955 & 0.05 & Não \\
\hline $1-3$ & 16.2 & 37.1955 & 0.05 & Não \\
\hline $1-4$ & 1.4 & 37.1955 & 0.05 & Não \\
\hline $1-5$ & 14.4 & 37.1955 & 0.05 & Não \\
\hline $1-6$ & 20.2 & 37.1955 & 0.05 & Não \\
\hline $1-7$ & 28.5 & 37.1955 & 0.05 & Não \\
\hline $1-8$ & 19 & 37.1955 & 0.05 & Não \\
\hline $1-9$ & 25.4 & 37.1955 & 0.05 & Não \\
\hline $1-10$ & 7.7 & 37.1955 & 0.05 & Não \\
\hline $1-11$ & 5.9 & 37.1955 & 0.05 & Não \\
\hline $1-12$ & 21.1 & 37.1955 & 0.05 & Não \\
\hline $2-3$ & 20.4 & 37.1955 & 0.05 & Não \\
\hline $2-4$ & 5.6 & 37.1955 & 0.05 & Não \\
\hline $2-5$ & 18.6 & 37.1955 & 0.05 & Não \\
\hline $2-6$ & 24.4 & 37.1955 & 0.05 & Não \\
\hline $2-7$ & 32.7 & 37.1955 & 0.05 & Não \\
\hline $2-8$ & 23.2 & 37.1955 & 0.05 & Não \\
\hline $2-9$ & 29.6 & 37.1955 & 0.05 & Não \\
\hline $2-10$ & 3.5 & 37.1955 & 0.05 & Não \\
\hline $2-11$ & 1.7 & 37.1955 & 0.05 & Não \\
\hline $2-12$ & 25.3 & 37.1955 & 0.05 & Não \\
\hline $3-4$ & 14.8 & 37.1955 & 0.05 & Não \\
\hline $3-5$ & 1.8 & 37.1955 & 0.05 & Não \\
\hline $3-6$ & 4 & 37.1955 & 0.05 & Não \\
\hline $3-7$ & 12.3 & 37.1955 & 0.05 & Não \\
\hline $3-8$ & 2.8 & 37.1955 & 0.05 & Não \\
\hline $3-9$ & 9.2 & 37.1955 & 0.05 & Não \\
\hline $3-10$ & 23.9 & 37.1955 & 0.05 & Não \\
\hline $3-11$ & 22.1 & 37.1955 & 0.05 & Não \\
\hline $3-12$ & 4.9 & 37.1955 & 0.05 & Não \\
\hline $4-5$ & 13 & 37.1955 & 0.05 & Não \\
\hline $4-6$ & 18.8 & 37.1955 & 0.05 & Não \\
\hline $4-7$ & 27.1 & 37.1955 & 0.05 & Não \\
\hline $4-8$ & 17.6 & 37.1955 & 0.05 & Não \\
\hline $4-9$ & 24 & 37.1955 & 0.05 & Não \\
\hline $4-10$ & 9.1 & 37.1955 & 0.05 & Não \\
\hline $4-11$ & 7.3 & 37.1955 & 0.05 & Não \\
\hline
\end{tabular}




\begin{tabular}{|c|c|c|c|c|}
\hline Comparação & Diferença & DiferençaCrít & alfa & Diferentes \\
\hline $4-12$ & 19.7 & 37.1955 & 0.05 & Não \\
\hline $5-6$ & 5.8 & 37.1955 & 0.05 & Não \\
\hline $5-7$ & 14.1 & 37.1955 & 0.05 & Não \\
\hline $5-8$ & 4.6 & 37.1955 & 0.05 & Não \\
\hline $5-9$ & 11 & 37.1955 & 0.05 & Não \\
\hline $5-10$ & 22.1 & 37.1955 & 0.05 & Não \\
\hline $5-11$ & 20.3 & 37.1955 & 0.05 & Não \\
\hline $5-12$ & 6.7 & 37.1955 & 0.05 & Não \\
\hline $6-7$ & 8.3 & 37.1955 & 0.05 & Não \\
\hline $6-8$ & 1.2 & 37.1955 & 0.05 & Não \\
\hline $6-9$ & 5.2 & 37.1955 & 0.05 & Não \\
\hline $6-10$ & 27.9 & 37.1955 & 0.05 & Não \\
\hline $6-11$ & 26.1 & 37.1955 & 0.05 & Não \\
\hline $6-12$ & 0.9 & 37.1955 & 0.05 & Não \\
\hline $7-8$ & 9.5 & 37.1955 & 0.05 & Não \\
\hline $7-9$ & 3.1 & 37.1955 & 0.05 & Não \\
\hline $7-10$ & 36.2 & 37.1955 & 0.05 & Não \\
\hline $7-11$ & 34.4 & 37.1955 & 0.05 & Não \\
\hline $7-12$ & 7.4 & 37.1955 & 0.05 & Não \\
\hline $8-9$ & 6.4 & 37.1955 & 0.05 & Não \\
\hline $8-10$ & 26.7 & 37.1955 & 0.05 & Não \\
\hline $8-11$ & 24.9 & 37.1955 & 0.05 & Não \\
\hline $8-12$ & 2.1 & 37.1955 & 0.05 & Não \\
\hline $9-10$ & 33.1 & 37.1955 & 0.05 & Não \\
\hline $9-11$ & 31.3 & 37.1955 & 0.05 & Não \\
\hline $9-12$ & 4.3 & 37.1955 & 0.05 & Não \\
\hline $10-11$ & 1.8 & 37.1955 & 0.05 & Não \\
\hline $10-12$ & 28.8 & 37.1955 & 0.05 & Não \\
\hline $11-12$ & 27 & 37.1955 & 0.05 & Não \\
\hline
\end{tabular}


ANEXO J - Dados de Adaptação Marginal $(\mu \mathrm{m})$ por implante pelo método MO

\begin{tabular}{r|r|r|r}
\hline & \multicolumn{1}{|c|}{ MBL } & \multicolumn{1}{c}{ CNV } & \multicolumn{1}{c}{ TIG } \\
\hline & & & \\
\hline IMPLANTE 1 & 26,83 & 52,16 & 34,16 \\
\hline & 104,33 & 24,83 & 32,16 \\
\hline & 94,16 & 36,33 & 22,83 \\
\hline & 35,5 & 54,49 & 45,66 \\
\hline & 49 & 38,99 & 35,66 \\
\hline IMPLANTE 2 & 57,66 & 16,83 & 24,83 \\
\hline & 77,16 & 20,66 & 19,5 \\
\hline & 25,33 & 25,83 & 19,83 \\
\hline & 45,16 & 25,99 & 24,83 \\
\hline & 39,83 & 44,33 & 43,83 \\
\hline & & & \\
\hline IMPLANTE 3 & 33,33 & 33,66 & 47,5 \\
\hline & 62,83 & 48,83 & 22,49 \\
\hline & 36,16 & 26 & 28,16 \\
\hline & 61,49 & 25 & 26 \\
\hline & 43,16 & 66,83 & 36,5 \\
\hline & & & \\
\hline & 28,66 & 33,33 & 24,99 \\
\hline & 54,33 & 18,49 & 35,33 \\
\hline & 77,16 & 77,66 & 25,33 \\
\hline & 51,83 & 43,16 & 36,83 \\
\hline & 87,16 & 141,83 & 27,66 \\
\hline
\end{tabular}

ANEXO K - Teste de Normalidade dos dados originais (alfa $=5 \%$ )

DADOS TRANSFORMADOS EM LOGARITMO

\begin{tabular}{ccccc}
\hline Teste (Estatística) & Valor & Vcrit & p-valor & Normal \\
\hline Shapiro-Wilk (W) & 0.87462 & - & 0.00002 & Não \\
\hline
\end{tabular}


ANEXO L - Logaritmo dos DADOS originais

\begin{tabular}{lllll}
\hline 1.428621 & 2.018409 & 1.973867 & 1.550228 & 1.690196 \\
1.760875 & 1.887392 & 1.403635 & 1.654754 & 1.600210 \\
1.522835 & 1.798167 & 1.558228 & 1.788805 & 1.635082 \\
1.457276 & 1.735040 & 1.887392 & 1.714581 & 1.940317 \\
1.717338 & 1.394977 & 1.560266 & 1.736317 & 1.590953 \\
1.226084 & 1.315130 & 1.412125 & 1.414806 & 1.646698 \\
1.527114 & 1.688687 & 1.414973 & 1.397940 & 1.824972 \\
1.522835 & 1.266937 & 1.890198 & 1.635082 & 1.621488 \\
1.533518 & 1.507316 & 1.358506 & 1.659536 & 1.552181 \\
1.394977 & 1.290035 & 1.297323 & 1.394977 & 1.641772 \\
1.676694 & 1.351990 & 1.449633 & 1.414973 & 1.562293 \\
1.397766 & 1.548144 & 1.403635 & 1.566202 & 1.441852 \\
\hline
\end{tabular}

ANEXO M - Teste de Normalidade do logaritmo dos dados originais (alfa $=5 \%$ )

\begin{tabular}{cccc}
\hline Teste (Estatística) & Valor & p-valor & Normal \\
\hline Shapiro-Wilk (W) & 0.97125 & 0.16795 & Sim \\
\hline
\end{tabular}

